Bruno Muniz e Souza

Obtenção do MgO a partir da decomposição do $\mathrm{MgSO}_{4}$ na presença de carbono

\author{
Dissertação de Mestrado
}

Dissertação apresentada como requisito parcial para obtenção do grau de Mestre pelo Programa de Pósgraduação em Engenharia de Materiais e de Processos Químicos e Metalúrgicos do Departamento de Engenharia Química e de Materiais do Centro Técnico Científico da PUC-Rio.

Orientador: Prof. Eduardo de Albuquerque Brocchi Co-orientador: Prof. Rodrigo Fernandes Magalhães de Souza

Rio de Janeiro Dezembro de 2016 


\section{Obtenção do MgO a partir da decomposição do MgSO4 na presença de carbono}

Dissertação apresentada como requisito parcial para obtenção do grau de Mestre pelo Programa de Pósgraduação em Engenharia de Materiais e de Processos Químicos e Metalúrgicos do Departamento de Engenharia Química e de Materiais do Centro Técnico Científico da PUC-Rio.

Prof. Eduardo de Albuquerque Brocchi

Orientador e Presidente

Departamento de Engenharia Química e de Materiais - PUC-Rio

Prof. Rodrigo Fernandes Magalhães de Souza

Co-orientador

Departamento de Engenharia Química e de Materiais - PUC-Rio

Prof. Bruno Ferreira dos Santos

Departamento de Engenharia Química e de Materiais - PUC-Rio

Patrícia Radino-Rouse Instituto Tecnológico Vale

Prof. Márcio da Silveira Carvalho Coordenador Setorial de PósGraduação do Centro Técnico

Científico da PUC-Rio

Rio de Janeiro, 30 de dezembro de 2016 
Todos os direitos reservados. É proibida a reprodução total ou parcial do trabalho sem autorização da universidade, do autor e do orientador.

\section{Bruno Muniz e Souza}

Graduou-se em Engenharia Química na URRRJ (Universidade Federal Rural do Rio de Janeiro) em 2012.

Ficha Catalográfica

Souza, Bruno Muniz e

Obtenção do $\mathrm{MgO}$ a partir da decomposição do MgSO4 na presença de carbono / Bruno Muniz e Souza ; orientador: Eduardo de Albuquerque Brocchi ; coorientador: Rodrigo Fernandes Magalhães de Souza. 2016.

80 f. : il. color. ; $30 \mathrm{~cm}$

Dissertação (mestrado) - Pontifícia Universidade Católica do Rio de Janeiro, Departamento de Engenharia Química e de Materiais, 2016.

Inclui bibliografia

1. Engenharia de Materiais - Teses. 2. Engenharia Química - Teses. 3. Óxido de magnésio. 4. Sulfato de magnésio. 5. Redução carbotérmica. 6. Decomposição térmica. I. Brocchi, Eduardo de Albuquerque. II. Souza, Rodrigo Fernandes Magalhães de. III. Pontifícia Universidade Católica do Rio de Janeiro. Departamento de Engenharia Química e de Materiais. IV. Título. 


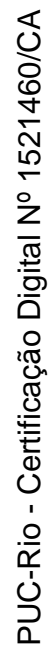

A minha esposa, melhor amiga e companheira Fabiola. 


\section{Agradecimentos}

Ao meu orientador, professor Eduardo de Albuquerque Brocchi, pela confiança depositada em mim e pelo apoio durante o período deste trabalho.

Ao meu coorientador, professor Rodrigo Fernandes Magalhães de Souza, pela dedicação, constante colaboração durante meus experimentos e pelo estimulo a novos desafios.

Aos demais professores do Departamento de Engenharia Química e de Materiais, pelos conhecimentos a mim transmitidos durante meu mestrado.

Aos funcionários do Departamento de Engenharia Química e de Materiais, Carmem Façanha, Leonardo Rabello, Rosely Gonçalves e Thiago Brito pela atenção a mim dedicada.

Aos meus pais, Jorge e Márcia, que sempre me apoiaram e me mostraram a importância dos estudos.

Aos meus amigos pelo apoio e por estarem presentes em todos os momentos. Em especial a meu amigo Felipe Zanone por me incentivar a realizar mais esta etapa.

À Pontifícia Universidade Católica do Rio de Janeiro pela oportunidade de estudar em uma instituição que preza pela excelência em seu ensino e pesquisa, sem deixar de apoiar os alunos nos momentos necessários.

À Coordenação de Aperfeiçoamento de Pessoal de Nível Superior, pelo apoio financeiro concedido, que tornou possível o cumprimento deste trabalho com a dedicação necessária. 


\section{Resumo}

Souza e, Bruno Muniz; Brocchi, Eduardo de Albuquerque. Obtenção do MgO a partir da decomposição do $\mathrm{MgSO}_{4}$ na presença de carbono. Rio de Janeiro, 2016. 83p. Dissertação de Mestrado - Departamento de Engenharia Química e de Materiais, Pontifícia Universidade Católica do Rio de Janeiro.

O sulfato de magnésio se caracteriza como um possível co-produto de alguns processos hidrometalúrgicos envolvendo concentrados minerais portadores desse metal quando submetidos à lixiviação envolvendo ácido sulfúrico. Dentro do contexto dos fluxogramas de processamento desses concentrados, uma etapa bastante comum é a neutralização da solução, usualmente levada a efeito por meio da solubilização de óxido de cálcio. Este, por sua vez, pode ser substituído por óxido de magnésio desde que determinadas propriedades, tais como superfície de contato e reatividade, estejam adequadas aos requisitos desta etapa. Desta forma, o processo de decomposição térmica do sulfato de magnésio, aparentemente, não se configura como uma possível rota de processamento visto que ocorre numa temperatura de aproximadamente $1100^{\circ} \mathrm{C}$, significativamente alta para a formação de um óxido de magnésio que atenda às condições necessárias para uma neutralização eficiente. $\mathrm{O}$ estudo termodinâmico realizado sugere que na presença de agentes redutores como o carbono, ocorre uma diminuição na temperatura, para aproximadamente $400{ }^{\circ} \mathrm{C}$, a partir da qual a transformação do sulfato em óxido de magnésio é teoricamente viável. Assim sendo, os objetivos do trabalho de pesquisa estão associados com a avaliação do comportamento do sistema reacional constituído por $\mathrm{MgSO}_{4}$ quando na presença de carbono oriundo de carvão vegetal. $\mathrm{O}$ estudo contempla também a caracterização dos materiais obtidos a fim de verificar a obtenção do $\mathrm{MgO}$ e avaliar se as propriedades do material encontram-se adequadas para a sua utilização como agente regulador de $\mathrm{pH}$ tal como o $\mathrm{CaO}$. Desta forma, além das técnicas de microscopia eletrônica de varredura e difração de Raios-X, também é prevista a quantificação da reatividade do produto em soluções ácidas. As análises realizadas com as variáveis, excesso de agente redutor, temperatura, vazão de arraste e 
homogeneidade da amostra, mostraram que a temperatura é a variável que mais influência a decomposição do $\mathrm{MgSO}_{4}$. Entre todos os ensaios analisados, os experimentos a $900{ }^{\circ} \mathrm{C}$ e com tempos de 25 e 30 minutos foram os que indicaram os melhores resultados experimentais de conversão, atingindo uma conversão próxima de $100 \%$. As análises de caracterização, em DR-X e MEV/EDS, indicaram que o $\mathrm{MgO}$ foi formado ao fim da reação. $\mathrm{O}$ teste de reatividade indicou que o $\mathrm{MgO}$ obtido pode ser utilizado como regulador de $\mathrm{pH}$, atendendo a proposta do trabalho.

\section{Palavras-chave}

Óxido de magnésio; sulfato de magnésio; redução carbotérmica; decomposição térmica. 


\section{Abstract}

Souza e, Bruno Muniz; Brocchi, Eduardo de Albuquerque (advisor). Production of $\mathrm{MgO}$ through $\mathrm{MgSO}_{4}$ decomposition in the presence of carbon Rio de Janeiro, 2016. 83p. Dissertação de Mestrado - Departamento de Engenharia Química e de Materiais, Pontifícia Universidade Católica do Rio de Janeiro.

Magnesium sulfate is characterized as a possible co-product of some Hydrometallurgical Processes involving mineral concentrates that has this metal when subjected to leaching involving sulfuric acid. In the context of the processes flowchart, a fairly common step is the neutralization of the solution that usually takes effect through the solubility of calcium oxide. This, in turn, can be substituted for magnesium oxide as long as these properties, such as contact surface and reactivity, are suitable for the requirements of this step. Thus, the thermal decomposition process of magnesium sulfate, apparently, it is not configured as a possible processing route because it occurs at a temperature of approximately $1100^{\circ} \mathrm{C}$, significantly elevated for the formation of a magnesium oxide which satisfies the conditions necessary for a neutralization efficient. The thermodynamic study suggests that in the presence of reducing agents such as carbon, a decrease in the temperature occurs to approximately $400^{\circ} \mathrm{C}$, where the conversion of sulfate to magnesium oxide is theoretically viable. Thus, the objectives of the research work are associated with an evaluation of the behavior of the reactive system constituted by $\mathrm{MgSO} 4$ when in the presence of carbon provided from the charcoal. The study also contemplates the characterization of the materials obtained in order to verify the attainment of $\mathrm{MgO}$ and to evaluate how the properties of the material are suitable for their use as a $\mathrm{pH}$ regulating agent such as $\mathrm{CaO}$. Thus, in addition to the techniques of scanning electron microscopy and X-ray diffraction, it is also expected the quantification of the reactivity of the product in acidic solutions. The analyzes performed with the variables, excess of reducing agent, temperature, drag flow and homogeneity of the sample, showed that temperature is the variable that most influences the decomposition of MgSO4. Among all the analyzed tests, the experiments at $900^{\circ} \mathrm{C}$ and with 25 and 30 minute were that indicated the best 
experimental results of conversion, reaching a conversion close to $100 \%$. The characterization analyzes, in DR-X and MEV/EDS, indicated that $\mathrm{MgO}$ was formed at the end of the reaction. The reactivity test indicated that the obtained $\mathrm{MgO}$ can be used as $\mathrm{pH}$ regulator, attending the work proposal.

\section{Keywords}

Magnesium oxide; magnesium sulfate; carbothermic reduction; thermal decomposition. 


\section{Sumário}

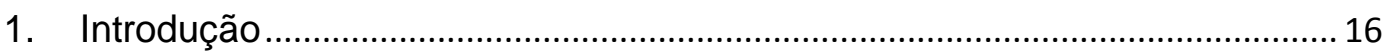

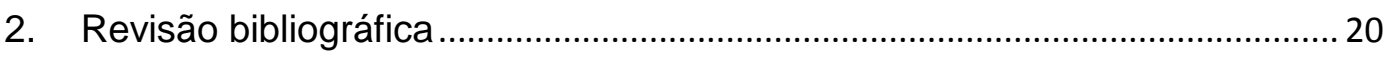

2.1. Estudos envolvendo decomposição de sulfatos.....................................220

2.2. Estudos envolvendo Sulfato de Magnésio ............................................... 21

2.3. Estudos envolvendo Óxido de Magnésio ................................................. 22

2.4. Utilização do Óxido de Magnésio como regulador de $\mathrm{pH}$......................23

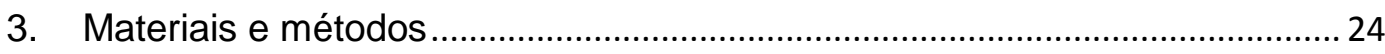

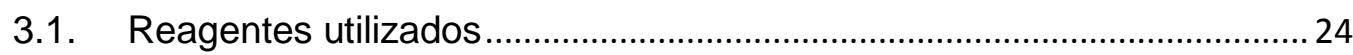

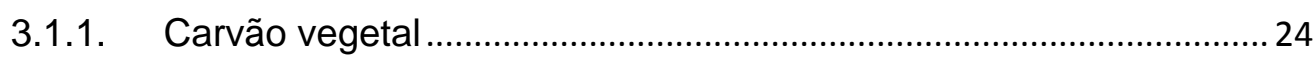

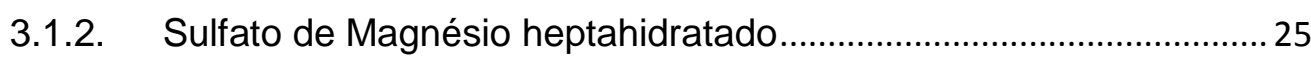

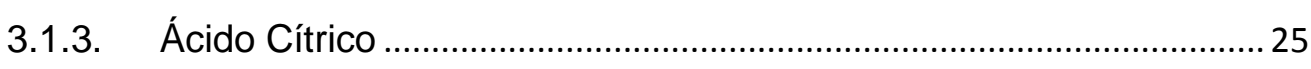

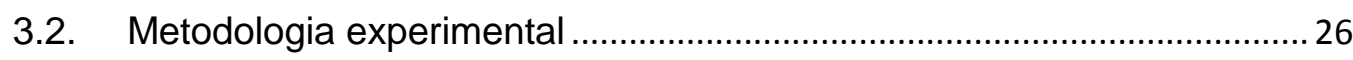

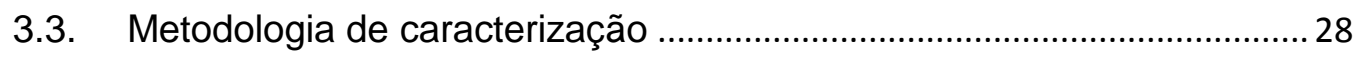

3.3.1. Metodologia de caracterização do Carvão vegetal ASTM D17628428

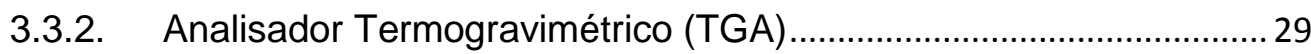

3.3.3. Microscópio Eletrônico de Varredura/Espectroscopia de Raios-X por Dispersão em Energia (MEV/EDS) ....................................................... 30

3.3.4. Difratômetro de Raios-X (DR-X) ......................................................... 31

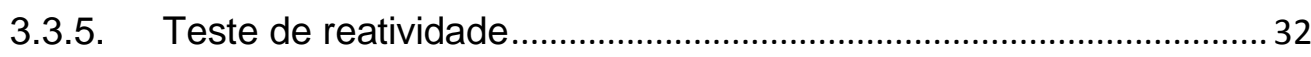

4. Apreciação termodinâmica................................................................................ 34

4.1. Estudo do sistema reacional da decomposição do $\mathrm{MgSO}_{4}$.......................34

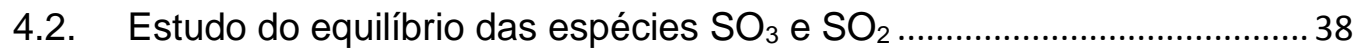

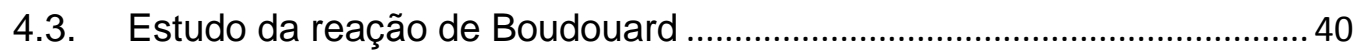

4.4. Estudo da influência do Carbono na temperatura de decomposição do

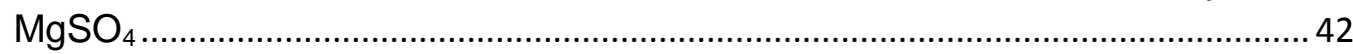

4.5. Estudo da composição de equilíbrio em função da composição química

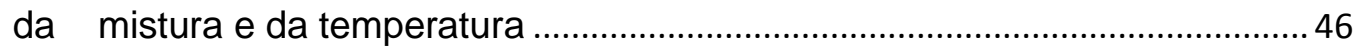

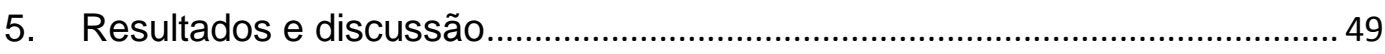

5.1. Caracterização do carvão vegetal ........................................................... 49

5.2. Análise termogravimétrica da perda de água do $\mathrm{MgSO}_{4} \cdot 7 \mathrm{H}_{2} \mathrm{O}$............... 49

5.3. Calibração da linha experimental............................................................. 51

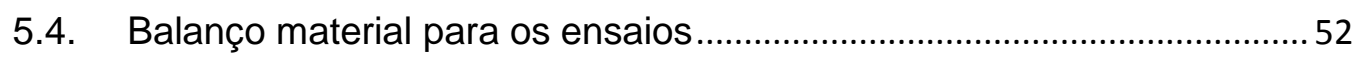


5.4.1. Avaliação da demanda de carbono por mol de $\mathrm{MgSO}_{4}$ em função da variação da temperatura.

5.4.2. Avaliação da relação da perda de massa com a conversão máxima por temperatura 54

5.5. Avaliação das variáveis experimentais 54

5.5.1. Estudo do efeito do excesso do carvão vegetal na conversão da decomposição

5.5.2. Avaliação do comportamento do sistema reacional $\mathrm{MgSO}_{4} .7 \mathrm{H}_{2} \mathrm{O}+$ $\mathrm{C}$ em função da temperatura ao longo do tempo ............................................. 58

5.5.3. Análise do efeito da homogeneidade dos reagentes.........................60

5.5.4. Análise do efeito da vazão do gás de arraste sobre o sistema

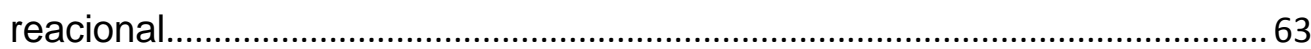

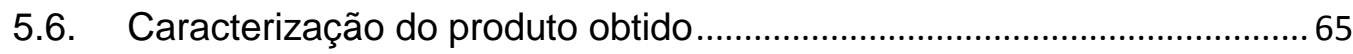

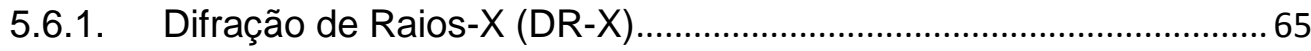

5.6.2. Microcopia eletrônica de varredura/Espectroscopia de Raios-X por

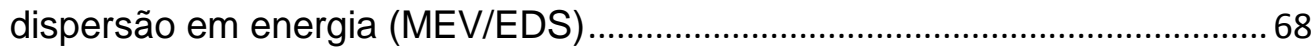

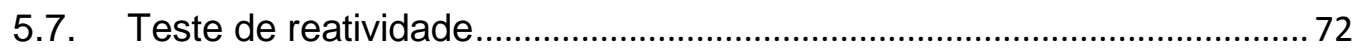

5.7.1. Análise do efeito da agitação da solução na reatividade do MgO.. 72

5.7.2. Análise da temperatura de formação do $\mathrm{MgO}$ na reatividade ..........73

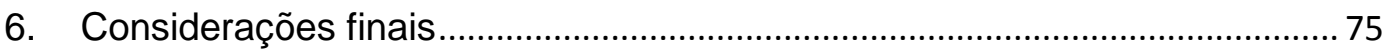

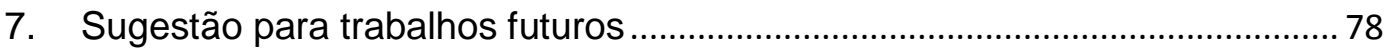

Referências bibliográficas ........................................................................................ 79 


\section{Lista de figuras}

Figura 1. Etapas principais de um fluxograma típico de metalurgia extrativa

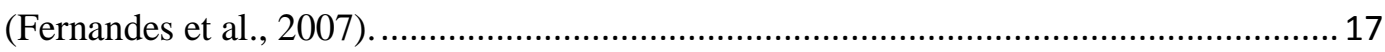

Figura 2. Carvão vegetal "Cariocão" produzido por Glades Distribuidora........................ 24

Figura 3. Sulfato de Magnésio heptahidratado produzido por VETEC. ............................ 25

Figura 4. Ácido Cítrico anidro P. A. produzido por Química Moderna............................. 26

Figura 5. Linha experimental para decomposição do $\mathrm{MgSO}_{4}$ com entrada de argônio .... 27

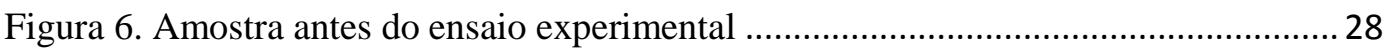

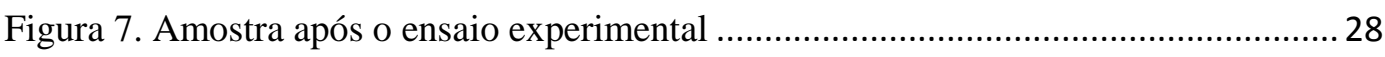

Figura 8. Carvão vegetal moído para caracterização. ……................................................. 29

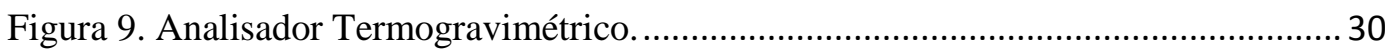

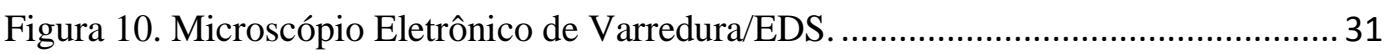

Figura 11. Difratômetro de Raio-X............................................................................. 31

Figura 12. Medidor de $\mathrm{pH}$ de bancada para realização do teste de reatividade. ................ 33

Figura 13. Diagrama de Predominância do Sistema Mg-O-S a temperatura constante de

$25{ }^{\circ} \mathrm{C}$, construído pelo autor com a utilização do HSC 6.0 .............................................. 35

Figura 14. Diagrama de Predominância do Sistema Mg-S-O a temperatura constante de $500{ }^{\circ} \mathrm{C}$, construído pelo autor com a utilização do HSC 6.0 ............................................. 35

Figura 15. Diagrama de Predominância do Sistema Mg-O-S a temperatura constante de $700{ }^{\circ} \mathrm{C}$, construído pelo autor com a utilização do HSC 6.0

Figura 16. Diagrama de Predominância do Sistema Mg-O-S a temperatura constante de $1200{ }^{\circ} \mathrm{C}$, construído pelo autor com a utilização do HSC 6.0.

Figura 17. $\Delta \mathrm{G}^{\mathrm{o}}$ das possíveis reações de decomposição do $\mathrm{MgSO} 4$ formando $\mathrm{MgO}$ e

$\mathrm{MgS}$, construída pelo autor com a utilização do HSC 6.0............................................. 38

Figura 18. $\Delta \mathrm{G}^{\circ}$ das reações de decomposição do $\mathrm{MgSO} 4$ e de equilíbrio $\mathrm{SO} 3 / \mathrm{SO}$,

construída pelo autor com a utilização do HSC 6.0 .................................................... 39

Figura 19. $\Delta \mathrm{G}^{\circ}$ das reações do sistema $\mathrm{C}+\mathrm{O} 2$ e reação de Boudouard, construída pelo autor com a utilização do HSC 6.0 ……………............................................. 41

Figura 20. $\Delta \mathrm{G}^{\circ}$ das reações de decomposição do MgSO4 com e sem a presença do carvão vegetal, construída pelo autor com a utilização do HSC 6.0.

Figura 21. Diagrama de Predominância a pressão de $\mathrm{O}_{2}$ constante de $0,21 \mathrm{~atm}$ variando a temperatura, construído pelo autor com a utilização do HSC 6.0

Figura 22. Diagrama de Predominância a pressão de $\mathrm{O}_{2}$ constante de $10^{-7} \mathrm{~atm}$ variando a temperatura, construído pelo autor com a utilização do HSC 6.0 ...

Figura 23. Diagrama de Predominância a pressão de $\mathrm{O}_{2}$ constante de $10^{-11} \mathrm{~atm}$ variando a temperatura, construído pelo autor com a utilização do HSC 6.0

Figura 24. Diagrama de distribuição de espécies no equilíbrio para a decomposição térmica do $\mathrm{MgSO}_{4}$, construído pelo autor com a utilização do HSC 6.0

Figura 25. Diagrama de distribuição de espécies no equilíbrio para a decomposição térmica do $\quad \mathrm{MgSO}_{4}$ na presença de carbono, construído pelo autor com a utilização do HSC 6.0

Figura 26. Variação mássica percentual do $\mathrm{MgSO} 4.7 \mathrm{H} 2 \mathrm{O}$ com o aumento de temperatura, construída a partir do analisador termogravimétrico...................................................... 50

Figura 27. Curva de calibração da linha experimental, construída pelo autor. ...................5 52 
Figura 28. Perda de massa em função do excesso do agente redutor por temperatura e com 30 minutos de residência.

Figura 29. Conversão da decomposição carbotérmica a $600{ }^{\circ} \mathrm{C}$ em função da homogeneidade do MgSO4.

Figura 30. Conversão da decomposição carbotérmica a $700{ }^{\circ} \mathrm{C}$ em função da homogeneidade do MgSO4.

Figura 31. Conversão da decomposição carbotérmica a $800{ }^{\circ} \mathrm{C}$ em função da homogeneidade do $\mathrm{MgSO} 4$

Figura 32. Conversão da decomposição carbotérmica a $900{ }^{\circ} \mathrm{C}$ em função da homogeneidade do $\mathrm{MgSO} 4$

Figura 33. Conversão da decomposição carbotérmica a $900{ }^{\circ} \mathrm{C}$ em função da homogeneidade do $\mathrm{MgSO} 4$

Figura 34. Espectro de difração de raios-X do produto da decomposição carbotérmica, construída a partir do Difratômetro de raios-X.

Figura 35. Estrutura morfológica do produto da decomposição carbotérmica obtida por EDS

Figura 36. Estrutura morfológica do produto da decomposição carbotérmica obtida por EDS

Figura 37. Espectro da análise por EDS na região 1

Figura 38. Estrutura morfológica do produto da decomposição carbotérmica obtida por EDS

Figura 39. Espectro da análise por EDS na região 2

Figura 40. Estrutura morfológica do produto da decomposição carbotérmica obtida por EDS

Figura 41. Espectro da análise por EDS na região 3 


\section{Lista de tabelas}

Tabela 1. Exemplos de processos voltados para a obtenção de metais (Fernandes et al., 2007).

Tabela 2. Resultados da caracterização do Carvão vegetal 49

Tabela 3. Dados de vazão para calibração da linha experimental 51

Tabela 4. Demanda de carvão vegetal por mol de MgSO4.7H2O em função das temperaturas operacionais

Tabela 5. Perda de massa em função da conversão máxima por temperaturas operacionais

Tabela 6. Análise visual do produto da decomposição carbotérmica em função do excesso do agente redutor por temperatura

Tabela 7. Resultados dos ensaios de decomposição em função do excesso de agente por temperatura

Tabela 8. Resultados dos ensaios de decomposição carbotérmica a $600{ }^{\circ} \mathrm{C}$

Tabela 9. Resultados dos ensaios de decomposição carbotérmica a $700{ }^{\circ} \mathrm{C} \quad 58$

Tabela 10. Resultados dos ensaios de decomposição carbotérmica a $800{ }^{\circ} \mathrm{C} \quad 58$

Tabela 11. Resultados dos ensaios de decomposição carbotérmica a $900{ }^{\circ} \mathrm{C}$

Tabela 12. Resultados de conversão dos ensaios de decomposição carbotérmica do $\mathrm{MgSO}_{4}$

Tabela 13. Resultados de perda de massa dos ensaios de decomposição carbotérmica do $\mathrm{MgSO}_{4} \quad$ com granulometria homogênea

Tabela 14. Comparativo entre as perdas de massa dos ensaios de decomposição carbotérmica do $\mathrm{MgSO} 4$ com granulometria heterogênea e homogênea

Tabela 15. Resultados de perda de massa dos ensaios com vazão de 1,61 L/min e temperatura de $800{ }^{\circ} \mathrm{C}$

Tabela 16. Resultados de perda de massa dos ensaios com vazão de 1,61 L/min e temperatura de $900{ }^{\circ} \mathrm{C}$

Tabela 17. Resultados da análise por EDS na região 1

Tabela 18. Resultados da análise por EDS na região 2 


\section{Lista de abreviaturas}

TGA Analisador Termogravimétrico

DR-X Difratômetro de Raio-X

MEV/EDS Microscópio Eletrônico de Varredura/ Espectroscopia de Raios-X por

Dispersão em Energia 


\section{Introdução}

Este trabalho cobre, essencialmente, comportamento do sistema reacional formado por $\mathrm{MgSO} 4$ heptahidratado na presença do carvão vegetal em diferentes temperaturas. Ele está inserido dentro de um contexto amplo, denominado metalurgia extrativa, o qual, em linhas gerais, cobre os processos físico-químicos voltados para a obtenção de metais a partir de minerais ou subprodutos industriais.

Segundo Habashi (2005) a origem da metalurgia extrativa está associada ao período dos alquimistas quando uma das grandes motivações era a transformação química e a obtenção de metais. Desta forma, se "transmutava" ferro em cobre ao se mergulhar limalhas contendo ferro em uma solução de sulfato de cobre, dissolvia-se o ouro em uma solução de aqua regia $\left(\mathrm{HNO}_{3} / \mathrm{HCl}\right)$ e se obtia salitre (nitrato de potássio) a partir de matéria orgânica putrefecida.

Com o conhecimento teórico crescente dos processos químicos, eles foram se diversificando e, assim, tornando possíveis reações cada vez mais seletivas, tais como a extração por solvente e a troca iônica por resinas, que podem ser aplicadas para a separação de metais específicos e terras raras, respectivamente.

Estudos específicos também chamam atenção para o nítido crescimento da demanda mundial por metais (Reuter et al, 2013), que deve ser acompanhado pela implementação de processos eficientes e amigáveis ambientalmente.

A figura 1 ilustra um fluxograma típico de metalurgia extrativa que pode ser aplicado para diferentes metais, conforme detalhamento incluso na tabela 1. 


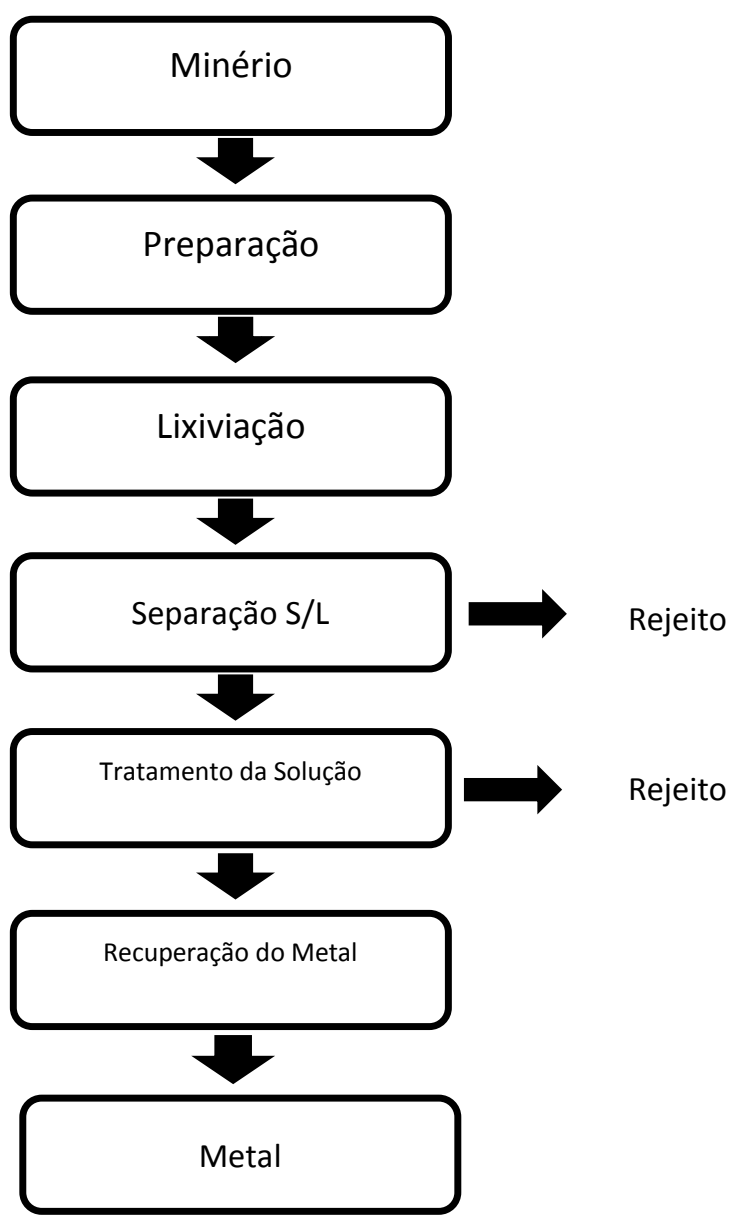

Figura 1. Etapas principais de um fluxograma típico de metalurgia extrativa (Fernandes et al., 2007).

Tabela 1. Exemplos de processos voltados para a obtenção de metais (Fernandes et al., 2007).

\begin{tabular}{|c|c|c|c|c|}
\hline $\begin{array}{c}\text { Meta } \\
1\end{array}$ & Minério & Preparação & Lixiviação & $\begin{array}{l}\text { Tratamento da Solução/ } \\
\text { Recuperação do Metal }\end{array}$ \\
\hline $\mathrm{Al}$ & Bauxita & $\begin{array}{l}\text { Britagem e } \\
\text { Moagem }\end{array}$ & $\begin{array}{l}\text { Sob pressão } \\
\text { com soda, } \\
\mathrm{NaOH}\end{array}$ & $\begin{array}{l}\text { Precipitação do } \mathrm{Al}(\mathrm{OH})_{3} \\
\text { Calcinação, Eletrólise em } \\
\text { Banhos de Sais Fundidos }\end{array}$ \\
\hline \multirow{2}{*}{$\mathrm{Cu}$} & $\begin{array}{l}\text { Minérios } \\
\text { oxidados }\end{array}$ & $\begin{array}{c}\text { Britagem e } \\
\text { Moagem } \\
\text { Aglomeração } \\
\text { (pré-cura ácida) }\end{array}$ & $\begin{array}{c}\text { Com } \mathrm{H}_{2} \mathrm{SO}_{4} \\
\text { em pilhas }\end{array}$ & - \\
\hline & $\begin{array}{l}\text { Baixo teor } \\
\text { parcialmente } \\
\text { oxidado }\end{array}$ & - & $\begin{array}{c}\text { Em pilhas } \\
\text { com } \\
\text { microrganism } \\
\text { os }\end{array}$ & $\begin{array}{c}\text { Extração por Solventes } \\
\text { seguida de } \\
\text { Eletrorrecuperação }\end{array}$ \\
\hline
\end{tabular}




\begin{tabular}{|c|c|c|c|c|}
\hline & $\begin{array}{l}\text { Concentrado } \\
\mathrm{s}\end{array}$ & Flotação & $\begin{array}{l}\text { Lixiviação } \\
\text { em } \\
\text { Autoclaves }\end{array}$ & - \\
\hline \multirow{2}{*}{$\begin{array}{l}\mathrm{Au}, \\
\mathrm{Ag}\end{array}$} & $\begin{array}{l}\text { Nativo e } \\
\text { associado a } \\
\text { sulfetos }\end{array}$ & $\begin{array}{c}\text { Britagem, } \\
\text { Moagem, } \\
\text { Concentração } \\
\text { gravítica, } \\
\text { Flotação }\end{array}$ & $\begin{array}{c}\text { Com } \mathrm{NaCN} \text { e } \\
\text { injeção de ar } \\
\left(\text { ou } \mathrm{O}_{2}\right)\end{array}$ & $\begin{array}{l}\text { Precipitação com Zn ou } \\
\text { Adsorção em Carvão Ativo }\end{array}$ \\
\hline & $\begin{array}{l}\text { Minérios } \\
\text { refratários: } \\
\text { ouro ocluso } \\
\text { em sulfetos }\end{array}$ & $\begin{array}{l}\text { Bioxidação } \\
\text { ustulação ou } \\
\text { oxidação em } \\
\text { autoclaves }\end{array}$ & - & $\begin{array}{c}\text { Cementação com Zn ou } \\
\text { Eletrorrecuperação }\end{array}$ \\
\hline $\mathrm{Zn}$ & $\begin{array}{l}\text { Sulfetado } \\
\text { (ZnS) }\end{array}$ & $\begin{array}{c}\text { Britagem, } \\
\text { Moagem, } \\
\text { Flotação, } \\
\text { Ustulação do } \\
\text { ZnS }\end{array}$ & $\mathrm{Com} \mathrm{H}_{2} \mathrm{SO}_{4}$ & $\begin{array}{l}\text { Precipitação do ferro e } \\
\text { eletrólise do Zn }\end{array}$ \\
\hline $\begin{array}{l}\mathrm{Ni}, \\
\mathrm{Co}\end{array}$ & Lateritas & $\begin{array}{c}\text { Britagem, } \\
\text { Moagem, Pré- } \\
\text { redução }\end{array}$ & $\begin{array}{l}\text { Amoniacal- } \\
\text { Caron (ou } \\
\text { sob pressão } \\
\text { com } \mathrm{H}_{2} \mathrm{SO}_{4}- \\
\text { HPAL) }\end{array}$ & $\begin{array}{c}\text { Precipitação como } \\
\text { carbonatos de Ni/Co, } \\
\text { Dissolução ácida, Extração } \\
\text { por Solventes, } \\
\text { Eletrorrecuperação }\end{array}$ \\
\hline
\end{tabular}

Dentro desde quadro pode-se perceber nitidamente, a abrangência e a importância do tratamento de soluções aquosas oriundas das lixiviações. Por sua vez, este tratamento pode envolver a precipitação seletiva ou uma mudança de $\mathrm{pH}$, as quais são realizadas com a adição de um agente com características, químicas e físicas, específicas.

Dentre estes agentes encontra-se o óxido de magnésio que pode exercer, por exemplo, a função de regulador de pH. Para isso, é fundamental que este óxido tenha uma elevada superfície especifica, propriedade esta, que deve ser estabelecida a partir da utilização de um processo adequado para obtenção deste óxido.

Por outro lado, sabe-se que durante a extração do Ni por lixiviação sulfúrica de minérios silicatados gera-se uma grande quantidade de sulfato de magnésio, o qual 
pode, então, se constituir numa fonte alternativa de $\mathrm{MgO}$ que, por sua vez, poderia vir a substituir o uso de $\mathrm{CaO}$ como regulador de $\mathrm{pH}$, durante uma etapa do próprio processo de extração do Ni.

Desta forma, torna-se motivante a busca por processos que possam atender às condições citadas em termo de granulometria e eficiência. Todavia, aparentemente em função da temperatura exigida para a decomposição, em torno de $1100{ }^{\circ} \mathrm{C}$, o óxido obtido apresenta uma baixa área superficial (Scheidema e Taskinen, 2011; Aphane, 2009).

Alternativas que podem viabilizar uma diminuição desta temperatura seriam uma calcinação submetida à vácuo ou a própria dissociação do sulfato, mas agora assistida com a presença de um agente redutor, seja ele o carbono, $\mathrm{CO}$ ou $\mathrm{H}_{2}$ redutoras (Zhang et al., 2012; Zhang et al., 2013; Hoteit et al., 2007).

Ganha destaque, dentre essas matérias-primas, o carvão vegetal cujo baixo custo de sua produção coloca o carbono à frente das demais opções (Benique, 2007). Dentre as três matérias-primas citadas, o carvão vegetal é a única renovável. Sendo o Brasil um dos maiores produtores desta matéria-prima (Dallastra, 2010).

Dentro deste contexto, este trabalho tem como objetivo geral avaliar o comportamento do sistema reacional constituído por $\mathrm{MgSO}_{4}$ heptahidratado quando na presença de carbono oriundo de carvão vegetal e a eficácia do produto obtido como agente regulador de $\mathrm{pH}$. Seguindo este propósito, foi realizada uma apreciação termodinâmica do sistema reacional e ensaios experimentais de decomposição térmica de $\mathrm{MgSO}_{4}$ heptahidratado com o carbono, analisando particularmente as variáveis do processo. Após esta análise e realização da decomposição carbotérmica, foram elaborados ensaios de caracterização do produto obtido com a proposta de determinar se esses são os produtos desejados. Além de testar se a reatividade do $\mathrm{MgO}$ (produto final) atende as necessidades da proposta. 


\section{Revisão bibliográfica}

\subsection{Estudos envolvendo decomposição de sulfatos}

Okumura et al., (2003) estudaram a decomposição redutora do $\mathrm{CaSO}_{4} \mathrm{em}$ um reator de leito fixo para produção de $\mathrm{CaO}$, com objetivo de servir de absorvente de $\mathrm{SO}_{2}$, em várias condições de atmosfera e de temperatura. Os ensaios foram realizados com atmosferas de $\mathrm{CO}$ e de $\mathrm{CO} / \mathrm{CO}_{2}$ (com razões de 0,067 a 1 ) e em temperaturas de $1396{ }^{\circ} \mathrm{C}$ e $1546{ }^{\circ} \mathrm{C}$. Em todos os ensaios, foi utilizado $\mathrm{N}_{2}$ como gás inerte. Os autores concluíram, após os ensaios, que a decomposição do $\mathrm{CaSO}_{4}$ era mais eficaz na atmosfera de $\mathrm{CO} / \mathrm{CO}_{2} / \mathrm{N}_{2}$ e depende da razão de $\mathrm{CO} / \mathrm{CO}_{2}$. A formação do $\mathrm{CaO}$ foi preterida pela formação do $\mathrm{CaS}$ em atmosfera de $\mathrm{CO} / \mathrm{N}_{2}$. A decomposição obteve o melhor valor de conversão, $91 \%$, a temperatura de $1546{ }^{\circ} \mathrm{C}$ e uma atmosfera de $2 \%$ de $\mathrm{CO}$ e $30 \%$ de $\mathrm{CO}_{2}$. Observou-se que o $\mathrm{CaO}$ obtido pela decomposição do $\mathrm{CaSO}_{4}$ nos ensaios teve uma maior capacidade de absorção de $\mathrm{SO}_{2}$ do que o proveniente da calcinação do calcário, devido a uma maior porosidade do $\mathrm{CaO}$ produzido.

Hoteit et al., (2007) avaliaram o efeito de algumas variáveis no processo de decomposição do $\mathrm{CaSO}_{4}$. Através da análise de isotermas entre $800{ }^{\circ} \mathrm{C}$ e $950{ }^{\circ} \mathrm{C}$ concluiu que a conversão da reação é fortemente afetada pela temperatura, uma vez que a $800{ }^{\circ} \mathrm{C}$ apenas $7 \%$ do sulfato foi decomposto e a $950{ }^{\circ} \mathrm{C}$ a conversão atinge valores de 52\%. Através de ensaios com $2 \%, 1 \%$ e 0,5\% de CO na atmosfera reacional, foi analisada a influência da presença de CO na conversão da decomposição e concluiu-se que a taxa inicial da reação aumenta com o aumento da concentração do $\mathrm{CO}$.

Kato et al., (2012) estudaram a decomposição do $\mathrm{CaSO}_{4}$ anidro na presença de carbono, avaliando o efeito da razão molar $\mathrm{C} / \mathrm{Ca}$ e o efeito da temperatura na decomposição. As razões molares variaram de 0 a 2, enquanto a temperatura foi analisada entre $700{ }^{\circ} \mathrm{C}$ e $1000{ }^{\circ} \mathrm{C}$. O autor obteve as maiores taxas de conversão de $\mathrm{CaSO}_{4}$ em $\mathrm{CaO}$ com uma razão molar de $\mathrm{C} / \mathrm{Ca}$ igual a 0,5 e uma temperatura operacional de $1000{ }^{\circ} \mathrm{C}$. As análises mostraram a importância do controle da razão 
$\mathrm{C} / \mathrm{Ca}$, uma vez que a razões menores que a ideal o $\mathrm{CaSO}_{4}$ não reduz para o óxido de sódio, enquanto em razões maiores o $\mathrm{CaS}$ é formado predominantemente.

\subsection{Estudos envolvendo Sulfato de Magnésio}

Scheidema e Taskinen (2011a) estudaram a estabilidade do sulfato de magnésio em diferentes condições atmosféricas, comparando dados termodinâmicos disponíveis pelo HSC Chemistry com os resultados obtidos pela análise térmica pelo TG-DSC. Os dados termodinâmicos mostraram que na presença de agentes redutores é possível reduzir a temperatura de decomposição do sulfato de magnésio de $1085^{\circ} \mathrm{C}$ para valores de $592{ }^{\circ} \mathrm{C}, 623{ }^{\circ} \mathrm{C}$ e $606{ }^{\circ} \mathrm{C}$ na presença de monóxido de carbono, enxofre e hidrogênio, respectivamente. Já a análise térmica pelo TG-DSC demonstrou que o sulfato de magnésio se decompõem a $1100{ }^{\circ} \mathrm{C}$ em atmosfera de $\mathrm{N}_{2}$, a $1070{ }^{\circ} \mathrm{C}$ em uma atmosfera de $10 \%$ de $\mathrm{CO}$ e $90 \%$ de $\mathrm{N}_{2}$ e a $950{ }^{\circ} \mathrm{C}$ com uma atmosfera de $5 \%$ de $\mathrm{H}_{2}$ e $95 \%$ de $\mathrm{N}_{2}$. Os autores ressaltam que na presença de agentes redutores a redução na temperatura de decomposição resulta em um menor gasto energético para o processo, uma vez que ocorre uma redução de $150{ }^{\circ} \mathrm{C}$ na decomposição do sulfato de magnésio, e uma produção de um $\mathrm{MgO}$ mais reativo.

Ding et al., (2011) estudaram a redução termoquímica do sulfato de magnésio pelo gás natural na presença de água. Os resultados encontrados apontam que o gás natural reagiu com $\mathrm{MgSO}_{4}$ para produzir $\mathrm{H}_{2} \mathrm{~S}, \mathrm{CO}_{2}, \mathrm{MgO}$ e betume sólido como os principais produtos. $\mathrm{O}$ trabalho alcançou tais resultados em temperaturas de $450^{\circ} \mathrm{C}$, $480^{\circ} \mathrm{C}, 510^{\circ} \mathrm{C}, 540^{\circ} \mathrm{C}$ e $570^{\circ} \mathrm{C}$. Os autores ressaltaram a importância da água no sistema devido ao fator a mesma influenciar na reatividade do sulfato de magnésio.

Plewa e Steindor (1987) comprovaram em seu trabalho que é possível reduzir o sulfato de magnésio por $\mathrm{CO}$ a partir de $550{ }^{\circ} \mathrm{C}$, para formar sulfeto de magnésio e óxido de magnésio. Os autores demonstraram experimentalmente que acima de 625 ${ }^{\circ} \mathrm{C}$ o sulfato de magnésio não é estável e não se forma. $\mathrm{O}$ controle da velocidade da reação de redução varia em função da temperatura. Pode-se observar que existe um controle de nucleação entre $600{ }^{\circ} \mathrm{C}$ e $625{ }^{\circ} \mathrm{C}$, enquanto o controle por reação química pode ser notado na faixa de $640^{\circ} \mathrm{C}$ à $675^{\circ} \mathrm{C}$. A temperaturas mais elevadas, 
a difusão desempenha um papel importante e ocorre a mudança da taxa de controle de acordo com o tempo a temperatura constante. Um modelo cinético foi utilizado para descrever o comportamento da reação na faixa de $640{ }^{\circ} \mathrm{C}$ à $675{ }^{\circ} \mathrm{C}$. Os resultados foram compatíveis com os encontrados experimentalmente e foi possível determinar uma energia de ativação da reação próxima a 209,7kJ/mol.

\subsection{Estudos envolvendo Óxido de Magnésio}

Scheidema e Taskinen (2011b) ressaltam em seu trabalho que a quantidade de agente redutor utilizado tem um efeito significativo na estrutura do produto de óxido de magnésio, a forma cristalina do $\mathrm{MgO}$ é claramente visível quando é utilizada uma ou duas vezes a quantidade estequiométrica de enxofre, mas a difusão ocorre quando se utiliza quatro vezes a quantidade estequiométrica. Isto gera um produto com uma área de superfície reduzida não desejada como resultado, portanto não se deve utilizar muito enxofre na reação. $O$ tamanho da partícula tem extrema importância no grau de decomposição, pois quanto menor o tamanho da partícula utilizada na reação maior será a conversão.

Segundo Aramendía (2003), o óxido de magnésio pode ser produzido por calcinação, a partir de $600{ }^{\circ} \mathrm{C}$, dos sais de magnésio, como os carbonatos, nitratos e sulfatos. A calcinação a altas temperaturas provoca a decomposição do sal, com a emissão de gases como $\mathrm{CO}_{2}, \mathrm{NO}_{2}$ e $\mathrm{SO}_{2}$, que quebram a estrutura sólida, aumentando assim a porosidade e a área superficial do material. O autor ressalta que industrialmente os óxidos de magnésio são usados em uma vasta série de aplicações, por exemplo, como precursores para muitos materiais cerâmicos e catalisadores e que como material catalítico, um aspecto interessante é seu caráter básico.

Em seu estudo, Aphane (2009) relaciona algumas propriedades físicas e químicas dos óxidos de magnésio formados a partir da decomposição térmica do carbonato de magnésio em diferentes temperaturas. $\mathrm{O}$ óxido formado por calcinação entre $600{ }^{\circ} \mathrm{Ce} 1000{ }^{\circ} \mathrm{C}$ apresentou, uma área superficial de até $200 \mathrm{~m}^{2} / \mathrm{g}$, uma fácil dissolução em ácidos diluídos e uma alta reatividade química. O óxido formado por calcinação entre $1100{ }^{\circ} \mathrm{C}$ e $1650{ }^{\circ} \mathrm{C}$ apresentou, uma área superficial 
entre 0,1 e $1 \mathrm{~m}^{2} / \mathrm{g}$, uma fácil dissolução em ácidos concentrados e uma baixa reatividade química. Já os óxidos formados por calcinação nas maiores temperaturas analisadas, entre $1450{ }^{\circ} \mathrm{C}$ e $2200{ }^{\circ} \mathrm{C}$ e entre $2800{ }^{\circ} \mathrm{C}$ e $3000{ }^{\circ} \mathrm{C}$, apresentaram, uma área superficial menor que $0,1 \mathrm{~m}^{2} / \mathrm{g}$, uma dissolução muito lenta em ácidos fortes e uma reatividade química muito baixa.

\subsection{Utilização do Óxido de Magnésio como regulador de pH}

Segundo Freitas et al., (2009), o MgO foi utilizado em conjunto com o carbonato de cálcio $\left(\mathrm{CaCO}_{3}\right)$ para corrigir a acidez de um solo Espodossolo Cárbico hidromófico, proveniente de uma área de deposição de escórias de uma empresa recicladora de baterias automotivas, elevando o $\mathrm{pH}$ para a faixa de 6,0 a 6,2.

Mo et al., (2010) em seu trabalho, sobre os efeitos das condições de calcinação na propriedade de expansão do $\mathrm{MgO}$ como agente expansivo para materiais a base de cimento, estudou o efeito da temperatura e o tempo de residência na produção do $\mathrm{MgO}$. O MgO foi produzido a partir da calcinação do Carbonato de Magnésio $\left(\mathrm{MgCO}_{3}\right)$ com uma variação na temperatura de $900{ }^{\circ} \mathrm{C}$ a $1300{ }^{\circ} \mathrm{C}$ e com tempos de residência de $30 \mathrm{~min}, 60 \mathrm{~min}$ e $90 \mathrm{~min}$. Após as análises em MEV, DR-X, BET e o teste de reatividade nas amostras obtidas, foi observado que com maiores temperaturas e mais tempo de residência o $\mathrm{MgO}$ obtido tem menor área superficial e menor reatividade. Os autores encontraram os seguintes tempos de nos testes de reatividade: 46 segundos para a amostra produzida a $900{ }^{\circ} \mathrm{C}, 352$ segundos para a amostra produzida a $1100{ }^{\circ} \mathrm{C}$ e 1966 segundos para a amostra produzida a $1300{ }^{\circ} \mathrm{C}$. 


\section{Materiais e métodos}

\subsection{Reagentes utilizados}

Ao longo do estudo foram utilizados o sulfato de magnésio sintético heptahidratado e o carvão vegetal, como agente redutor, para a realização dos experimentos de decomposição carbotérmica com o intuito de obter o óxido de magnésio, além da utilização de ácido cítrico para os testes de reatividade do produto obtido.

\subsubsection{Carvão vegetal}

Nos ensaios experimentais foi utilizado o carvão vegetal, disponível em supermercados como fonte de carbono (Figura 2). O carvão vegetal utilizado foi produzido pela Glades Distribuidora, lote 17. O carvão vegetal foi moído para aumentar sua homogeneidade e sua superfície de contato durante as reações, ele também passou por etapas de caracterização, conforme metodologia estabelecida pela norma internacional ASTM D1762-84 para a determinação das porcentagens de umidade, de voláteis, de cinzas e carbono fixo presentes em sua estrutura. O carvão utilizado nos ensaios foi seco e destilado para utilização de um carvão com elevador teor de carbono. Os processos de secagem e destilação do carvão têm o intuito de realizar a retirada das impurezas presentes no carvão que será utilizado como agente redutor e assim diminuir a possível influência destas impurezas nos ensaios.

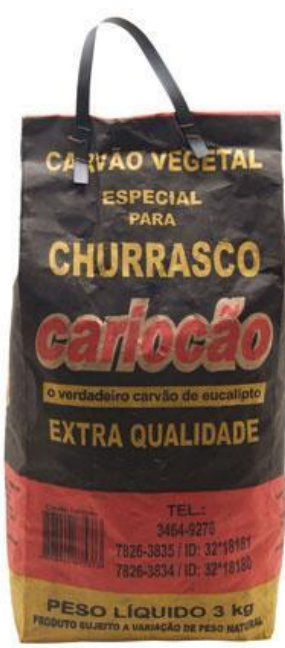

Figura 2. Carvão vegetal "Cariocão" produzido por Glades Distribuidora. 


\subsubsection{Sulfato de Magnésio heptahidratado}

O Sulfato de Magnésio utilizado nos ensaios experimentais foi o Sulfato de Magnésio heptahidratado sintético com um grau de pureza de aproximadamente 98\% produzido pela VETEC, exemplificado na Figura 3. Para os ensaios o $\mathrm{MgSO}_{4} .7 \mathrm{H}_{2} \mathrm{O}$ foi moído, para aumentar a superfície de contato durante os ensaios e a homogeneidade do material. $\mathrm{O} \mathrm{MgSO}_{4}$ é normalmente encontrado em diferentes graus de hidratação, que por sua vez são determinados pela temperatura em que ocorrem estas cristalizações. $\mathrm{O} \mathrm{MgSO}_{4}$ heptahidratado foi escolhido para os ensaios por ser o mais facilmente obtido, já que em seu processo de cristalização este grau de hidratação é o mais estável em condições padrões de temperatura e pressão (Perry e Green, 2010).

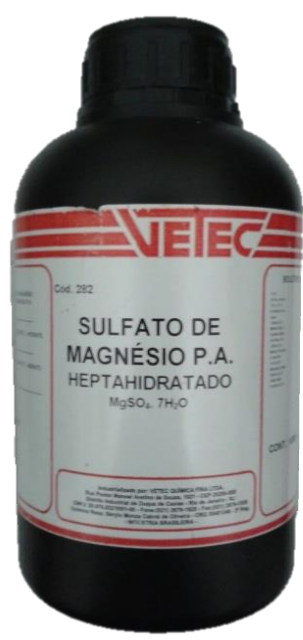

Figura 3. Sulfato de Magnésio heptahidratado produzido por VETEC.

\subsection{3. Ácido Cítrico}

$\mathrm{O}$ ácido cítrico utilizado nos testes de reatividade do $\mathrm{MgO}$ foi o ácido cítrico anidro sólido com um grau de pureza de 99,5\% produzido pela Química Moderna (Figura 4). O teste de reatividade envolvendo o ácido cítrico foi o escolhido por estar presente em vários estudos como os de Mo et al., (2010), Canteford (1985) e Aphane (2009) que foram utilizados como referências para este trabalho. 


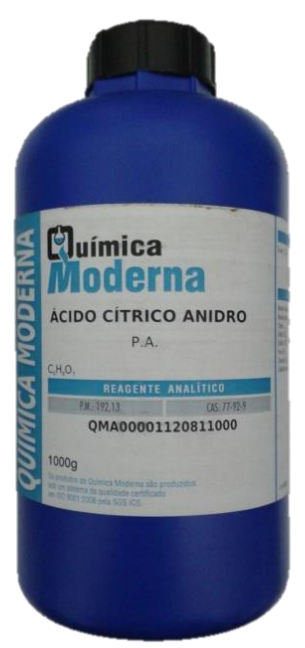

Figura 4. Ácido Cítrico anidro P. A. produzido por Química Moderna.

\subsection{Metodologia experimental}

Os ensaios experimentais de decomposição carbotérmica do $\mathrm{MgSO}_{4} .7 \mathrm{H}_{2} \mathrm{O}$ foram realizados em um forno experimental tubular apresentado na Figura 5. Em cada ensaio foi utilizado aproximadamente 0,5 grama da mistura do $\mathrm{MgSO}_{4} \cdot 7 \mathrm{H}_{2} \mathrm{O}$ com o carvão vegetal alocada em uma forma de porcelana do tipo barquete. $\mathrm{O}$ sulfato de magnésio heptahidratado foi utilizado com duas distribuições granulométricas distintas, uma heterogênea e com uma granulometria variando de $2,8 \mathrm{~mm}$ a $0,5 \mathrm{~mm}$ e outra homogênea com granulometria menor que $1 \mathrm{~mm}$. O carvão vegetal utilizado nos ensaios foi destilado e moído de forma homogênea, com uma granulometria menor que $1 \mathrm{~mm}$.

Estas amostras foram submetidas a ensaios com variadas temperaturas e diferentes fluxos do gás inerte ultrapuro, o argônio. Seguindo a apreciação termodinâmica, foram realizados ensaios com uma variação de temperatura entre $600{ }^{\circ} \mathrm{C}$ e $900{ }^{\circ} \mathrm{C}$. As vazões utilizadas foram determinadas de acordo com a capacidade de vazão apresentada na linha experimental. Abaixo estão os ensaios realizados:

$\rightarrow$ Temperatura de $600{ }^{\circ} \mathrm{C}$ e vazão do gás de arraste de aproximadamente 0,33 L/min;

$\rightarrow$ Temperatura de $700{ }^{\circ} \mathrm{C}$ e vazão do gás de arraste de aproximadamente 0,33 L/min; 
$\rightarrow \quad$ Temperatura de $800{ }^{\circ} \mathrm{C}$ e vazão do gás de arraste de aproximadamente 0,33 $\mathrm{L} / \mathrm{min}$

$\rightarrow \quad$ Temperatura de $800{ }^{\circ} \mathrm{C}$ e vazão do gás de arraste de aproximadamente 1,61 L/min;

$\rightarrow$ Temperatura de $900{ }^{\circ} \mathrm{C}$ e vazão do gás de arraste de aproximadamente 0,33 L/min;

$\rightarrow$ Temperatura de $900{ }^{\circ} \mathrm{C}$ e vazão do gás de arraste de aproximadamente 1,61 L/min.

De acordo com Brocchi et al., (2013), a decomposição carbotérmica do sulfato de magnésio é uma reação relativamente rápida que atinge valores de conversão que tendem a se estabilizar após 30 minutos de residência em reatores de escala similares ao utilizado neste trabalho, portanto este intervalo foi o utilizado no experimento como tempo máximo dos ensaios.

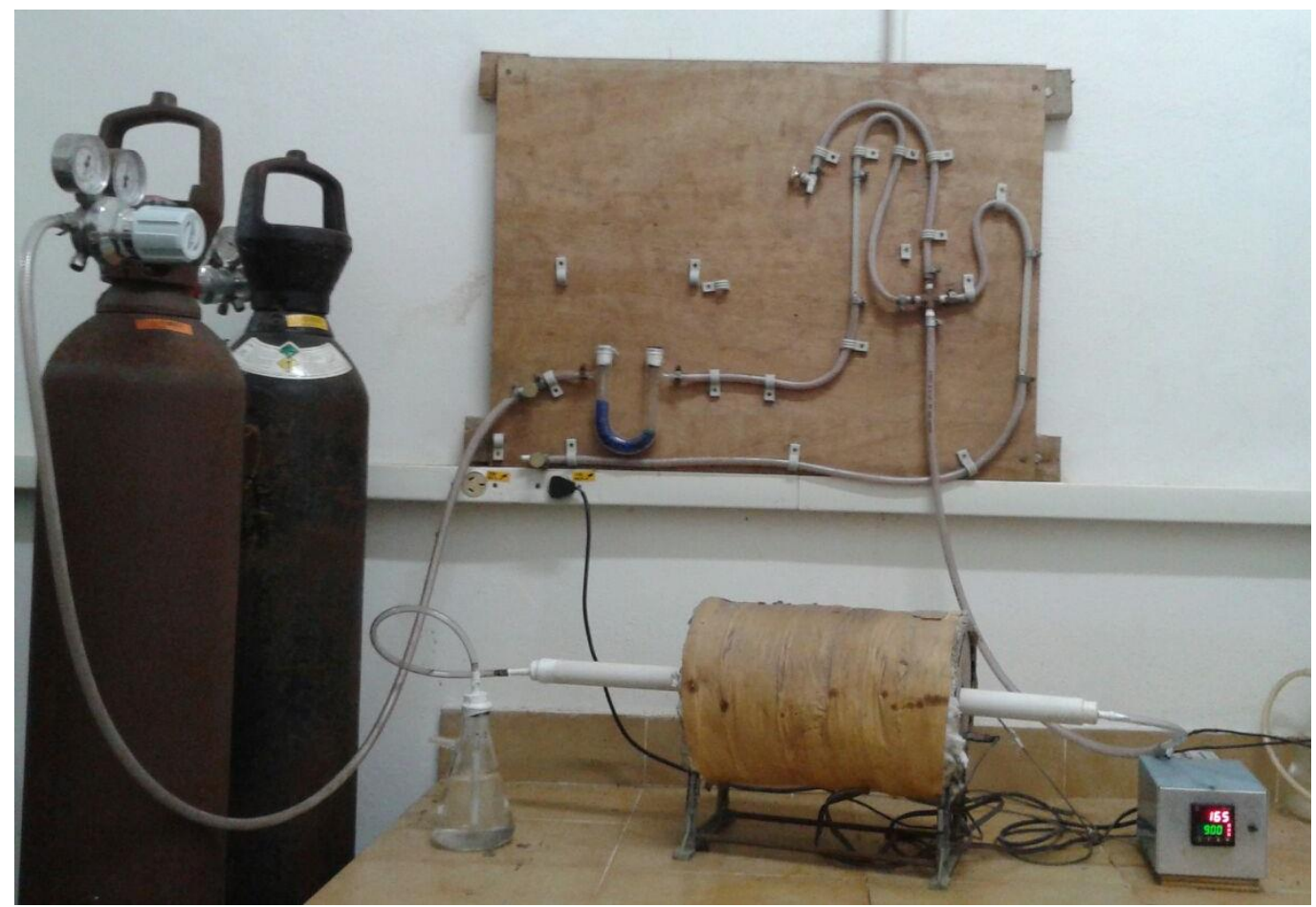

Figura 5. Linha experimental para decomposição do $\mathrm{MgSO}_{4}$ com entrada de argônio

Após o aquecimento do forno até a temperatura de processo, as amostras eram inseridas e acondicionadas na parte central, região isotérmica, do forno para garantia de um aquecimento homogêneo da amostra. As amostras durante o ensaio eram submetidas a um fluxo de argônio com a vazão desejada para o ensaio, com o 
propósito de retirar os gases formados pela decomposição do sulfato de magnésio e garantir uma atmosfera favorável à reação. As Figuras 6 e 7 apresentam o aspecto físico das amostras antes e depois dos ensaios.

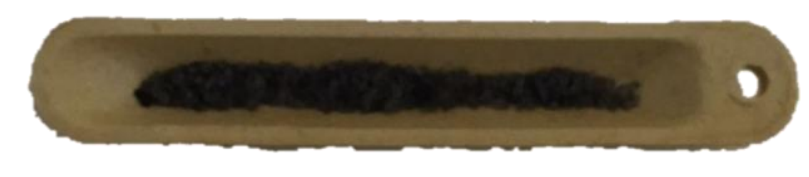

Figura 6. Amostra antes do ensaio experimental

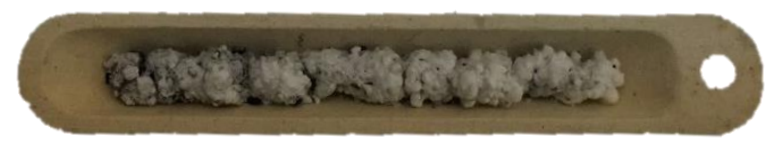

Figura 7. Amostra após o ensaio experimental

\subsection{Metodologia de caracterização}

As matérias-primas passaram por análises específicas para os devidos ajustes experimentais. Sob estas condições, portanto, o carvão foi caracterizado pela metodologia ASTM D1762-84, enquanto o sulfato de magnésio heptahidratado passou pelo analisador termogravimétrico. A fim de identificar se $\mathrm{MgO}$, objetivo do estudo, está sendo formado e auxiliar no entendimento do comportamento do sistema reacional, o produto obtido pelo ensaio de maior conversão passou por uma caracterização fazendo uso da Microscopia Eletrônica de Varredura/Espectroscopia de Raios-X por Dispersão em Energia (MEV/EDS) e Difração de Raios-X (DR-X) e uma análise de reatividade.

\subsubsection{Metodologia de caracterização do Carvão vegetal ASTM D1762-} 84

A caracterização do carvão vegetal teve três etapas, sendo elas: secagem, destilação e queima, seguindo a metodologia determinada pela norma internacional ASTM D1762-84 de 2013. Entretanto, para iniciar o processo de caracterização o carvão vegetal foi moído a uma granulometria menor que $1 \mathrm{~mm}$, como exemplificado na Figura 8. 
A secagem do carvão foi realizada com o material já moído em um forno à aproximadamente $100{ }^{\circ} \mathrm{C}$ por duas horas, em atmosfera inerte para a retirada da umidade presente na amostra. Passadas as duas horas o material foi pesado e retornado ao forno para um intervalo de mais dez minutos, quando se realizou outra medição para verificar se houve nova perda de umidade. Estas medições em curtos espaços de tempo foram realizadas até se atingir um peso constante de massa seca.

Após a secagem a mesma amostra seguiu para um forno à $950{ }^{\circ} \mathrm{C}$, onde ficou por 10 minutos, sob atmosfera inerte, para a retirada dos materiais voláteis. Em seguida a amostra foi pesada e retornada ao forno para mais dois minutos à $950{ }^{\circ} \mathrm{C}$. Após este tempo uma nova pesagem foi realizada a fim de confirmar a retirada total dos materiais voláteis.

Na última destas etapas, o material restante foi levado para uma mufla à $750{ }^{\circ} \mathrm{C}$ por seis horas, para a queima completa do carvão. Após estas seis horas a perda de massa foi medida a cada meia hora até que o valor obtido não se alterasse.

Com os valores encontrados de perda de massa em cada etapa foram calculadas as porcentagens de umidade, de voláteis e de cinzas (ASTM ,2013). A porcentagem de carbono fixo foi calculada pela diferença entre as porcentagens medidas e o total da amostra.

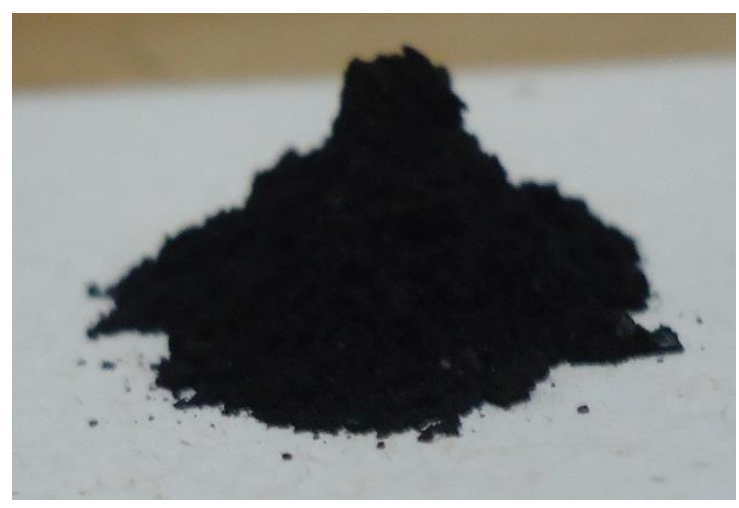

Figura 8. Carvão vegetal moído para caracterização.

\subsubsection{Analisador Termogravimétrico (TGA)}

O Analisador Termogravimétrico da Netzsch modelo STA 449 F3 Jupiter, Figura 9, do Departamento de Engenharia Química e de Materiais da Pontifícia Universidade Católica do Rio de Janeiro (DEQM/PUC-Rio) foi utilizado para 
observar o comportamento da perda de água do $\mathrm{MgSO} 4.7 \mathrm{H} 2 \mathrm{O}$ sintético durante variação da temperatura de $25{ }^{\circ} \mathrm{C}$ a $900{ }^{\circ} \mathrm{C}$. As condições operacionais da análise foram:

$\rightarrow$ Um cadinho de alumina;

$\rightarrow$ Atmosfera de nitrogênio ultrapuro;

$\rightarrow$ Rampa de aquecimento de $15{ }^{\circ} \mathrm{C}$ por minuto.

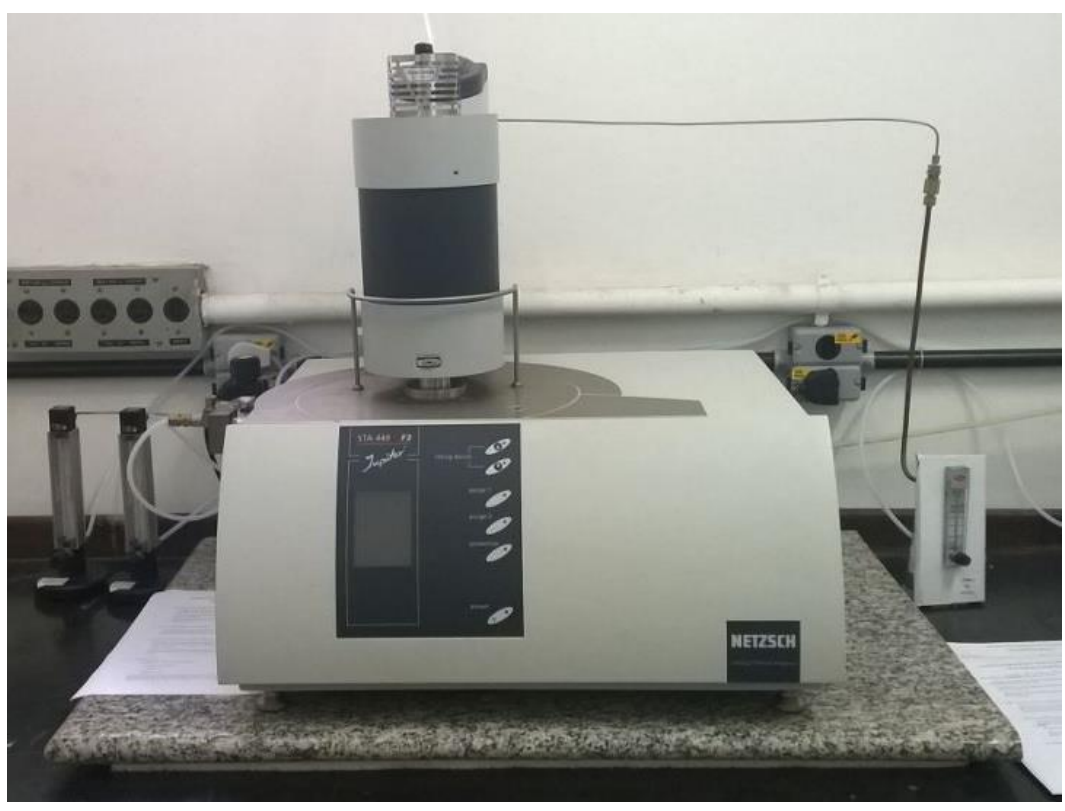

Figura 9. Analisador Termogravimétrico.

\subsubsection{Microscópio Eletrônico de Varredura/Espectroscopia de Raios- $X$ por Dispersão em Energia (MEV/EDS)}

O Microscópio Eletrônico de Varredura/ Espectroscopia de Raios-X por Dispersão em Energia (MEV/EDS) da Hitachi modelo TM-3000, Figura 10, foi utilizado para a análise da morfologia e uma análise química elementar do produto obtido pelos ensaios. As análises foram realizadas por um equipamento do Departamento de Engenharia Química e de Materiais da Pontifícia Universidade Católica do Rio de Janeiro (DEQM/PUC-Rio). Para a análise química dos elementos presentes nas regiões analisadas das amostras foi utilizada a técnica detecção de Raios-X característicos, oriundos da amostra quando submetida ao feixe de elétrons. As análises realizadas não captam a presença de oxigênio ou elementos de menor número atômico. 


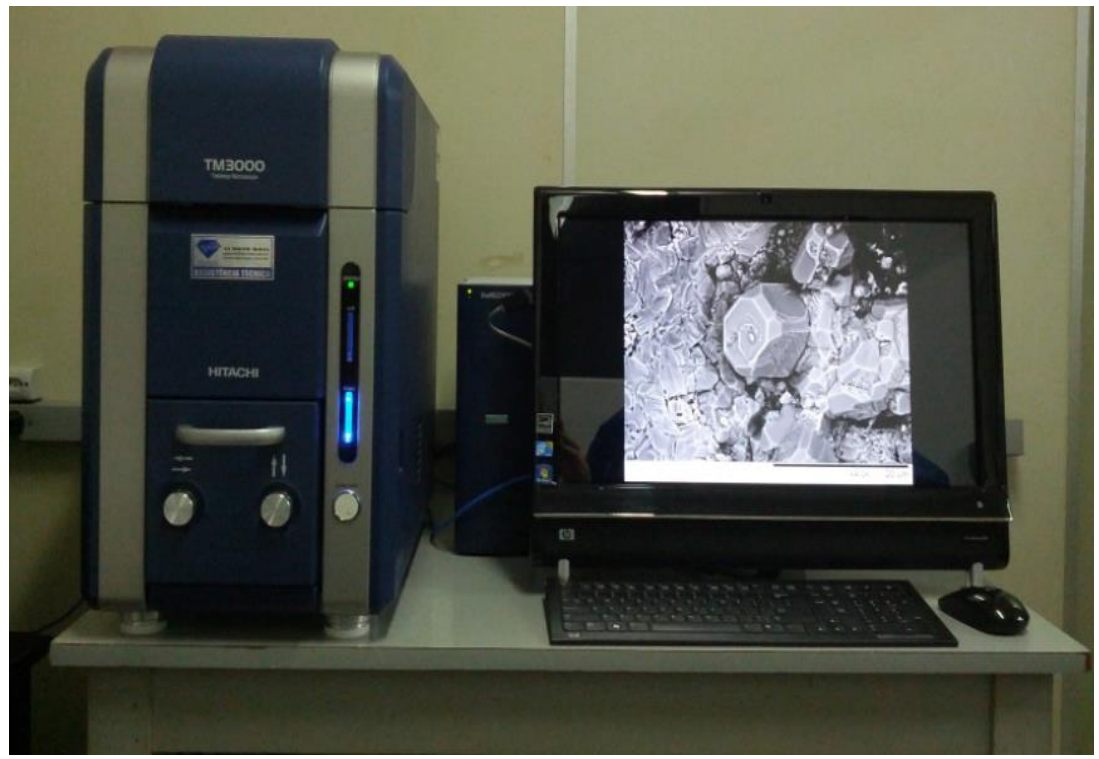

Figura 10. Microscópio Eletrônico de Varredura/EDS.

\subsubsection{Difratômetro de Raios-X (DR-X)}

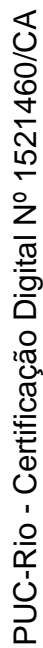

A utilização do Difratômetro de Raios-X da Bruker modelo D8 Discover, Figura 11, se fez necessária para uma avaliação da composição mineralógica do produto obtido. O Difratômetro de Raios-X utilizado faz parte do Departamento de Engenharia Química e de Materiais da Pontifícia Universidade Católica do Rio de Janeiro (DEQM/PUC-Rio).

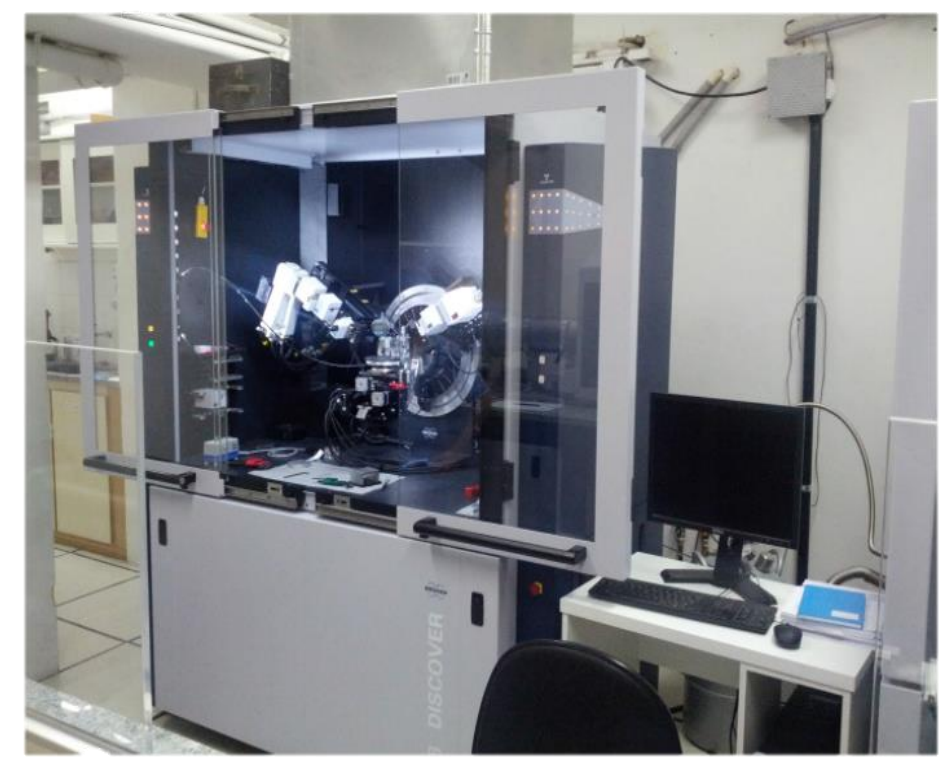

Figura 11. Difratômetro de Raio-X. 


\subsubsection{Teste de reatividade}

Segundo Canteford (1985) e Aphane (2009) existem vários métodos para se determinar a reatividade do óxido de magnésio produzido a partir de uma calcinação. Entre esses métodos estão: por absorção de iodo, por BET e por reatividade com ácido. $\mathrm{O}$ método por absorção de iodo determina a reatividade pela quantidade de iodo absorvido pela amostra. O método BET determina a área superficial do $\mathrm{MgO}$ pelo método de adsorção. Por fim, a reatividade com ácido utiliza o tempo que uma massa de $\mathrm{MgO}$ leva para reagir com um determinado volume de ácido cítrico ou acético. Neste trabalho vamos determinar a reatividade do óxido de magnésio pelo último método aqui apresentado.

Os testes de reatividade do $\mathrm{MgO}$ com ácido, obtido pela decomposição carbotérmica do $\mathrm{MgSO}_{4}$, foram realizados na presença de ácido cítrico $\left(\mathrm{C}_{6} \mathrm{H}_{8} \mathrm{O}_{7}\right)$ e foram baseados na metodologia descrita por Yi et al., (2016).

Para a realização dos testes, o $\mathrm{MgO}$ foi moído para tamanhos abaixo de $63 \mu \mathrm{m}$. Uma solução de $100 \mathrm{~mL}$ de ácido cítrico $0,07 \mathrm{~mol} / \mathrm{L}$ foi preparada e mantida a 40 ${ }^{\circ} \mathrm{C}$ sob agitação constante em um béquer de $500 \mathrm{~mL}$. O então $\mathrm{MgO}$ foi vertido na solução de ácido cítrico e foram utilizados $0,850 \mathrm{~g}$ de $\mathrm{MgO}$ para cada teste.

Este teste consiste em uma análise quantitativa do tempo de reação do $\mathrm{MgO}$ com o ácido cítrico $\left(\mathrm{C}_{6} \mathrm{H}_{8} \mathrm{O}_{7}\right)$. Desta forma, o tempo de reação foi medido a partir do instante em que os reagentes entraram em contato até o momento em que o pH da solução atingiu os valores necessários. Para que a proposta de utilização do $\mathrm{MgO}$ como regulador de $\mathrm{pH}$ seja eficiente, o pH da solução teve que atingir valores maiores que oito e meio em um tempo menor que dois minutos. Os tempos encontrados, por fim, foram anotados para análise posterior.

O medidor de $\mathrm{pH}$ utilizado foi o mPA-210 da MS Tecnopon Instrumentação, Figura 12, o aparelho foi calibrado para marcação de uma variação de 0,01 no pH. 


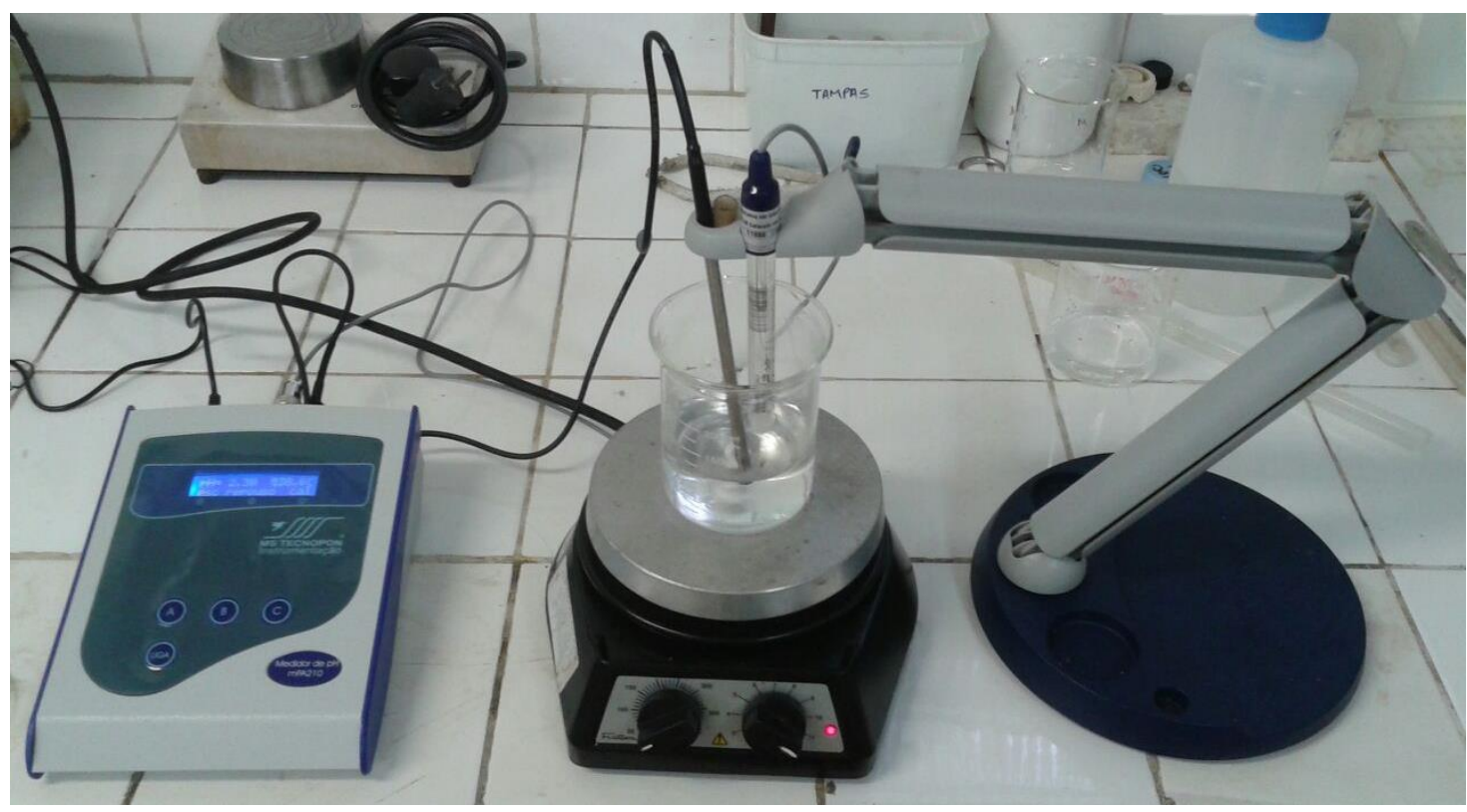

Figura 12. Medidor de $\mathrm{pH}$ de bancada para realização do teste de reatividade.

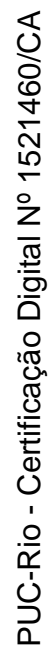




\section{Apreciação termodinâmica}

Antes dos ensaios experimentais foi necessária a realização de uma apreciação termodinâmica que ajudou no entendimento do comportamento do sistema reacional abordado no presente trabalho.

Tal apreciação serviu como base para a realização dos ensaios que a seguiram, abordando as espécies predominantes nas temperaturas já apresentadas, as possíveis reações envolvidas no sistema, as necessidades operacionais do sistema, os possíveis produtos e subprodutos das reações, entre outros aspectos.

\subsection{Estudo do sistema reacional da decomposição do $\mathrm{MgSO}_{4}$}

Uma vez que este trabalho tem como objetivo a formação de óxido de magnésio.

O estudo do sistema Mg-O-S se fez necessário para uma análise das possíveis espécies que seriam formadas a partir da decomposição do sulfato de magnésio, pois esta decomposição poderia se dar por meio de várias reações:

$$
\begin{aligned}
& \mathrm{MgSO}_{4} \rightarrow \mathrm{MgO}+\mathrm{SO}_{3}(\mathrm{~g}) \\
& \mathrm{MgSO}_{4} \rightarrow \mathrm{MgO}+\mathrm{SO}_{2}(\mathrm{~g})+0,5 \mathrm{O}_{2}(\mathrm{~g}) \\
& \mathrm{MgSO}_{4} \rightarrow \mathrm{MgSO}+0,5 \mathrm{O}_{2}(\mathrm{~g}) \\
& \mathrm{MgSO}_{4} \rightarrow \mathrm{MgS}+2 \mathrm{O}_{2}(\mathrm{~g}) \\
& \mathrm{MgSO}_{4} \rightarrow \mathrm{MgO}+\mathrm{SO}_{2}(\mathrm{~g}) \\
& \mathrm{MgSO}_{4} \rightarrow \mathrm{Mg}+\mathrm{SO}_{2}(\mathrm{~g})+\mathrm{O}_{2}(\mathrm{~g}) \\
& \mathrm{MgSO}_{4} \rightarrow \mathrm{Mg}+\mathrm{SO}_{3}(\mathrm{~g})+0,5 \mathrm{O}_{2}(\mathrm{~g})
\end{aligned}
$$

Para isso, é interessante a realização de uma abordagem das condições de equilíbrio das espécies a partir de diagramas de predominância construídos com o HSC Chemistry 6.0 (Roine, 2006). As Figuras 13 a 16 apresentam os diagramas de predominância para o sistema $\mathrm{Mg}-\mathrm{O}-\mathrm{S}$, a temperaturas constantes entre $25^{\circ} \mathrm{C}$ e $1200{ }^{\circ} \mathrm{C}$ e pressões de $\mathrm{O}_{2}$ e $\mathrm{SO}_{2}$ variando, estes apresentaram informações cruciais para o prosseguimento do estudo. 


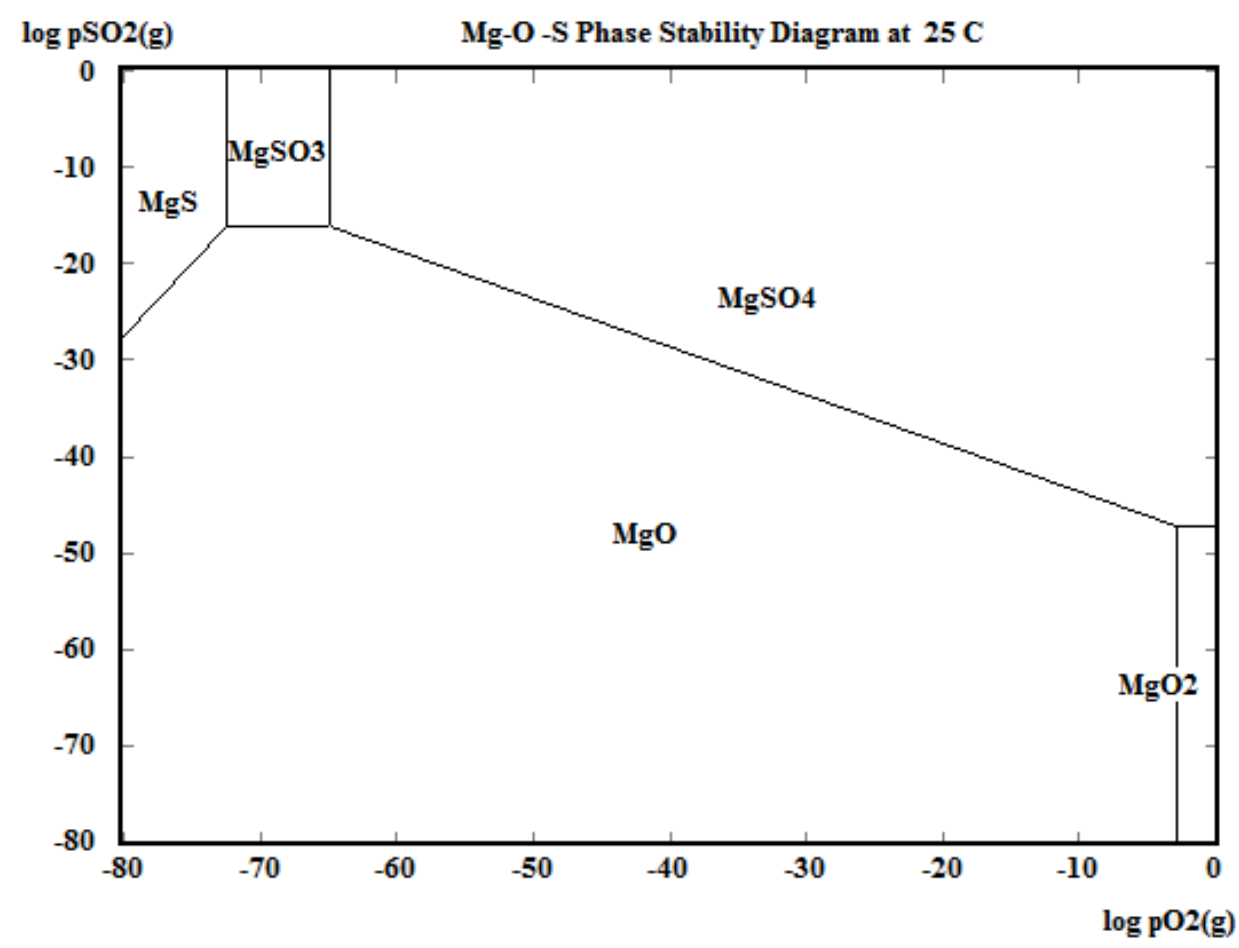

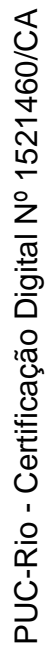

Figura 13. Diagrama de Predominância do Sistema Mg-O-S a temperatura constante de $25{ }^{\circ} \mathrm{C}$, construído pelo autor com a utilização do HSC 6.0

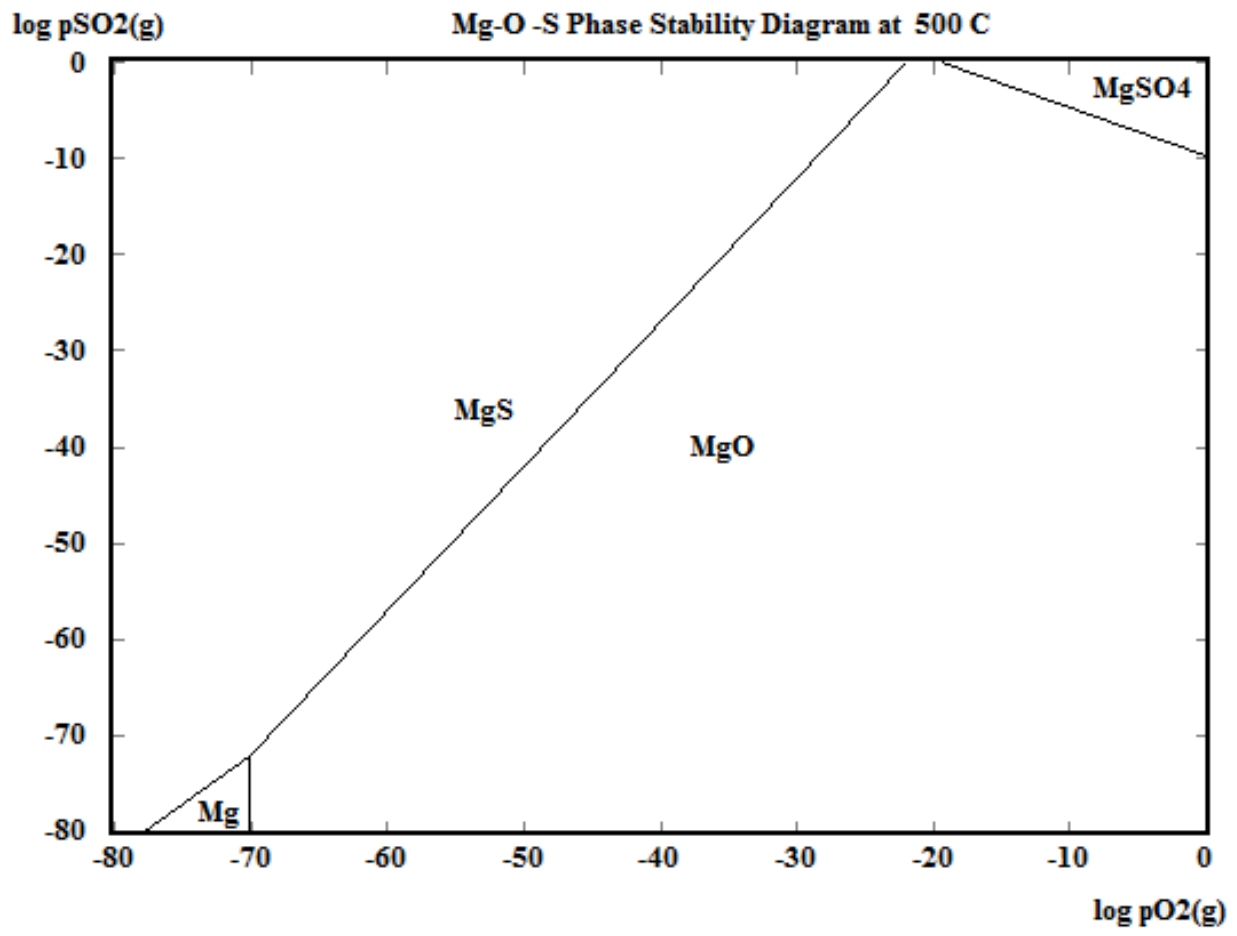

Figura 14. Diagrama de Predominância do Sistema Mg-S-O a temperatura constante de $500{ }^{\circ} \mathrm{C}$, construído pelo autor com a utilização do HSC 6.0 


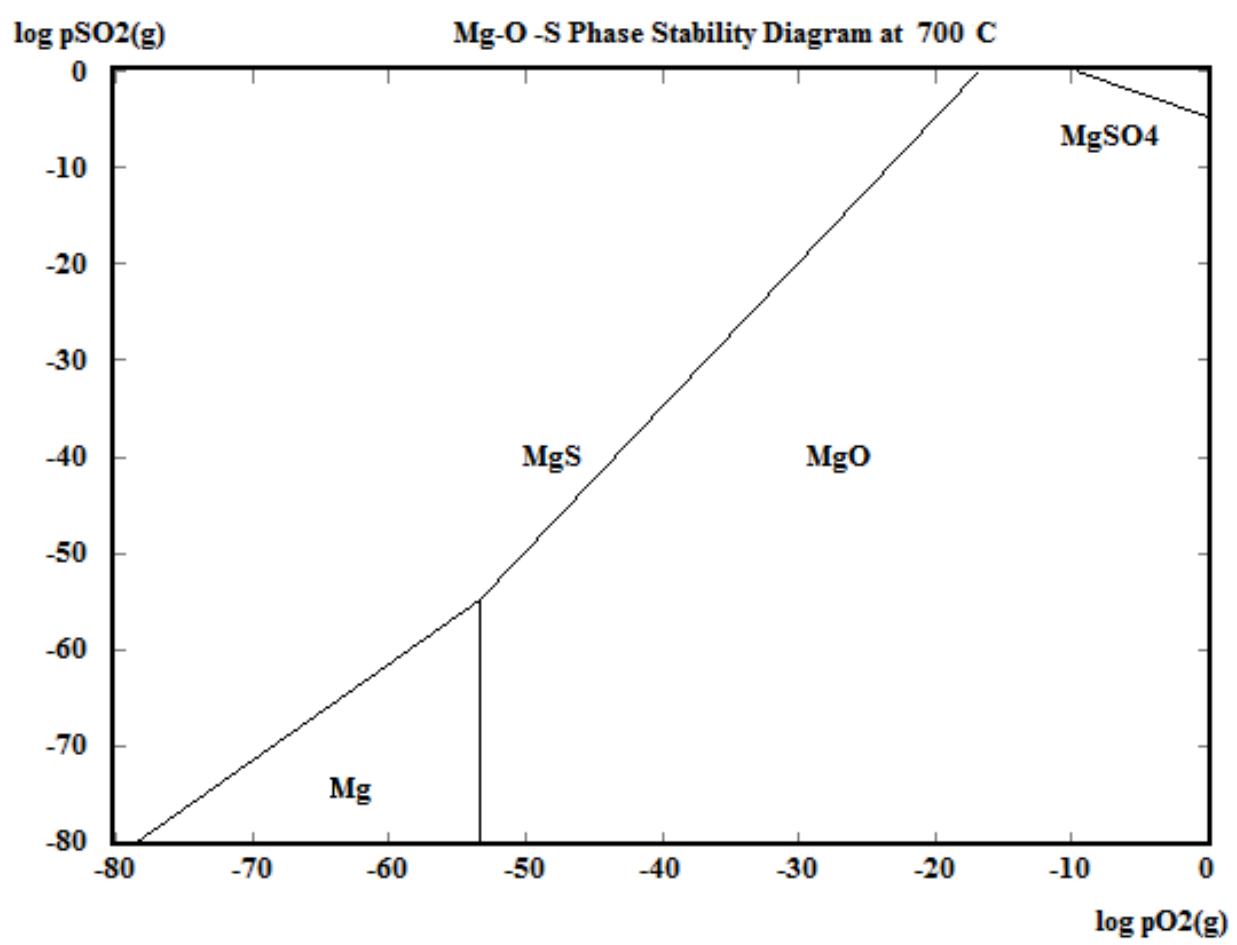

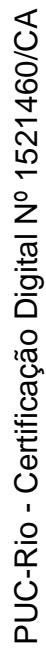

Figura 15. Diagrama de Predominância do Sistema Mg-O-S a temperatura constante de $700{ }^{\circ} \mathrm{C}$, construído pelo autor com a utilização do HSC 6.0

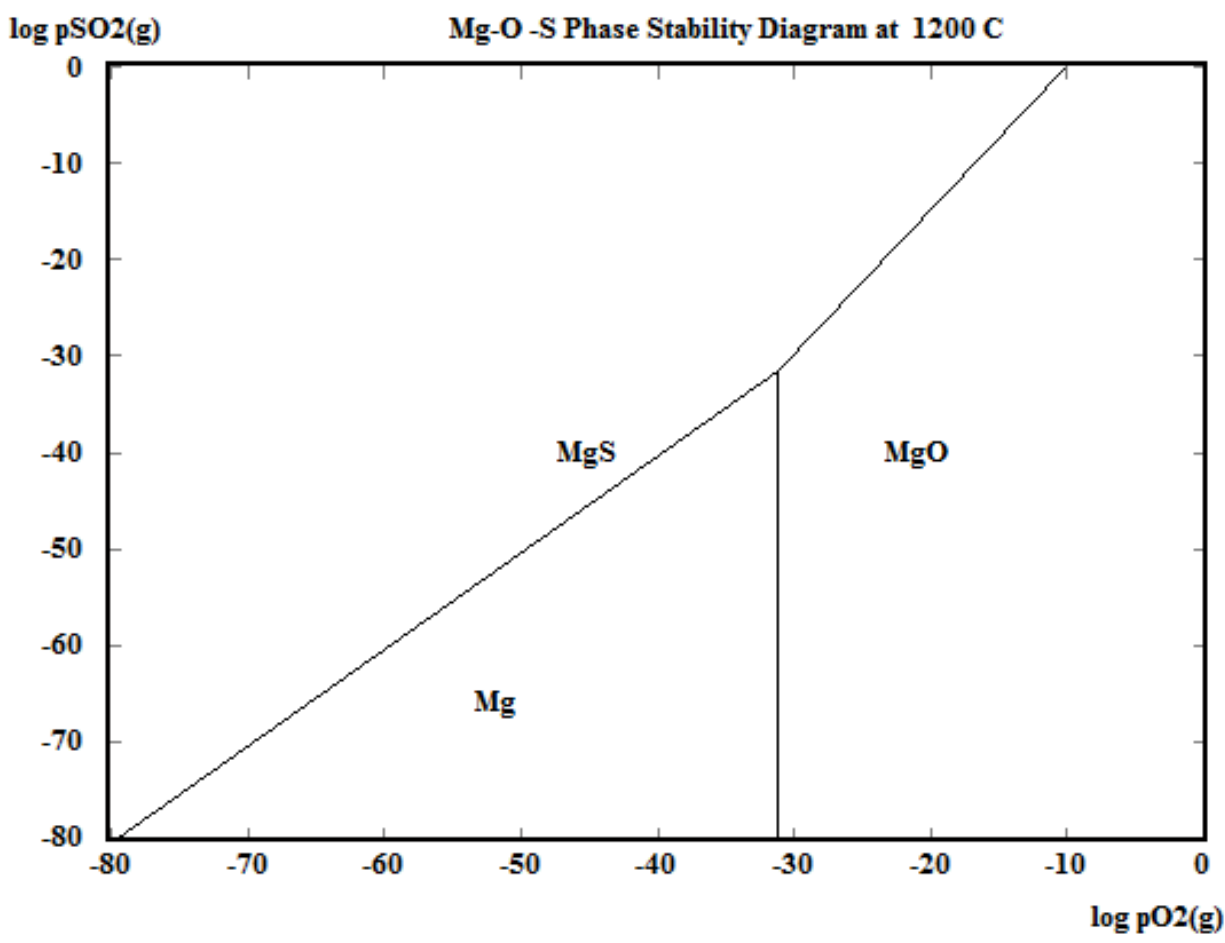

Figura 16. Diagrama de Predominância do Sistema Mg-O-S a temperatura constante de $1200{ }^{\circ} \mathrm{C}$, construído pelo autor com a utilização do HSC 6.0 
A análise destes diagramas de predominância possibilitou a determinação de quais são as possíveis reações de decomposição existente no sistema estudado, uma vez que com o aumento da temperatura o $\mathrm{MgSO}_{4}$ apresenta uma perda de estabilidade favorecendo a formação do $\mathrm{MgO}$, do $\mathrm{MgS}$ e do Magnésio metálico. Cada um desses compostos tem condições que favorecem a sua formação, o $\mathrm{MgO}$ é favorecido por uma atmosfera mais oxidante enquanto o $\mathrm{MgS}$ é favorecido por uma atmosfera menos oxidante. Já a formação do magnésio metálico é favorecida por uma atmosfera fortemente redutora e com baixa concentração de $\mathrm{SO}_{2}(\mathrm{~g})$. Essa análise permitiu determinar a temperatura máxima em que os ensaios poderiam ser realizados, pois como o $\mathrm{MgSO}_{4}$ não está presente como composto estável a 1200 ${ }^{\circ} \mathrm{C}$, ele apresenta uma temperatura de decomposição menor, portanto as análises foram realizadas com temperaturas abaixo à $1200{ }^{\circ} \mathrm{C}$.

Podemos reduzir as possíveis reações de decomposição do $\mathrm{MgSO}_{4}$ para as reações 1, 2 e 4, visto que a formação do Mg metálico se dá em condições difíceis de serem alcançadas e os compostos $\mathrm{MgSO}_{3}$ e $\mathrm{MgO}_{2}$ não são estáveis nas condições abordadas. Com os dados encontrados com o HSC Chemistry 6.0 (Roine, 2006) da variação da energia livre padrão de Gibbs $\left(\Delta \mathrm{G}^{0}\right)$ em função da temperatura dessas reações foi construído o gráfico da Figura 17. 


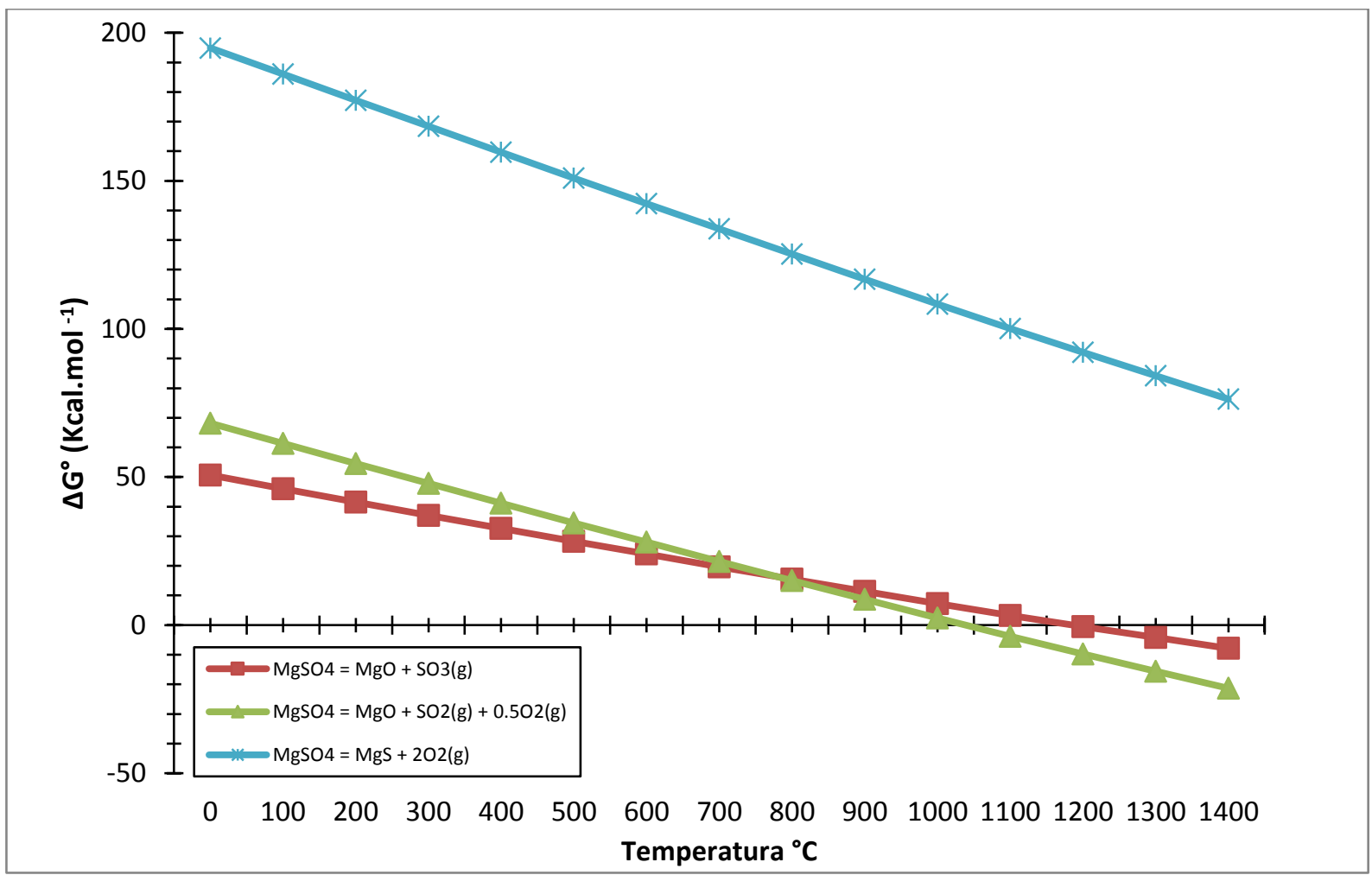

Figura 17. $\Delta \mathrm{G}^{\mathrm{o}}$ das possíveis reações de decomposição do $\mathrm{MgSO} 4$ formando $\mathrm{MgO}$ e $\mathrm{MgS}$, construída pelo autor com a utilização do HSC 6.0.

Uma reação é considerada espontânea termodinamicamente quando apresenta um valor de $\Delta \mathrm{G}^{0}$ negativo e sendo possível realizar reações em condições onde a constante de equilíbrio $\left(\mathrm{K}_{\mathrm{eq}}\right)$ é maior que $10^{-3}$, pode-se determinar como que a decomposição do $\mathrm{MgSO}_{4}$ acontece nas condições abordadas.

De acordo com os dados encontrados, a reação de formação do $\mathrm{MgS}$ apresenta em toda a faixa de temperatura analisada valores de $\Delta \mathrm{G}^{\mathrm{o}}$ positivos e $\mathrm{K}_{\mathrm{eq}}$ menores que $10^{-3}$. Já as reações de formação do $\mathrm{MgO}$, reações 1 e 2, apresentam um $\Delta \mathrm{G}^{\mathrm{o}}$ negativo em temperaturas de aproximadamente $1190{ }^{\circ} \mathrm{C}$ e $1040{ }^{\circ} \mathrm{C}$, respectivamente e um $\mathrm{K}_{\mathrm{eq}}$ menor que $10^{-3}$ para valores de temperatura superiores a aproximadamente $850{ }^{\circ} \mathrm{C}$. Sendo assim pode-se concluir que as reações 1 e 2 são as prováveis reações que estão presentes no sistema.

\subsection{Estudo do equilíbrio das espécies $\mathrm{SO}_{3}$ e $\mathrm{SO}_{2}$}

Conforme demonstrado na Figura 16 o sulfato de magnésio não se apresenta como uma espécie estável a $1200{ }^{\circ} \mathrm{C}$, o que indica que o mesmo se decompõe completamente a uma temperatura abaixo dessa. Por meio dessa decomposição 
pode-se formar o óxido de magnésio e dois óxidos de enxofre, o trióxido de enxofre, conforme a reação 1, e o dióxido de enxofre, conforme reação 2. Frente a estas duas possibilidades, tem-se que avaliar o equilíbrio entre a formação dos dois óxidos de enxofre. Tal equilíbrio pode ser avaliado pelos valores de $\Delta \mathrm{G}^{\mathrm{o}}$ pela reação abaixo:

$$
\mathrm{SO}_{3}(\mathrm{~g}) \rightarrow \mathrm{SO}_{2}(\mathrm{~g})+0,5 \mathrm{O}_{2}(\mathrm{~g})
$$

Com os dados, encontrados com o HSC Chemistry 6.0 (Roine, 2006), de $\Delta$ Go em função da temperatura para as reações 1, 2 e 9 foi possível construir o gráfico da Figura 18.

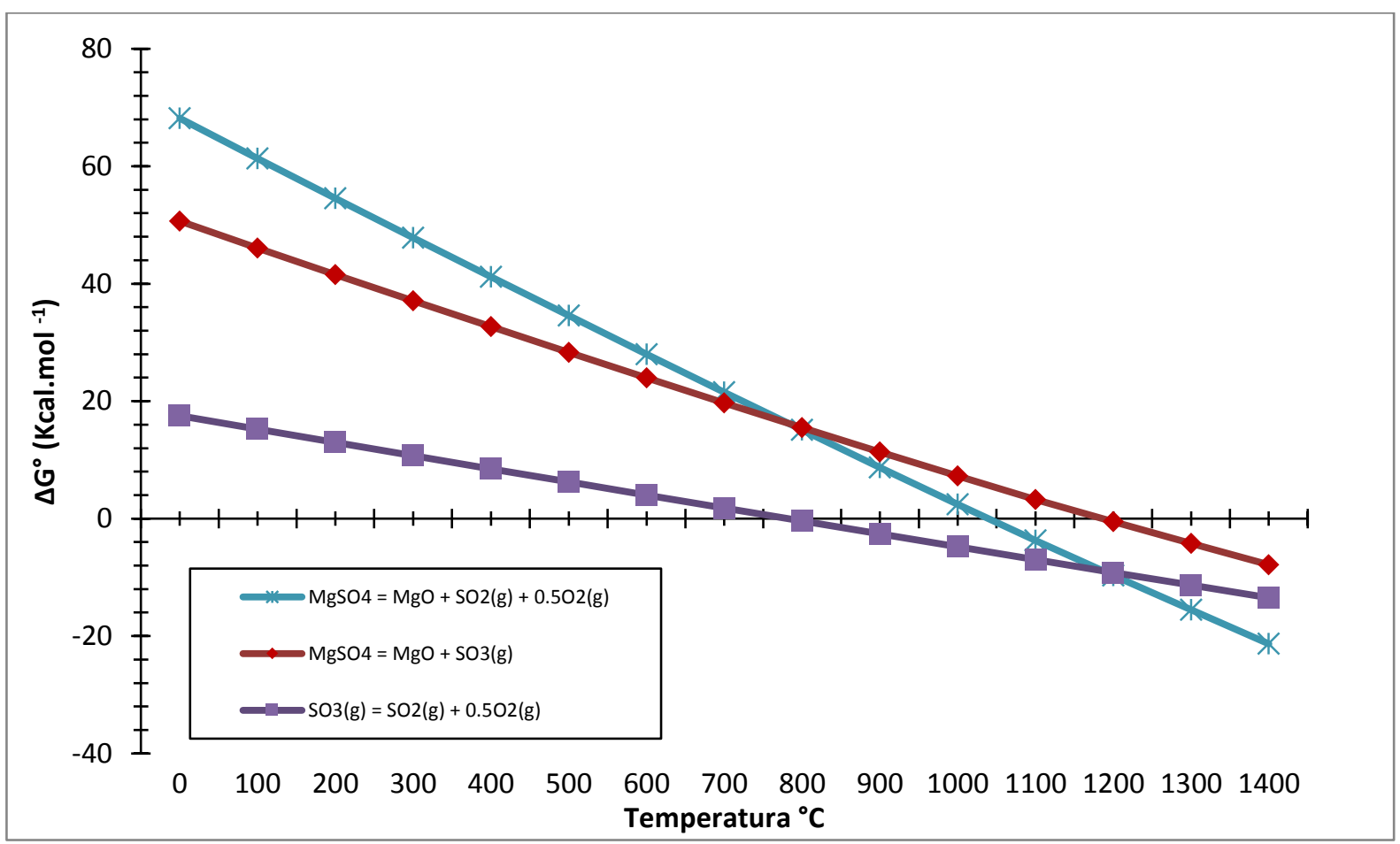

Figura 18. $\Delta \mathrm{G}^{\circ}$ das reações de decomposição do MgSO4 e de equilíbrio SO3/SO2, construída pelo autor com a utilização do HSC 6.0

Através da análise do gráfico da Figura 18 foi possível concluir que, uma vez que o $\mathrm{SO}_{3}$ é instável a temperaturas acima de $800{ }^{\circ} \mathrm{C}$ e a decomposição espontânea do $\mathrm{MgSO}_{4}$ só ocorre para temperaturas acima de $1040{ }^{\circ} \mathrm{C}$, para a reação 2, e $1190{ }^{\circ} \mathrm{C}$, para a reação 1 , a reação de decomposição espontânea é descrita pela reação 2.

$$
\mathrm{MgSO}_{4} \rightarrow \mathrm{MgO}+\mathrm{SO}_{2}(\mathrm{~g})+0,5 \mathrm{O}_{2}(\mathrm{~g})
$$


Uma vez determinada que a reação de decomposição espontânea do sulfato de magnésio forma óxido de magnésio, dióxido de enxofre e oxigênio, foi preciso avaliar o comportamento destas substancias quando na presença do agente redutor, o carbono.

\subsection{Estudo da reação de Boudouard}

Com a presença do carbono na reação de decomposição o $\mathrm{O}_{2}$ liberado é capturado pelo carbono formando um óxido com o mesmo. Dois óxidos são possíveis de serem formados, o monóxido de carbono e o dióxido de carbono, com isso o estudo do comportamento dos gases presentes no sistema reacional se fez importante para o entendimento. As duas reações de formação destes óxidos são descritas pelas reações abaixo:

$$
\begin{aligned}
& \mathrm{C}+\mathrm{O}_{2}(\mathrm{~g}) \rightarrow \mathrm{CO}_{2}(\mathrm{~g}) \\
& 2 \mathrm{C}+\mathrm{O}_{2}(\mathrm{~g}) \rightarrow 2 \mathrm{CO}(\mathrm{g})
\end{aligned}
$$

Essas duas reações têm comportamentos distintos em relação à variação da temperatura. Enquanto a reação de formação do dióxido de carbono tem valores praticamente constantes de $\Delta \mathrm{G}^{\mathrm{o}}$, a reação de formação do monóxido de carbono apresenta variação de $\Delta \mathrm{G}^{\mathrm{o}}$. Essa diferença de comportamento faz com que a tendência de formação dos óxidos seja alterada a partir de certa temperatura. Esta tendência é descrita pela reação de Boudouard (reação 12) e é o equilíbrio entre as reações do carbono com o oxigênio, reações 10 e 11.

$$
\mathrm{C}+\mathrm{CO}_{2}(\mathrm{~g}) \rightarrow 2 \mathrm{CO}(\mathrm{g})
$$




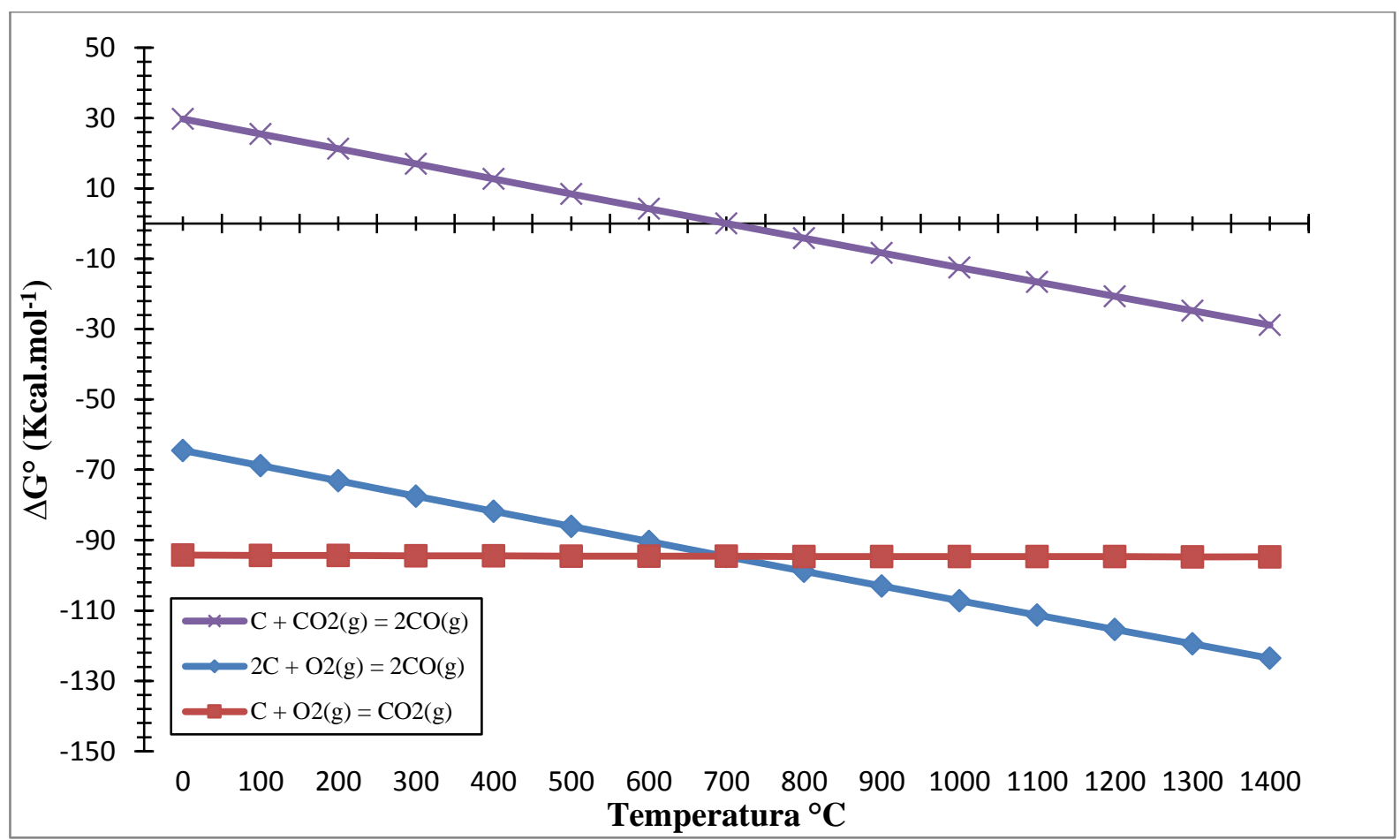

Figura 19. $\Delta \mathrm{G}^{\circ}$ das reações do sistema $\mathrm{C}+\mathrm{O} 2$ e reação de Boudouard, construída pelo autor com a utilização do HSC 6.0

Através da observação do comportamento dos valores de $\Delta \mathrm{G}^{\mathrm{o}}$ da reação de Boudouard (reação 12) presente no gráfico da Figura 19 foi verificado que a mesma apresenta valores negativos de $\Delta \mathrm{G}^{\mathrm{o}}$ para temperaturas maiores que $700{ }^{\circ} \mathrm{C}$, o que favorece o sentido da formação do CO. Já para temperaturas menores que $700{ }^{\circ} \mathrm{C}$ o sentido da formação do $\mathrm{CO}_{2}$ é favorecido. Esta observação pode ser confirmada pelo fato de que em temperaturas abaixo de $700{ }^{\circ} \mathrm{C}$ a reação de formação do $\mathrm{CO}_{2}$ (reação 10) apresenta valores de $\Delta \mathrm{G}^{0}$ menores que os da reação de formação do $\mathrm{CO}$ (reação 11) indicando o favorecimento da formação de $\mathrm{CO}_{2}$ sobre a formação de CO. A partir de $700{ }^{\circ} \mathrm{C}$ o favorecimento se inverte e os valores de $\Delta \mathrm{G}^{\mathrm{o}}$ da formação de $\mathrm{CO}$ são menores que os da formação de $\mathrm{CO}_{2}$.

Como as reações 10 e 11 tem valores de $\Delta \mathrm{G}^{\mathrm{o}}$ menores que zero em toda a faixa de temperatura abordada nos ensaios, pode-se afirmar que as duas reações acontecem ao mesmo tempo. Pela reação de Boudouard (reação 12) é possível determinar o equilíbrio entre a formação de $\mathrm{CO}$ e $\mathrm{CO}_{2}$ no sistema reacional, através da constante de equilíbrio da mesma (equação 3).

$\mathrm{PCO}_{2}+\mathrm{PCO}=1 \mathrm{~atm}$

$\mathrm{PCO}=1-\mathrm{PCO}_{2}$ 


$$
\begin{aligned}
& \mathrm{K}_{\mathrm{eq}}=(\mathrm{PCO})^{2} / \mathrm{PCO}_{2} \\
& \mathrm{~K}_{\mathrm{eq}}=\left(1-\mathrm{PCO}_{2}\right)^{2} / \mathrm{PCO}_{2} \\
& \mathrm{~K}_{\mathrm{eq}}=\left(1-\mathrm{XCO}_{2}\right)^{2} / \mathrm{XCO}_{2}
\end{aligned}
$$

\subsection{Estudo da influência do Carbono na temperatura de decomposição do $\mathrm{MgSO}_{4}$}

Fez-se necessário o estudo da decomposição na presença do agente redutor, utilizado neste trabalho, o carvão vegetal. $\mathrm{O} \mathrm{MgSO}_{4}$ pode reagir com o carbono do carvão vegetal através de duas reações diferentes:

$$
\begin{aligned}
& \mathrm{MgSO}_{4}+\mathrm{C} \rightarrow \mathrm{MgO}+\mathrm{SO}_{2}(\mathrm{~g})+\mathrm{CO}(\mathrm{g}) \\
& \mathrm{MgSO}_{4}+0,5 \mathrm{C} \rightarrow \mathrm{MgO}+\mathrm{SO}_{2}(\mathrm{~g})+\mathrm{CO}_{2}(\mathrm{~g})
\end{aligned}
$$

Utilizando os dados encontrados com o HSC Chemistry 6.0 (Roine, 2006), de $\Delta \mathrm{G}^{\mathrm{o}}$ em função da temperatura para as reações 2, 13 e 14, foi possível construir um gráfico comparativo das reações de decomposição com e sem a presença do carvão vegetal.

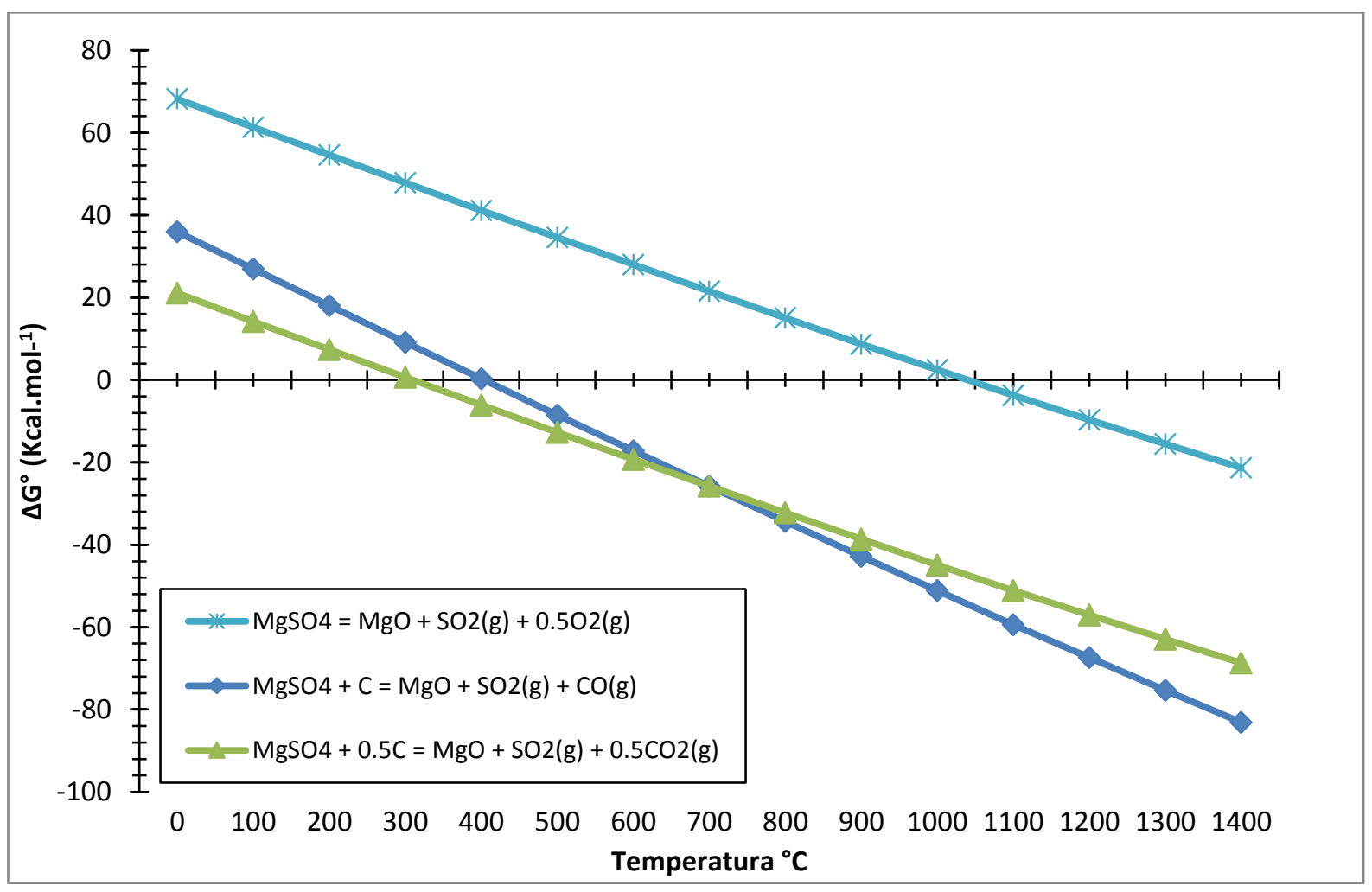


Figura 20. $\Delta \mathrm{G}^{\circ}$ das reações de decomposição do $\mathrm{MgSO} 4$ com e sem a presença do carvão vegetal, construída pelo autor com a utilização do HSC 6.0

A presença do carvão vegetal no sistema reacional serve para a redução da energia livre padrão de Gibbs da decomposição do $\mathrm{MgSO}_{4}$ conforme demonstrado no gráfico da Figura 20. As duas reações na presença do carvão vegetal apresentaram valores de $\Delta \mathrm{G}^{\mathrm{o}}$ negativos em temperaturas inferiores diferentemente da decomposição sem o carvão vegetal, esses valores negativos indicam a tendência de a reação ocorrer a partir das temperaturas de $300{ }^{\circ} \mathrm{C}$ para a reação 14 e de 400 ${ }^{\circ} \mathrm{C}$ para a reação 13. Como os ensaios ocorreram em temperaturas superiores a essas o sistema reacional da decomposição carbotérmica foi definido como tendo as duas reações em paralelo.

Outra apreciação possível de ser realizada e que demonstra a importância da utilização de um agente redutor é a observação aos diagramas de predominância do sistema $\mathrm{Mg}-\mathrm{O}-\mathrm{S}$ a pressões de $\mathrm{O}_{2}$ constantes e variação da temperatura e pressão de $\mathrm{SO}_{2}$ (Figuras 21 a 23), os diagramas foram construídos com o HSC Chemistry 6.0 (Roine, 2006).

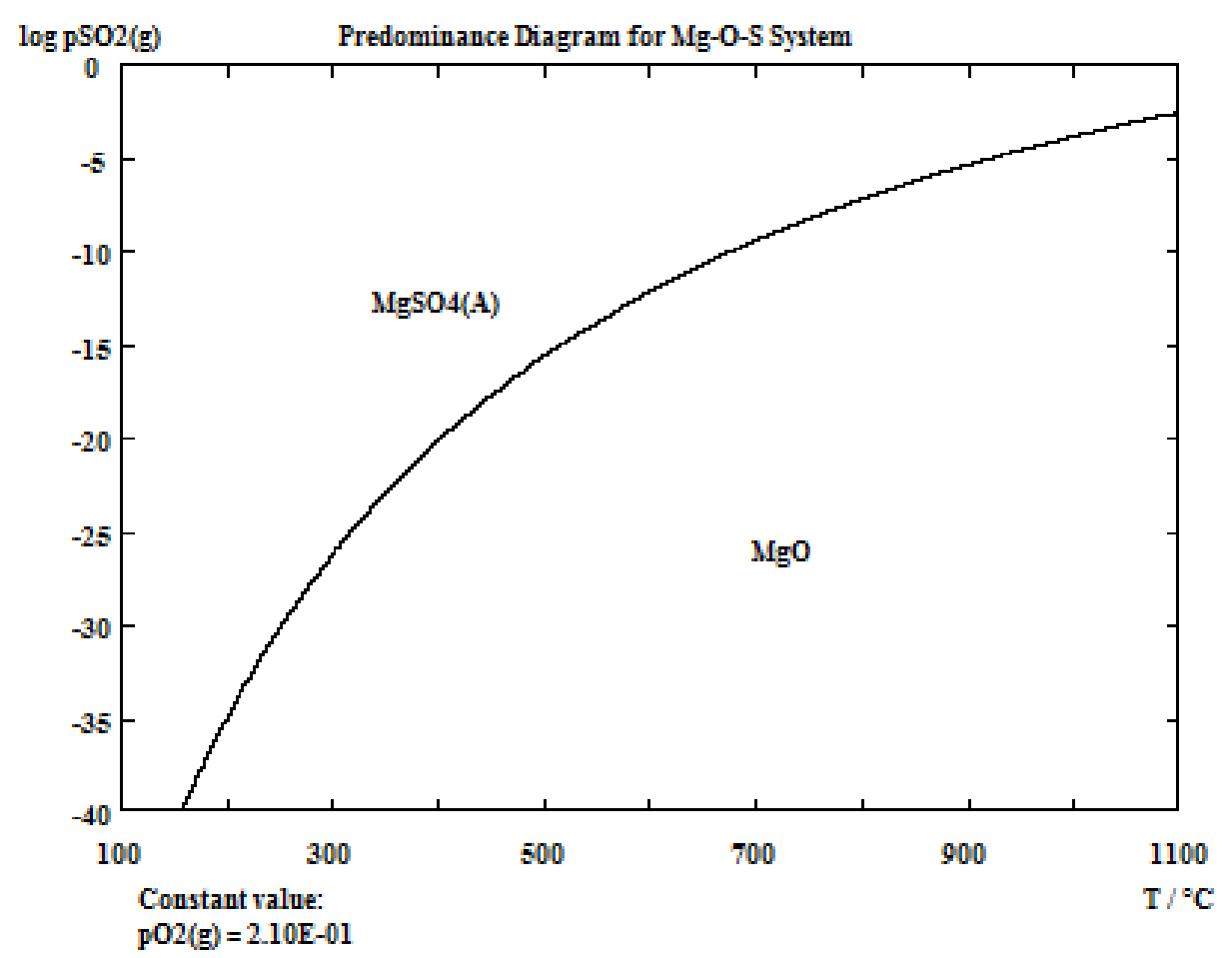


Figura 21. Diagrama de Predominância a pressão de $\mathrm{O}_{2}$ constante de 0,21 atm variando a temperatura, construído pelo autor com a utilização do HSC 6.0

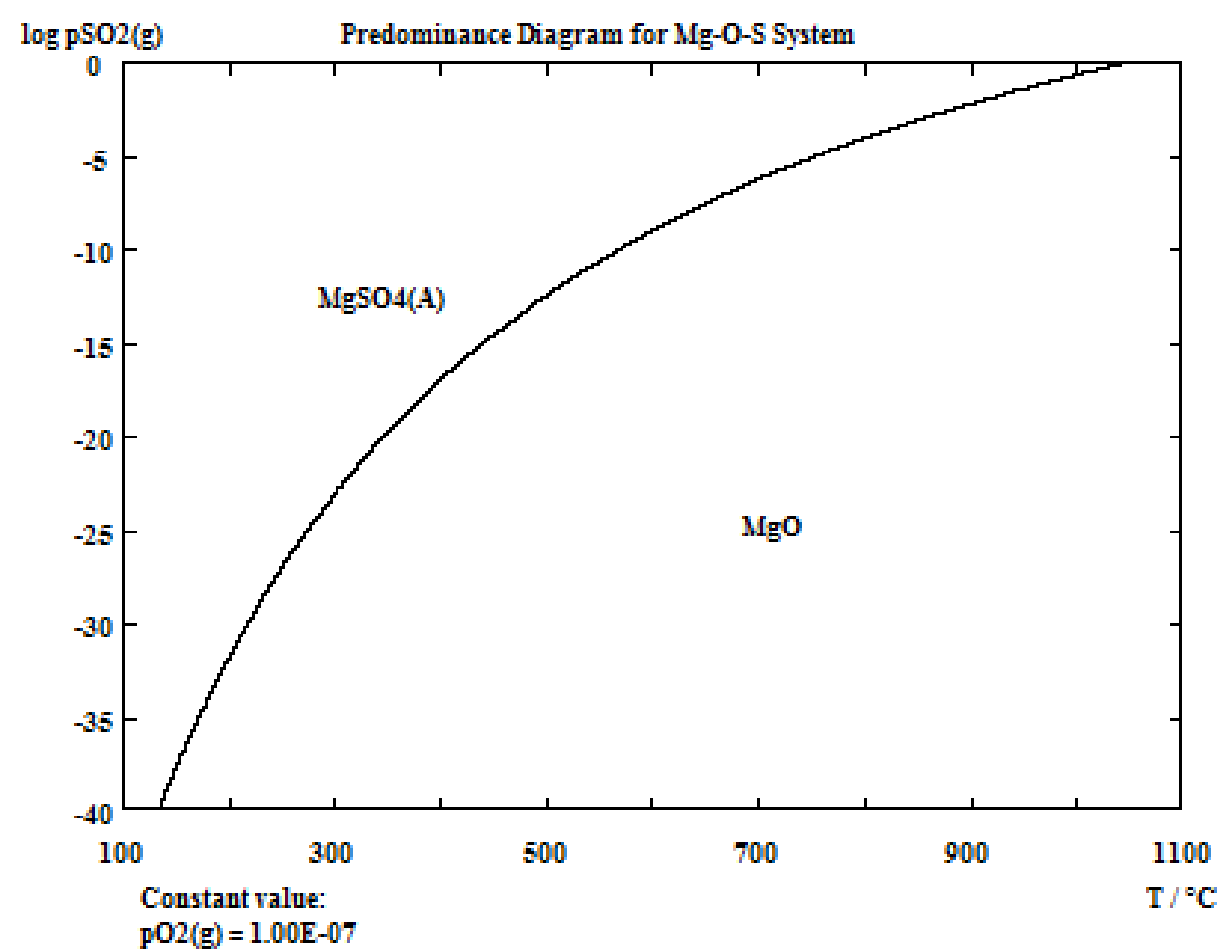

Figura 22. Diagrama de Predominância a pressão de $\mathrm{O}_{2}$ constante de $10^{-7}$ atm variando a temperatura, construído pelo autor com a utilização do HSC 6.0 


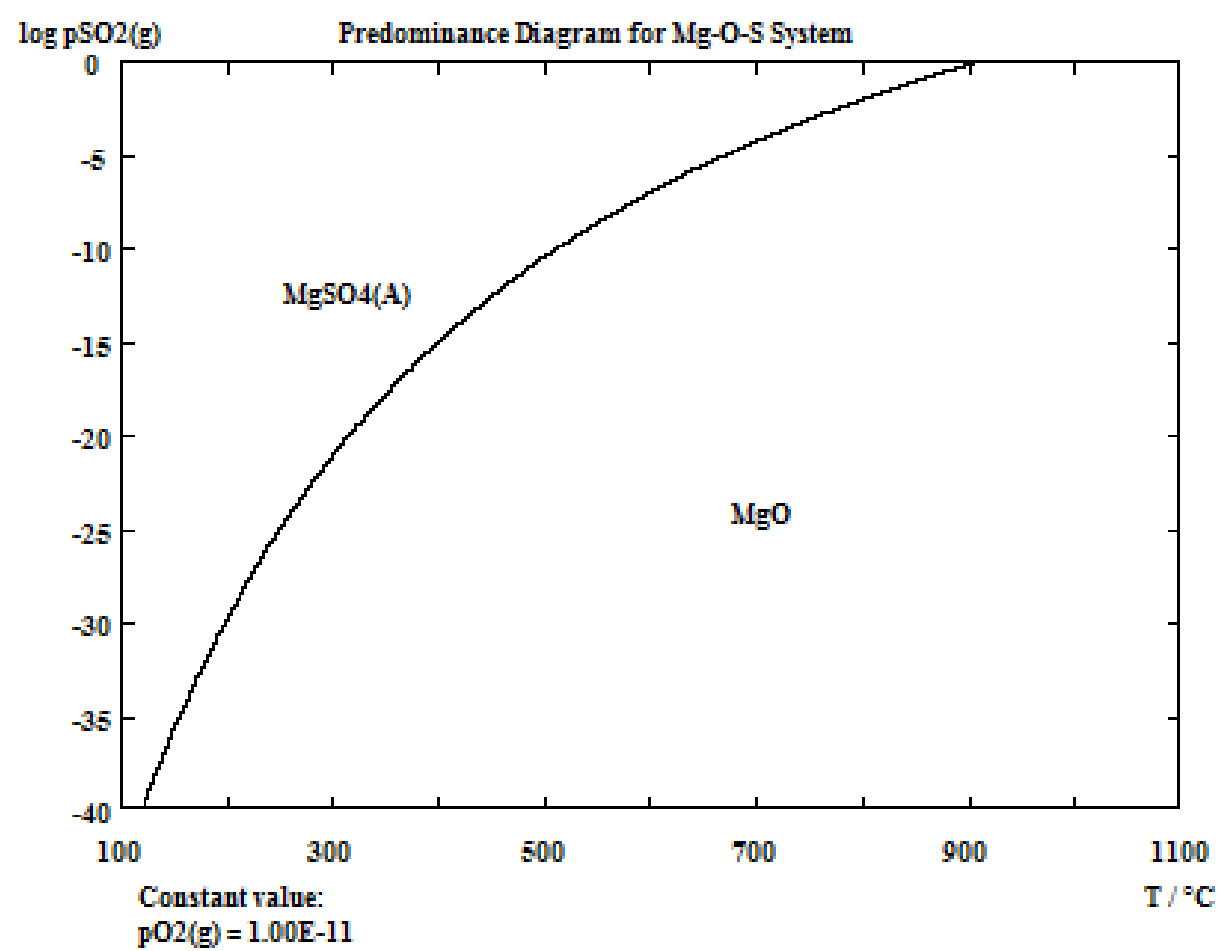

Figura 23. Diagrama de Predominância a pressão de $\mathrm{O}_{2}$ constante de $10^{-11}$ atm variando a temperatura, construído pelo autor com a utilização do HSC 6.0

Por meio desses diagramas de predominância é possível observar que à medida que a pressão de $\mathrm{O}_{2}$ diminui a região de predominância do $\mathrm{MgO}$ apresenta um aumento, deslocando a curva de equilíbrio $\mathrm{MgSO}_{4} / \mathrm{MgO}$ para a esquerda dos diagramas. Este deslocamento caracteriza uma diminuição da temperatura de decomposição térmica do $\mathrm{MgSO}_{4}$ em função da quantidade de $\mathrm{SO}_{2}$ presente no sistema. Este é mais um indício que aponta a importância de um agente redutor, uma vez que ele diminui a pressão de $\mathrm{O}_{2}$ presente no sistema.

É importante salientar também que em pressões mais baixas de $\mathrm{SO}_{2}$ a decomposição se torna mais favorável ainda. Este fato incentiva a realização de ensaios onde a presença deste gás esteja mais branda, para tornar o sistema mais favorável possível para a decomposição do $\mathrm{MgSO}_{4}$ em $\mathrm{MgO}$. Assim, os ensaios foram realizados na presença do gás argônio como gás de arraste, diminuindo assim a concentração dos gases provenientes da decomposição na atmosfera reacional. 


\subsection{Estudo da composição de equilíbrio em função da composição química da mistura e da temperatura}

De modo a complementar o estudo termodinâmico do sistema reacional, um estudo da composição de equilíbrio em função da composição química da mistura e da temperatura foi realizada. Este estudo é importante porque possibilita a avaliação de ocorrências de formação simultânea de espécies. As Figuras 24 e 25 apresentam os diagramas de distribuição de espécies no equilíbrio, construídos a partir do HSC Chemistry 6.0 (Roine, 2006), em função da temperatura e de uma composição química inicial da decomposição do sulfato de magnésio com ou sem agente redutor.

$1 \mathrm{kmol}$ de $\mathrm{MgSO}_{4} \rightarrow$

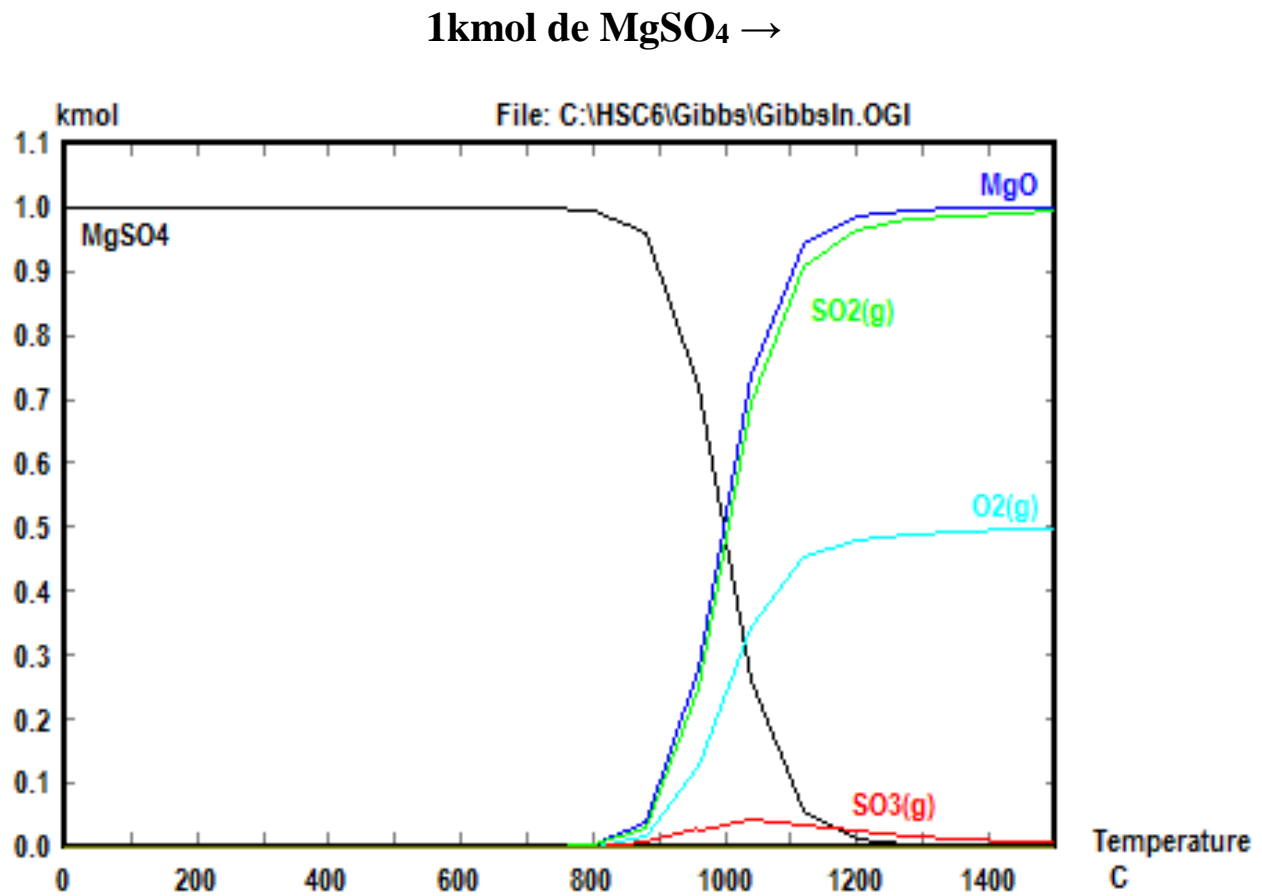

Figura 24. Diagrama de distribuição de espécies no equilíbrio para a decomposição térmica do $\mathrm{MgSO}_{4}$, construído pelo autor com a utilização do HSC 6.0 


\section{$1 \mathrm{kmol}$ de $\mathrm{MgSO}_{4}+1 / 2 \mathrm{kmol}$ de $\mathrm{C} \rightarrow$}

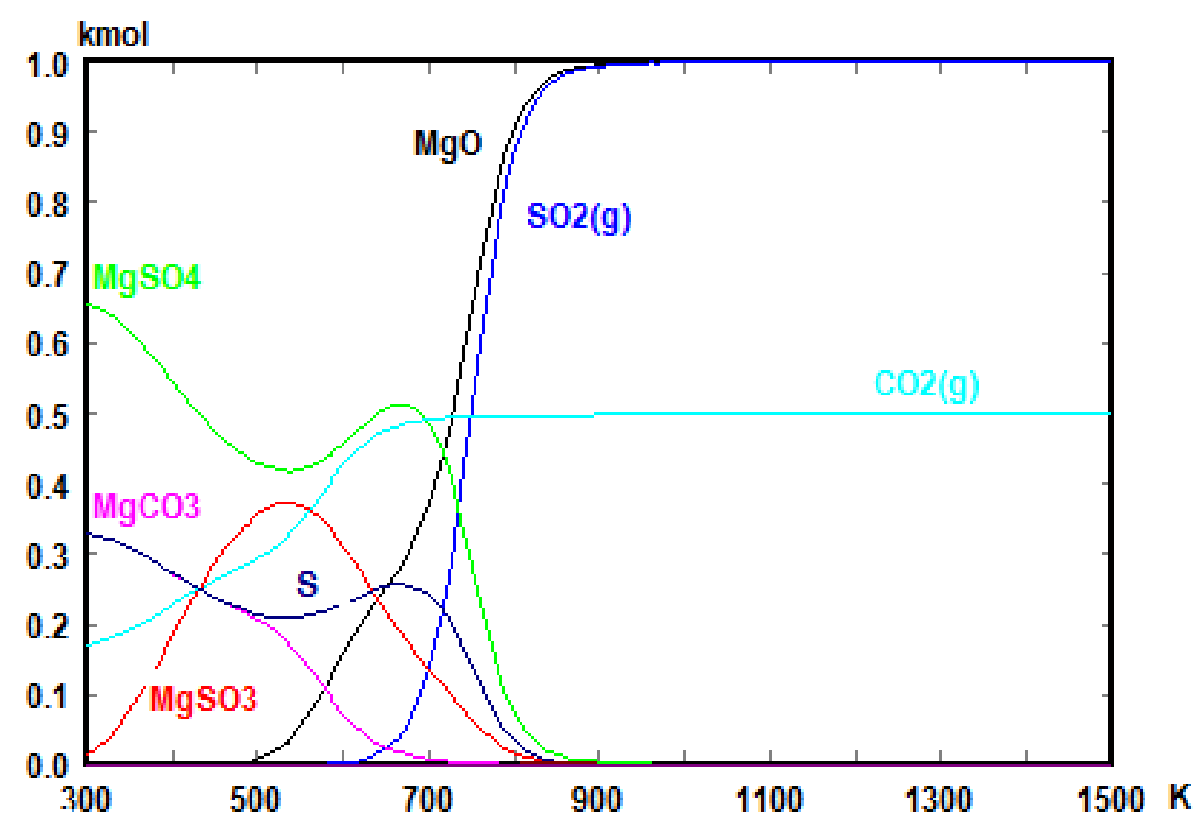

Figura 25. Diagrama de distribuição de espécies no equilíbrio para a decomposição térmica do $\mathrm{MgSO}_{4}$ na presença de carbono, construído pelo autor com a utilização do HSC 6.0

A Figura 24 indica que o $\mathrm{MgSO}_{4}$ permanece estável aproximadamente até 800 ${ }^{\circ} \mathrm{C}$, quando começa sua decomposição, a partir desta temperatura o magnésio está presente em duas espécies, $\mathrm{MgSO}_{4}$ e $\mathrm{MgO}$. Essa existência simultânea ocorre até $1200{ }^{\circ} \mathrm{C}$, quando o $\mathrm{MgSO}_{4}$ é completamente decomposto e o $\mathrm{MgO}$ passa a ser a única espécie portadora de magnésio. Além de identificar o $\mathrm{MgO}$ como o único óxido de magnésio formado no sistema, é possível notar a formação do $\mathrm{SO}_{3}$ no início da decomposição do $\mathrm{MgSO}_{4}$. Entretanto devido à instabilidade da espécie já discutida anteriormente, $\mathrm{o} \mathrm{SO}_{3}$ que se forma é logo decomposto, não permitindo que o $\mathrm{SO}_{3}$ atinja uma concentração elevada durante o processo. Ao final da decomposição do $\mathrm{MgSO}_{4}, \mathrm{o} \mathrm{SO}_{3}$ está praticamente todo decomposto.

Na presença do agente redutor, na Figura 25, há uma expressiva redução na temperatura inicial da decomposição. Uma vez que a decomposição começa a ocorrer por volta de $300{ }^{\circ} \mathrm{C}$ e por volta de $850{ }^{\circ} \mathrm{C}$ o $\mathrm{MgO}$ é a única espécie portadora de magnésio. É possível observar que na presença do carbono, ocorrem dois 
produtos intermediários que contêm o magnésio: o $\mathrm{MgSO}_{3}$ e o $\mathrm{MgCO}_{3}$. Estes subprodutos se tornam instáveis com o aumento da temperatura e se decompõem em $\mathrm{MgO}$.

De forma geral, os diagramas de equilíbrio de espécies estão de acordo com os demais dados apresentados neste estudo. Uma vez que todos apontam a redução da temperatura de decomposição na presença do carbono como agente redutor e a formação do $\mathrm{MgO}$ como única espécie portadora de magnésio estável a altas temperaturas. Os gráficos apresentados indicam que a decomposição do sulfato de magnésio na presença do carbono deve ocorrer de forma satisfatória a temperaturas entre $600{ }^{\circ} \mathrm{C}$ a $900{ }^{\circ} \mathrm{C}$, portanto tais condições foram as escolhidas para $\mathrm{o}$ desenvolvimento experimental do trabalho. 


\section{Resultados e discussão}

\subsection{Caracterização do carvão vegetal}

Após a realização da caracterização do carvão vegetal seguindo a metodologia determinada pela norma internacional ASTM D1762-84 de 2013, os dados da Tabela 1 foram obtidos.

Tabela 2. Resultados da caracterização do Carvão vegetal

\begin{tabular}{|c|c|c|c|c|c|c|c|c|}
\hline Amostra & $\begin{array}{c}\mathrm{M}_{\mathrm{o}} \\
(\mathrm{g})\end{array}$ & $\begin{array}{c}\mathrm{M}_{\text {seca }} \\
(\mathrm{g})\end{array}$ & $\begin{array}{c}\% \\
\text { Umidade }\end{array}$ & $\begin{array}{c}\mathrm{M}_{\text {sólida }} \\
(\mathrm{g})\end{array}$ & $\begin{array}{c}\% \\
\text { Voláteis }\end{array}$ & $\begin{array}{c}\mathrm{M}_{\text {cinza }} \\
(\mathrm{g})\end{array}$ & $\begin{array}{c}\% \\
\text { Cinza }\end{array}$ & $\begin{array}{c}\% \\
\text { Carbono }\end{array}$ \\
\hline 1 & 0,509 & 0,484 & 4,91 & 0,286 & 38,90 & 0,010 & 1,96 & 54,22 \\
\hline 2 & 0,506 & 0,483 & 4,55 & 0,284 & 39,33 & 0,009 & 1,78 & 54,35 \\
\hline 3 & 0,521 & 0,493 & 5,37 & 0,293 & 38,39 & 0,011 & 2,11 & 54,13 \\
\hline
\end{tabular}

Através dos dados obtidos nos testes de caracterização nas amostras do carvão vegetal utilizado nos ensaios experimentais o carvão vegetal apresenta valores médios de umidade, materiais voláteis e cinza, respectivamente, de 4,94\%, 38,87\% e $1,96 \%$.

Então o mesmo apresenta 54,22\% de carbono fixo em sua estrutura. Após a secagem e destilação do mesmo, o percentual de carbono fixo restante em sua estrutura subiu para 96,5\% enquanto o percentual de cinza foi para 3,5\%. Com base nessas porcentagens foram calculadas as quantidades de carvão necessárias para a realização dos ensaios a cada temperatura.

\subsection{Análise termogravimétrica da perda de água do $\mathrm{MgSO}_{4} \cdot 7 \mathrm{H}_{2} \mathrm{O}$}

A análise termogravimétrica foi realizada para a avaliação do comportamento da desidratação do $\mathrm{MgSO}_{4} .7 \mathrm{H}_{2} \mathrm{O}$ para observação da estabilidade do $\mathrm{MgSO}_{4}$, até a temperatura máxima trabalhada, $900{ }^{\circ} \mathrm{C}$. A Figura 26 apresenta os dados da variação mássica percentual do $\mathrm{MgSO}_{4} \cdot 7 \mathrm{H}_{2} \mathrm{O}$ obtidos através do TGA. 


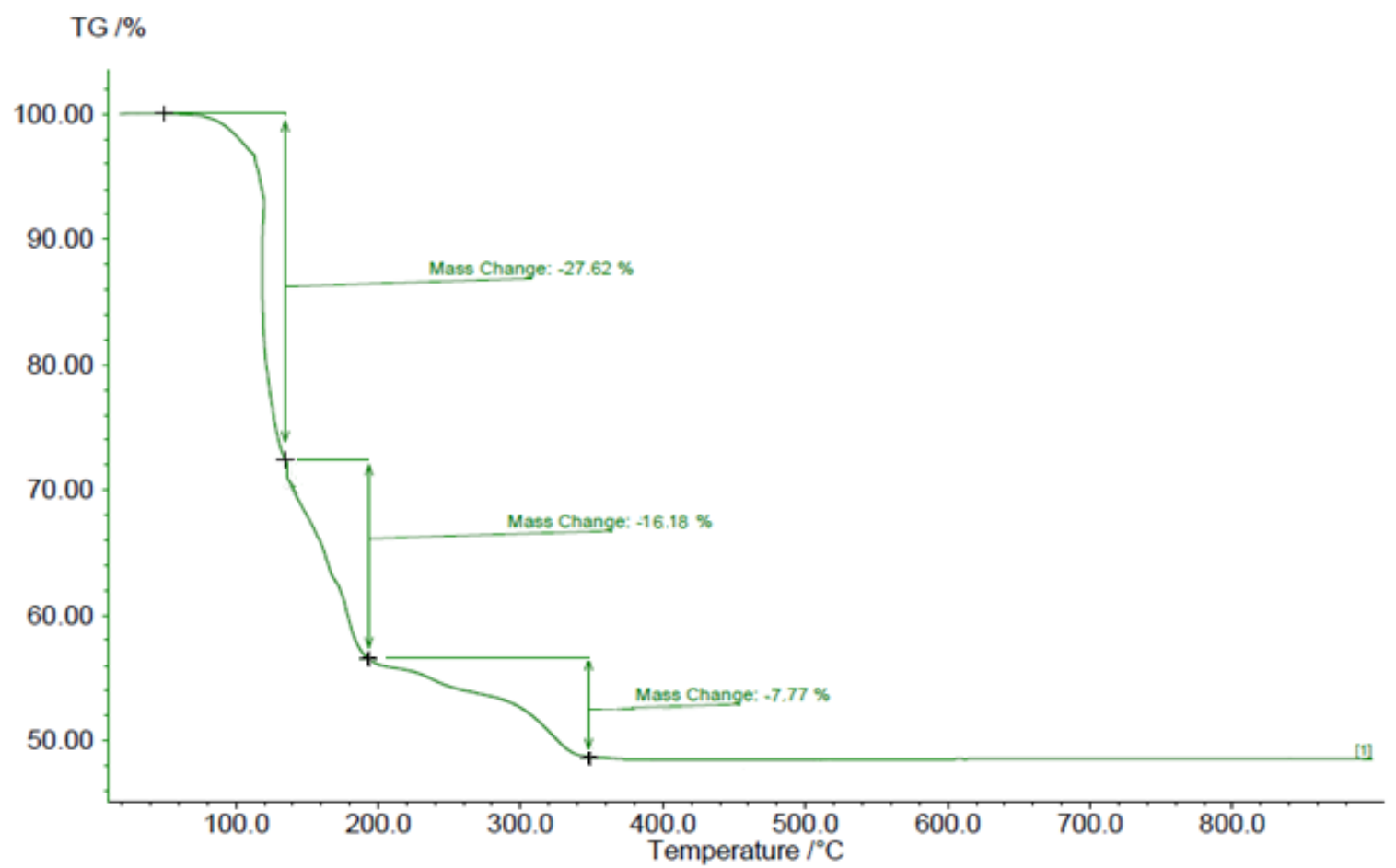

Figura 26. Variação mássica percentual do MgSO4.7H2O com o aumento de temperatura, construída a partir do analisador termogravimétrico

Observa-se que o $\mathrm{MgSO}_{4} .7 \mathrm{H}_{2} \mathrm{O}$ apresenta uma significativa variação mássica entre, aproximadamente, as temperaturas de $100{ }^{\circ} \mathrm{C}$ e $350{ }^{\circ} \mathrm{C}$. Esta variação ocorre em três etapas que ajudam uma possível análise do mecanismo de desidratação do $\mathrm{MgSO}_{4}$ e elas representam uma perda de massa total de 51,57\%, valor expressivamente próximo ao esperado de perda de massa, já que as sete moléculas de água ligadas ao sulfato representam $51,16 \%$ da massa total da molécula do $\mathrm{MgSO}_{4} .7 \mathrm{H}_{2} \mathrm{O}$. Deste modo, é plausível indicar que entre $100{ }^{\circ} \mathrm{C}$ e $120^{\circ} \mathrm{C}$ ocorre a perda de aproximadamente 4 moléculas de água, entre $120{ }^{\circ} \mathrm{C}$ e $190{ }^{\circ} \mathrm{C}$ ocorre a perda de duas moléculas de água e entre $190{ }^{\circ} \mathrm{C}$ e $350{ }^{\circ} \mathrm{C}$ ocorre a perda de uma molécula de água. A análise das diferentes inclinações das retas complementa esta argumentação, sendo que na primeira etapa a inclinação da reta está associada com uma perda maior de massa.

Após aproximadamente $350{ }^{\circ} \mathrm{C}$ o sulfato de magnésio passa a ser anidro, uma vez que todas as moléculas de água foram perdidas. Observa-se que após a perda de 51,57\% da massa, visivelmente não há mais nenhuma perda de massa até a temperatura final compreendida pela análise. Essa constatação demonstra que o 
sulfato permanece estável nestas temperaturas e com isso podemos supor que qualquer perda de massa, acima da registrada nesta análise, pode ser associada a uma influência quando na presença do agente redutor.

\subsection{Calibração da linha experimental}

Antes da realização dos ensaios de decomposição do sulfato de magnésio foi efetuada uma calibração da linha experimental para medição das vazões a serem utilizadas nos ensaios. Para a calibração foi utilizado uma bureta de vidro de $50 \mathrm{~mL}$. Os dados dessa calibração se encontram na Tabela 3 e na Figura 27.

Tabela 3. Dados de vazão para calibração da linha experimental

\begin{tabular}{|c|c|c|c|c|c|}
\hline Marcação & Tempo (s) & Tempo médio (s) & Volume (mL) & Vazão (mL/s) & Vazão (L/min) \\
\hline \multirow{3}{*}{3} & 13,13 & \multirow{3}{*}{13,21} & \multirow{3}{*}{50,00} & \multirow{3}{*}{3,79} & \multirow{3}{*}{0,23} \\
\hline & 13,37 & & & & \\
\hline & 13,12 & & & & \\
\hline \multirow{3}{*}{4} & 9,96 & \multirow{3}{*}{9,96} & \multirow{3}{*}{50,00} & \multirow{3}{*}{5,02} & \multirow{3}{*}{0,30} \\
\hline & 9,92 & & & & \\
\hline & 10,00 & & & & \\
\hline \multirow{3}{*}{5} & 7,13 & \multirow{3}{*}{7,11} & \multirow{3}{*}{50,00} & \multirow{3}{*}{7,03} & \multirow{3}{*}{0,42} \\
\hline & 7,07 & & & & \\
\hline & 7,13 & & & & \\
\hline \multirow{3}{*}{6} & 5,62 & \multirow{3}{*}{5,61} & \multirow{3}{*}{50,00} & \multirow{3}{*}{8,91} & \multirow{3}{*}{0,53} \\
\hline & 5,61 & & & & \\
\hline & 5,61 & & & & \\
\hline \multirow{3}{*}{7} & 4,57 & \multirow{3}{*}{4,59} & \multirow{3}{*}{50,00} & \multirow{3}{*}{10,90} & \multirow{3}{*}{0,65} \\
\hline & 4,60 & & & & \\
\hline & 4,59 & & & & \\
\hline \multirow{3}{*}{8} & 3,70 & \multirow{3}{*}{3,72} & \multirow{3}{*}{50,00} & \multirow{3}{*}{13,44} & \multirow{3}{*}{0,81} \\
\hline & 3,75 & & & & \\
\hline & 3,71 & & & & \\
\hline \multirow{3}{*}{9} & 3,23 & & & & \\
\hline & 3,11 & 3,19 & 50,00 & 15,66 & 0,94 \\
\hline & 3,24 & & & & \\
\hline & 2,69 & & & & \\
\hline 10 & 2,72 & 2,70 & 50,00 & 18,50 & 1,11 \\
\hline & 2,70 & & & & \\
\hline & 2,39 & & & & \\
\hline 11 & 2,42 & 2,39 & 50,00 & 20,89 & 1,25 \\
\hline & 2,37 & & & & \\
\hline & 2,05 & & & & \\
\hline 12 & 2,16 & 2,12 & 50,00 & 23,58 & 1,42 \\
\hline & 2,15 & & & & \\
\hline
\end{tabular}




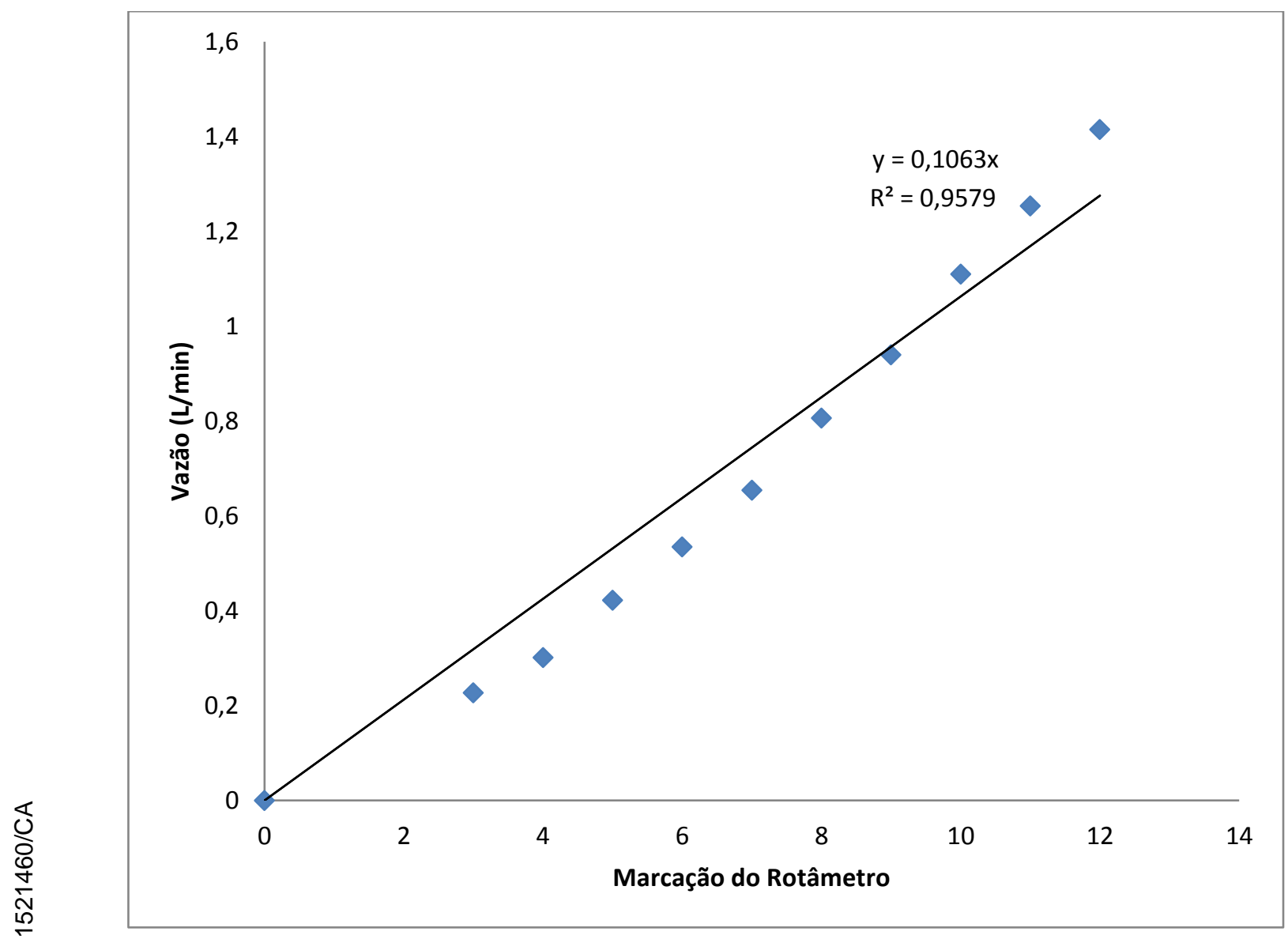

Figura 27. Curva de calibração da linha experimental, construída pelo autor.

Visto que dentro da faixa de vazão da linha os materiais não sofreram arraste, foi possível trabalhar com quaisquer valores dentro desta faixa.

\subsection{Balanço material para os ensaios}

\subsubsection{Avaliação da demanda de carbono por $\mathrm{mol}^{\text {de }} \mathrm{MgSO}_{4}$ em função da variação da temperatura}

Uma vez que as reações de decomposição carbotérmica do $\mathrm{MgSO}_{4}$ podem gerar os dois óxidos de carbono foi preciso um estudo da demanda de carbono, necessário para cada temperatura operacional. Este estudo foi realizado com base nas condições de equilíbrio da reação de Boudouard apresentadas no item 4.3 deste trabalho.

$$
\begin{aligned}
& \mathrm{PCO}=1-\mathrm{PCO}_{2} \\
& \mathrm{~K}_{\mathrm{eq}}=\left(1-\mathrm{XCO}_{2}\right)^{2} / \mathrm{XCO}_{2}
\end{aligned}
$$


Através da equação 2 e 5 e dos dados da constante de equilíbrio fornecidos pelo HSC Chemistry 6.0 foi possível determinar as frações molares de $\mathrm{CO}$ e $\mathrm{CO}_{2}$ para as reações 13 e 14. Conforme demonstrado abaixo:

$$
\begin{aligned}
& \mathrm{Y} \mathrm{MgSO}_{4}+\mathrm{Y} \mathrm{C} \rightarrow \mathrm{Y} \mathrm{MgO}+\mathrm{Y} \mathrm{SO}_{2}(\mathrm{~g})+\mathrm{Y} \mathrm{CO}(\mathrm{g}) \\
& (1-\mathrm{Y}) \mathrm{MgSO}_{4}+(1-\mathrm{Y}) 0,5 \mathrm{C} \rightarrow(1-\mathrm{Y}) \mathrm{MgO}+(1-\mathrm{Y}) \mathrm{SO}_{2}(\mathrm{~g})+(1-\mathrm{Y}) \\
& \mathrm{CO}_{2}(\mathrm{~g})
\end{aligned}
$$

Sendo Y a fração molar de CO encontrada em cada temperatura operacional. Com esses dados foi possível calcular a demanda de carvão vegetal necessária para os ensaios em cada temperatura, a cada mol de $\mathrm{MgSO}_{4}$.

A Tabela 3 apresenta os dados de demanda de carvão vegetal em função das temperaturas operacionais, onde os valores de $\mathrm{K}_{\mathrm{eq}}$ de Boudouard e das frações molares $\mathrm{X}_{\mathrm{CO}}$ e $\mathrm{X}_{\mathrm{CO} 2}$ foram calculados a partir dos dados termodinâmicos fornecidos pelo HSC Chemistry 6.0, $\mathrm{M}_{\mathrm{C} / \mathrm{CO} 2}$ e $\mathrm{M}_{\mathrm{C} / \mathrm{CO}}$ são as massas estequiométricas, em grama, de carbono para a decomposição do sulfato de magnésio seguindo as reações 14 e 13 de acordo com as frações molares de Boudouard.

Tabela 4. Demanda de carvão vegetal por mol de MgSO4.7H2O em função das temperaturas operacionais

\begin{tabular}{|c|c|c|c|c|c|c|c|}
\hline $\begin{array}{c}\text { Temperatur } \\
\mathrm{a}\left({ }^{\circ} \mathrm{C}\right)\end{array}$ & $\begin{array}{c}\text { Keq } \\
\text { Boudouard }\end{array}$ & $\begin{array}{c}\mathrm{X}_{\mathrm{CO}} \\
2\end{array}$ & $\mathrm{X}_{\mathrm{CO}}$ & $\begin{array}{c}\mathrm{M}_{\mathrm{C} / \mathrm{CO}} \\
2(\mathrm{~g})\end{array}$ & $\begin{array}{c}\mathrm{M}_{\mathrm{C} / \mathrm{CO}} \\
(\mathrm{g})\end{array}$ & $\begin{array}{c}\text { Massa } \\
\text { Total de C } \\
(\mathrm{g})\end{array}$ & $\begin{array}{c}\text { Massa Total } \\
\text { de Carvão } \\
(\mathrm{g})\end{array}$ \\
\hline 600 & $8,862 \mathrm{E}-02$ & $\begin{array}{c}0,74 \\
3\end{array}$ & 0,256 & 4,459 & 3,080 & 7,540 & 7,813 \\
\hline 700 & $1,002 \mathrm{E}+00$ & $\begin{array}{c}0,38 \\
1\end{array}$ & 0,618 & 2,289 & 7,421 & 9,710 & 10,062 \\
\hline 800 & $7,131 \mathrm{E}+00$ & $\begin{array}{c}0,11 \\
0\end{array}$ & 0,889 & 0,665 & $\begin{array}{c}10,66 \\
9\end{array}$ & 11,335 & 11,745 \\
\hline 900 & $3,397 \mathrm{E}+01$ & $\begin{array}{c}0,02 \\
6\end{array}$ & 0,973 & 0,158 & $\begin{array}{c}11,68 \\
3\end{array}$ & 11,842 & 12,271 \\
\hline
\end{tabular}




\subsubsection{Avaliação da relação da perda de massa com a conversão máxima por temperatura}

Ao observarmos as duas reações que estão presentes neste sistema, é possível analisar que a partir dos dois reagentes sólidos envolvidos na reação são produzidos um composto sólido e três gasosos.

$$
\begin{aligned}
& \mathrm{MgSO}_{4} \cdot 7 \mathrm{H}_{2} \mathrm{O}+\mathrm{C}=\mathrm{MgO}+\mathrm{SO}_{2}(\mathrm{~g})+\mathrm{CO}(\mathrm{g})+7 \mathrm{H}_{2} \mathrm{O}(\mathrm{g}) \\
& \mathrm{MgSO}_{4} .7 \mathrm{H}_{2} \mathrm{O}+0,5 \mathrm{C}=\mathrm{MgO}+\mathrm{SO}_{2}(\mathrm{~g})+\mathrm{CO}_{2}(\mathrm{~g})+7 \mathrm{H}_{2} \mathrm{O}(\mathrm{g})
\end{aligned}
$$

Os componentes gasosos gerados são carreados pelo gás de arraste e deixam o sistema, sendo possível calcular a conversão pela massa perdida por meio do sistema em forma de gás. Para uma conversão total da reação 15 , temos uma perda de massa de $84,40 \%$, já para a reação 16 essa perda de massa é de $84,03 \%$. Através do mesmo balanço utilizado para calcular a demanda de carbono para a reação, é possível calcular a perda de massa para uma conversão plena por temperatura do processo, onde os valores das frações molares $\mathrm{X}_{\mathrm{CO}}$ e $\mathrm{X}_{\mathrm{CO} 2}$ foram calculados a partir dos dados termodinâmicos fornecidos pelo HSC Chemistry 6.0, P M $\mathrm{C} / \mathrm{CO} 2$ e P M C/CO são as perdas de massas estequiométricas, em porcentagem, as reações 16 e 15 de acordo com as frações molares de Boudouard.

Tabela 5. Perda de massa em função da conversão máxima por temperaturas operacionais

\begin{tabular}{|c|c|c|c|c|c|}
\hline $\begin{array}{c}\text { Temperatura } \\
\left({ }^{\circ} \mathrm{C}\right)\end{array}$ & $\mathrm{X}_{\mathrm{CO} 2}$ & $\mathrm{X}_{\mathrm{CO}}$ & $\begin{array}{c}\mathrm{P}^{\mathrm{M}_{\mathrm{C} / \mathrm{CO} 2}} \\
(\%)\end{array}$ & $\begin{array}{c}\mathrm{P}_{\mathrm{C} / \mathrm{CO}} \\
(\%)\end{array}$ & $\begin{array}{c}\text { Perda de massa Total } \\
(\%)\end{array}$ \\
\hline 600 & $\begin{array}{c}0.743 \\
3\end{array}$ & $\begin{array}{c}0.256 \\
7\end{array}$ & 62.735 & 21.571 & 84.305 \\
\hline 700 & $\begin{array}{c}0.381 \\
6\end{array}$ & $\begin{array}{c}0.618 \\
4\end{array}$ & 32.207 & 51.964 & 84.171 \\
\hline 800 & $\begin{array}{c}0.110 \\
9\end{array}$ & $\begin{array}{c}0.889 \\
1\end{array}$ & 9.360 & 74.711 & 84.071 \\
\hline 900 & $\begin{array}{c}0.026 \\
4\end{array}$ & $\begin{array}{c}0.973 \\
6\end{array}$ & 2.228 & 81.812 & 84.040 \\
\hline
\end{tabular}

\subsection{Avaliação das variáveis experimentais}

Após a apreciação termodinâmica do sistema e de acordo com o item 3.2 deste trabalho, os ensaios experimentais de decomposição carbotérmica do sulfato de 
magnésio foram realizados a diferentes valores de temperatura e vazão do gás de arraste.

Estes ensaios têm como objetivo determinar as melhores condições operacionais para a obtenção de um óxido de magnésio que possa ser utilizado como regulador de $\mathrm{pH}$.

\subsubsection{Estudo do efeito do excesso do carvão vegetal na conversão da decomposição}

O excesso do agente redutor pode influenciar positivamente a conversão de $\mathrm{MgSO}_{4}$ no sistema reacional caso o mesmo desloque o equilíbrio da reação no sentido de favorecer a formação de mais produto. Entretanto, o excesso também pode ser um obstáculo para a reação e causar um efeito de barreira, separando uma porção de um reagente do outro.

Para determinar que efeito esse excesso possa causar na conversão final foram realizados experimentos com o carvão vegetal estequiométrico e em condições de excesso de 10, 20 e 30\% com um tempo de residência de $30 \mathrm{~min}$, conforme apontado por Brocchi et al., (2013) como um tempo necessário para se atingir a conversão máxima desta reação. Os valores de excesso foram calculados a partir das demandas de carvão da Tabela 4. Os resultados obtidos se encontram na Tabela 6 e 7 e nas Figuras 28. 
Tabela 6. Análise visual do produto da decomposição carbotérmica em função do excesso do agente redutor por temperatura

\begin{tabular}{|c|c|c|c|c|}
\hline \multirow[b]{2}{*}{ Temperatura $\left({ }^{\circ} \mathrm{C}\right)$} & \multicolumn{4}{|c|}{ Variação do teor de carbono } \\
\hline & Estequiométrico & $\begin{array}{l}10 \% \text { de } \\
\text { excesso }\end{array}$ & $\begin{array}{l}20 \% \text { de } \\
\text { excesso }\end{array}$ & $\begin{array}{l}30 \% \text { de } \\
\text { excesso }\end{array}$ \\
\hline $600^{\circ} \mathrm{C}$ & & & & \\
\hline $700^{\circ} \mathrm{C}$ & & & & \\
\hline $800^{\circ} \mathrm{C}$ & & & & \\
\hline $900^{\circ} \mathrm{C}$ & & & & \\
\hline
\end{tabular}

Através da Tabela 6 é possível realizar uma análise visual do produto da decomposição carbotérmica em função do excesso do agente redutor por temperatura. Observa-se que, após 30 min no reator, o produto final do processo apresenta uma aparência uniforme por cada temperatura. Tal aparência permite supor que o excesso do agente redutor não causa grande influência na conversão final.

A Tabela 7 e a Figura 28 aprimoram esta discussão, onde fica evidenciado que o excesso de agente redutor não tem influência direta sobre a conversão final da decomposição, visto que, a diferença entre a maior e a menor perda de massa registrada não chega a $3 \%$ por temperatura, sendo de $1,52 \%$ nos ensaios a $600{ }^{\circ} \mathrm{C}$, de $1 \%$ nos ensaios a $700{ }^{\circ} \mathrm{C}$, de $2,19 \%$ nos ensaios a $800{ }^{\circ} \mathrm{C}$ e de $2,90 \%$ nos ensaios a $900{ }^{\circ} \mathrm{C}$.

Uma vez que o excesso de agente redutor não influi na conversão final da reação de decomposição, os demais experimentos foram realizados em condições estequiométricas. 
Tabela 7. Resultados dos ensaios de decomposição em função do excesso de agente por temperatura

\begin{tabular}{|c|c|c|c|c|}
\hline Temperatura $\left({ }^{\circ} \mathrm{C}\right)$ & \% Excesso & $\mathrm{M}_{\mathrm{Ao}}(\mathrm{g})$ & $\mathrm{M}_{\mathrm{Af}}(\mathrm{g})$ & \% Perda de Massa \\
\hline 600 & 0 & 0,506 & 0,247 & $51,19 \%$ \\
\hline 600 & 10 & 0,526 & 0,252 & $52,09 \%$ \\
\hline 600 & 20 & 0,530 & 0,262 & $50,57 \%$ \\
\hline 600 & 30 & 0,534 & 0,260 & $51,31 \%$ \\
\hline 700 & 0 & 0,516 & 0,243 & $52,91 \%$ \\
\hline 700 & 10 & 0,499 & 0,230 & $53,91 \%$ \\
\hline 700 & 20 & 0,528 & 0,247 & $53,22 \%$ \\
\hline 700 & 30 & 0,512 & 0,241 & $52,93 \%$ \\
\hline 800 & 0 & 0,514 & 0,162 & $68,48 \%$ \\
\hline 800 & 10 & 0,502 & 0,162 & $67,73 \%$ \\
\hline 800 & 20 & 0,447 & 0,147 & $67,11 \%$ \\
\hline 800 & 30 & 0,505 & 0,155 & $69,31 \%$ \\
\hline 900 & 0 & 0,519 & 0,082 & $84,20 \%$ \\
\hline 900 & 10 & 0,516 & 0,075 & $85,47 \%$ \\
\hline 900 & 20 & 0,519 & 0,068 & $86,90 \%$ \\
\hline 900 & 30 & 0,527 & 0,068 & $87,10 \%$ \\
\hline
\end{tabular}

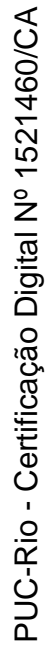

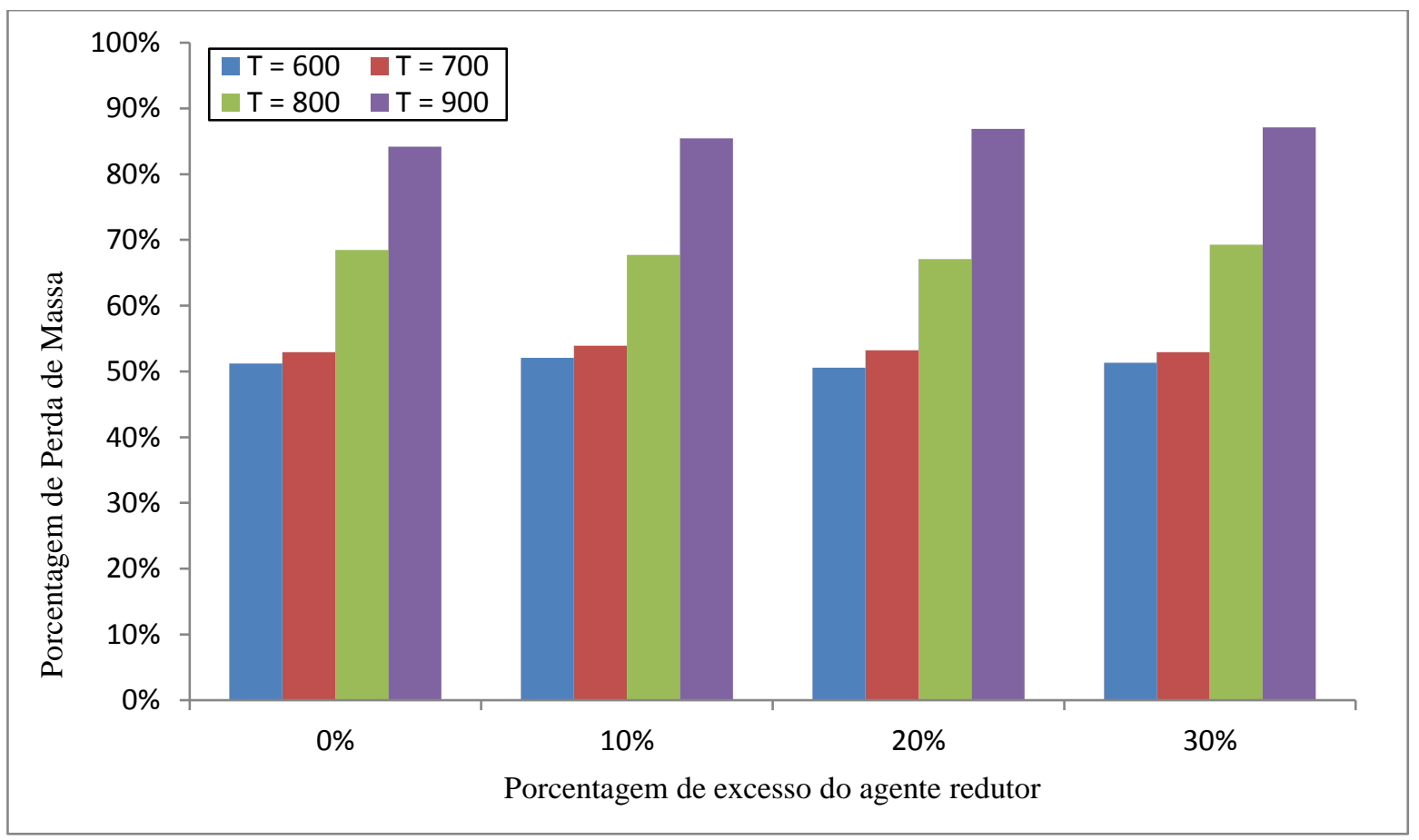

Figura 28. Perda de massa em função do excesso do agente redutor por temperatura e com 30 minutos de residência. 


\subsubsection{Avaliação do comportamento do sistema reacional $\mathrm{MgSO}_{4} \cdot 7 \mathrm{H}_{2} \mathrm{O}$ + C em função da temperatura ao longo do tempo}

Devido ao fato de que o $\mathrm{MgO}$ obtido será utilizado como regulador de $\mathrm{pH}$ é fundamental que o mesmo apresente boa reatividade. É sabido que quanto menor for a temperatura de obtenção do composto maior será sua área superficial e quanto maior for a área superficial melhor será sua chance de apresentar boa reatividade. Pressuposto isso, os ensaios foram realizados das temperaturas mais baixas para as mais altas e em intervalos de 5, 10, 15, 20, 25 e 30 minutos, que tem seus resultados apresentados nas Tabelas 8 a 11 .

Tabela 8. Resultados dos ensaios de decomposição carbotérmica a $600{ }^{\circ} \mathrm{C}$

\begin{tabular}{|c|c|c|c|}
\hline Tempo $(\min )$ & $\mathrm{M}_{\text {Ao }}(\mathrm{g})$ & $\mathrm{M}_{\mathrm{Af}}(\mathrm{g})$ & $\%$ Perda de Massa \\
\hline 5 & 0,505 & 0,235 & $53,47 \%$ \\
\hline 10 & 0,530 & 0,253 & $52,26 \%$ \\
\hline 15 & 0,531 & 0,257 & $51,60 \%$ \\
\hline 20 & 0,499 & 0,242 & $51,50 \%$ \\
\hline 25 & 0,503 & 0,232 & $53,88 \%$ \\
\hline 30 & 0,495 & 0,231 & $53,33 \%$ \\
\hline
\end{tabular}

Tabela 9. Resultados dos ensaios de decomposição carbotérmica a $700{ }^{\circ} \mathrm{C}$

\begin{tabular}{|c|c|c|c|}
\hline Tempo $(\min )$ & $\mathrm{M}_{\text {Ao }}(\mathrm{g})$ & $\mathrm{M}_{\mathrm{Af}}(\mathrm{g})$ & $\%$ Perda de Massa \\
\hline 5 & 0,503 & 0,234 & $53,48 \%$ \\
\hline 10 & 0,529 & 0,251 & $52,55 \%$ \\
\hline 15 & 0,505 & 0,235 & $53,47 \%$ \\
\hline 20 & 0,513 & 0,232 & $54,78 \%$ \\
\hline 25 & 0,515 & 0,239 & $53,59 \%$ \\
\hline 30 & 0,513 & 0,239 & $53,41 \%$ \\
\hline
\end{tabular}

Tabela 10. Resultados dos ensaios de decomposição carbotérmica a $800{ }^{\circ} \mathrm{C}$

\begin{tabular}{|c|c|c|c|}
\hline Tempo $(\min )$ & $\mathrm{M}_{\text {Ao }}(\mathrm{g})$ & $\mathrm{M}_{\mathrm{Af}}(\mathrm{g})$ & \% Perda de Massa \\
\hline 5 & 0,503 & 0,227 & $54,87 \%$ \\
\hline 10 & 0,546 & 0,242 & $55,68 \%$ \\
\hline 15 & 0,544 & 0,221 & $59,38 \%$ \\
\hline 20 & 0,514 & 0,212 & $58,75 \%$ \\
\hline 25 & 0,519 & 0,210 & $59,54 \%$ \\
\hline
\end{tabular}




\begin{tabular}{|l|l|l|l|}
\hline 30 & 0,480 & 0,188 & $60,83 \%$ \\
\hline
\end{tabular}

Tabela 11. Resultados dos ensaios de decomposição carbotérmica a $900{ }^{\circ} \mathrm{C}$

\begin{tabular}{|c|c|c|c|}
\hline Tempo $(\min )$ & $\mathrm{M}_{\text {Ao }}(\mathrm{g})$ & $\mathrm{M}_{\mathrm{Af}}(\mathrm{g})$ & \% Perda de Massa \\
\hline 5 & 0,529 & 0,188 & $64,46 \%$ \\
\hline 10 & 0,572 & 0,153 & $73,35 \%$ \\
\hline 15 & 0,524 & 0,113 & $78,44 \%$ \\
\hline 20 & 0,515 & 0,086 & $83,30 \%$ \\
\hline 25 & 0,515 & 0,090 & $82,51 \%$ \\
\hline 30 & 0,475 & 0,076 & $84,00 \%$ \\
\hline
\end{tabular}

Os resultados obtidos foram condizentes com a apreciação termodinâmica no que diz respeito à relação proporcional da conversão com a temperatura de operação, uma vez que à medida que a temperatura aumenta a conversão tende a aumentar. Entretanto, enquanto o estudo termodinâmico indicava que o sulfato de magnésio iniciaria sua conversão em torno de $300{ }^{\circ} \mathrm{C}$ para a reação 14 e em torno de $400{ }^{\circ} \mathrm{C}$ para a reação 13 , os ensaios apontaram um resultado diferente. $\mathrm{O}$ sulfato de magnésio não se decompôs nas temperaturas de $500{ }^{\circ} \mathrm{C}$ e $600{ }^{\circ} \mathrm{C}$, tento atingido uma perda de massa entre $51,50 \%$ e $54,78 \%$, valores muito próximos da perda de água indicada pelo resultado do TGA.

Para as temperaturas de $800{ }^{\circ} \mathrm{C}$ e $900{ }^{\circ} \mathrm{C}$ podemos afirmar que houve algum grau de conversão, já que, as perdas de massa ficaram entre $54,87 \%$ e $60,83 \%$ para os ensaios a $800{ }^{\circ} \mathrm{C}$ e entre $64,46 \%$ e $84,00 \%$ para os ensaios a $900{ }^{\circ} \mathrm{C}$. Apesar de parecer ser uma pequena diferença entre uma perda de massa de $51 \%$ e $60 \%$, quando transformamos essa perda para uma conversão da reação fica mais explícito o significado que esses valores distintos têm.

Tabela 12. Resultados de conversão dos ensaios de decomposição carbotérmica do $\mathrm{MgSO}_{4}$

\begin{tabular}{|c|c|c|c|c|}
\hline \multirow{2}{*}{ Tempo (min) } & \multicolumn{4}{|c|}{ Temperatura } \\
\cline { 2 - 5 } & $600{ }^{\circ} \mathrm{C}$ & $700{ }^{\circ} \mathrm{C}$ & $800{ }^{\circ} \mathrm{C}$ & $900{ }^{\circ} \mathrm{C}$ \\
\hline 5 & $7,44 \%$ & $7,45 \%$ & $11,60 \%$ & $40,32 \%$ \\
\hline 10 & $3,82 \%$ & $4,67 \%$ & $14,02 \%$ & $66,64 \%$ \\
\hline 15 & $1,81 \%$ & $7,41 \%$ & $25,10 \%$ & $82,17 \%$ \\
\hline
\end{tabular}




\begin{tabular}{|c|c|c|c|c|}
\hline 20 & $1,52 \%$ & $11,35 \%$ & $23,25 \%$ & $96,74 \%$ \\
\hline 25 & $8,69 \%$ & $7,79 \%$ & $25,59 \%$ & $94,38 \%$ \\
\hline 30 & $7,05 \%$ & $7,25 \%$ & $29,48 \%$ & $98,83 \%$ \\
\hline
\end{tabular}

Pela análise da Tabela 12, é possível avaliar melhor o comportamento da decomposição em relação à temperatura ao longo do tempo. Enquanto os ensaios a $600{ }^{\circ} \mathrm{C}$ e $700{ }^{\circ} \mathrm{C}$ apresentam, respectivamente, conversões máximas de 8,69\% e $11,35 \%$, os ensaios a $800{ }^{\circ} \mathrm{C}$ já apresentam uma conversão máxima de $29,48 \%$. Ou seja, mesmo que a diferença de perda de massa seja pequena, menos de $10 \%$, a diferença na conversão é considerável, quase 03 vezes maior. Os melhores resultados obtidos, como esperado, foram para os ensaios a $900{ }^{\circ} \mathrm{C}$, onde a conversão para os intervalos de 20 a 30 minutos foram próximos a 100\%.

Outras analise que pode ser feita é em relação ao caráter de linearidade da evolução das conversões. Nas temperaturas mais baixas $\left(600{ }^{\circ} \mathrm{C}\right.$ e $\left.700{ }^{\circ} \mathrm{C}\right)$ a conversão da reação não apresenta uma evolução em relação ao acréscimo de tempo nos ensaios, isso ocorre devido à dificuldade de decomposição do $\mathrm{MgSO}_{4}$ nestas temperaturas. Nas temperaturas mais altas $\left(800{ }^{\circ} \mathrm{C}\right.$ e $\left.900{ }^{\circ} \mathrm{C}\right)$ já é possível observar uma evolução mais linear na conversão da reação nos 15 primeiros minutos dos ensaios, indicando uma forte reatividade inicial. Próximo a estabilização deste sistema a variação da conversão com o tempo diminui, indicando uma reação mais branda.

\subsubsection{Análise do efeito da homogeneidade dos reagentes}

Todos os ensaios foram realizados com o carvão vegetal moído, entretanto os cristais do sulfato de magnésio heptahidratado utilizados nos ensaios anteriores apresentavam uma distribuição granulométrica heterogênea e com tamanhos razoavelmente acima daqueles associados com os do carvão vegetal.

De acordo com Scheidema e Taskinen (2011b), o granulometria da partícula tem grande importância durante a reação, uma vez que quanto menor a partícula maior será a conversão do sistema reacional. Para analisar a importância da granulometria da partícula e consequentemente a importância da área superficial da mesma em uma reação sólido-sólido, foram realizados experimentos com as mesmas variáveis dos ensaios de análise do comportamento da decomposição em 
função da temperatura, entretanto, com um sulfato moído de forma a ficar com uma granulometria homogênea e com tamanhos próximos aos do carvão vegetal.

Estes ensaios serviram para avaliar se a homogeneidade do sulfato foi um fator importante na decomposição carbotérmica do $\mathrm{MgSO}_{4}$, os resultados estão apresentados na Tabela 13.

Tabela 13. Resultados de perda de massa dos ensaios de decomposição carbotérmica do $\mathrm{MgSO}_{4}$ com granulometria homogênea

\begin{tabular}{|c|c|c|c|c|}
\hline \multirow{2}{*}{ Tempo (min) } & \multicolumn{4}{|c|}{ Temperatura } \\
\cline { 2 - 5 } & $600{ }^{\circ} \mathrm{C}$ & $700{ }^{\circ} \mathrm{C}$ & $800{ }^{\circ} \mathrm{C}$ & $900{ }^{\circ} \mathrm{C}$ \\
\hline 5 & $51,37 \%$ & $52,24 \%$ & $53,83 \%$ & $62,17 \%$ \\
\hline 10 & $50,89 \%$ & $52,23 \%$ & $55,38 \%$ & $71,51 \%$ \\
\hline 15 & $51,81 \%$ & $51,15 \%$ & $57,11 \%$ & $75,78 \%$ \\
\hline 20 & $54,76 \%$ & $52,38 \%$ & $58,83 \%$ & $85,35 \%$ \\
\hline 25 & $52,15 \%$ & $52,17 \%$ & $60,48 \%$ & $86,44 \%$ \\
\hline 30 & $52,12 \%$ & $51,98 \%$ & $62,10 \%$ & $87,05 \%$ \\
\hline
\end{tabular}

Com os dados de perda de massa das Tabelas 8 a 11 e 13 foi possível construir uma comparação sobre as duas condições de operação a fim de se determinar qual a influência da homogeneidade do sulfato de magnésio sobre a conversão da decomposição. Esta comparação está demonstrada na Tabela 14 e nas Figuras 29 a 32.

Tabela 14. Comparativo entre as perdas de massa dos ensaios de decomposição carbotérmica do MgSO4 com granulometria heterogênea e homogênea

\begin{tabular}{|c|c|c|c|c|c|c|c|c|}
\hline \multirow{3}{*}{$\begin{array}{c}\text { Tempo } \\
(\min )\end{array}$} & \multicolumn{8}{|c|}{ Temperatura } \\
\hline & \multicolumn{2}{|c|}{$600{ }^{\circ} \mathrm{C}$} & \multicolumn{2}{|c|}{$700^{\circ} \mathrm{C}$} & \multicolumn{2}{|c|}{$800{ }^{\circ} \mathrm{C}$} & \multicolumn{2}{|c|}{$900{ }^{\circ} \mathrm{C}$} \\
\hline & G. He & G. Ho & G. $\mathrm{He}$ & G. Ho & G. $\mathrm{He}$ & G. Ho & G. $\mathrm{He}$ & G. Ho \\
\hline 5 & $\begin{array}{c}53,47 \\
\%\end{array}$ & 51,37 & 53,48 & 52,24 & $\begin{array}{c}54,87 \\
0\end{array}$ & 53,83 & 64,46 & 62,17 \\
\hline 10 & $\begin{array}{c}52,26 \\
\%\end{array}$ & $\begin{array}{c}50,89 \\
\%\end{array}$ & $\begin{array}{c}52,55 \\
\%\end{array}$ & $\begin{array}{c}52,23 \\
\%\end{array}$ & $\begin{array}{c}55,68 \\
\%\end{array}$ & $\begin{array}{c}55,38 \\
\%\end{array}$ & $\begin{array}{c}73,35 \\
\%\end{array}$ & $\begin{array}{c}71,51 \\
\%\end{array}$ \\
\hline 15 & $\begin{array}{c}51,60 \\
\%\end{array}$ & $\begin{array}{c}51,81 \\
\%\end{array}$ & $\begin{array}{c}53,47 \\
\%\end{array}$ & $\begin{array}{c}51,15 \\
\%\end{array}$ & $\begin{array}{c}59,38 \\
\%\end{array}$ & $\begin{array}{c}57,11 \\
\%\end{array}$ & $\begin{array}{c}78,26 \\
\%\end{array}$ & $\begin{array}{c}75,78 \\
\%\end{array}$ \\
\hline 20 & $\begin{array}{c}51,50 \\
\%\end{array}$ & $\begin{array}{c}54,76 \\
\%\end{array}$ & $\begin{array}{c}54,78 \\
\%\end{array}$ & $\begin{array}{c}52,38 \\
\%\end{array}$ & $\begin{array}{c}58,75 \\
\%\end{array}$ & $\begin{array}{c}58,83 \\
\%\end{array}$ & $\begin{array}{c}83,30 \\
\%\end{array}$ & $\begin{array}{c}85,35 \\
\%\end{array}$ \\
\hline 25 & $\begin{array}{c}53,88 \\
\%\end{array}$ & $\begin{array}{c}52,15 \\
\%\end{array}$ & $\begin{array}{c}53,59 \\
\%\end{array}$ & $\begin{array}{c}52,17 \\
\%\end{array}$ & $\begin{array}{c}59,54 \\
\%\end{array}$ & $\begin{array}{c}60,48 \\
\%\end{array}$ & $\begin{array}{c}85,40 \\
\%\end{array}$ & $\begin{array}{c}86,44 \\
\%\end{array}$ \\
\hline
\end{tabular}




\begin{tabular}{|c|c|c|c|c|c|c|c|c|}
\hline 30 & $\begin{array}{c}53,33 \\
\%\end{array}$ & $\begin{array}{c}52,12 \\
\%\end{array}$ & $\begin{array}{c}53,41 \\
\%\end{array}$ & $\begin{array}{c}51,98 \\
\%\end{array}$ & $\begin{array}{c}60,83 \\
\%\end{array}$ & $\begin{array}{c}62,10 \\
\%\end{array}$ & $\begin{array}{c}84,00 \\
\%\end{array}$ & $\begin{array}{c}87,05 \\
\%\end{array}$ \\
\hline
\end{tabular}

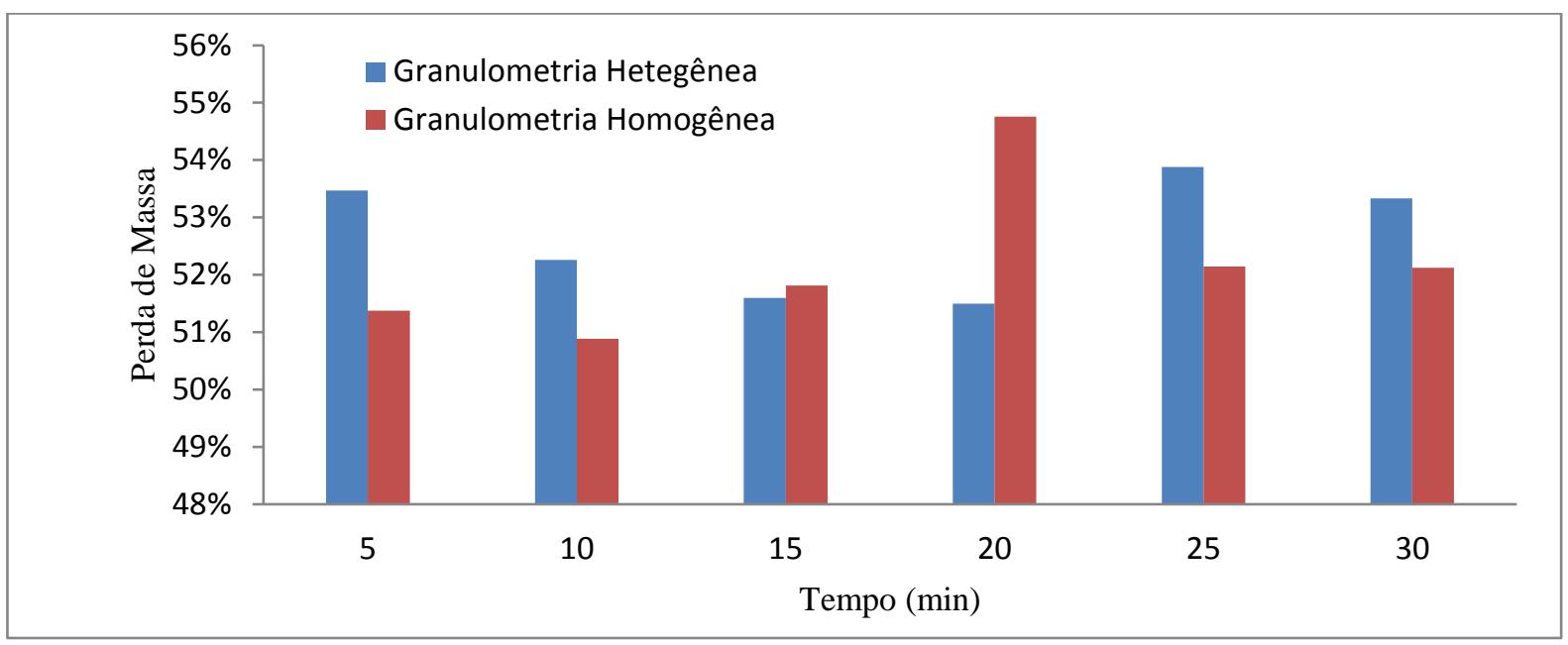

Figura 29. Conversão da decomposição carbotérmica a $600{ }^{\circ} \mathrm{C}$ em função da homogeneidade do $\mathrm{MgSO} 4$

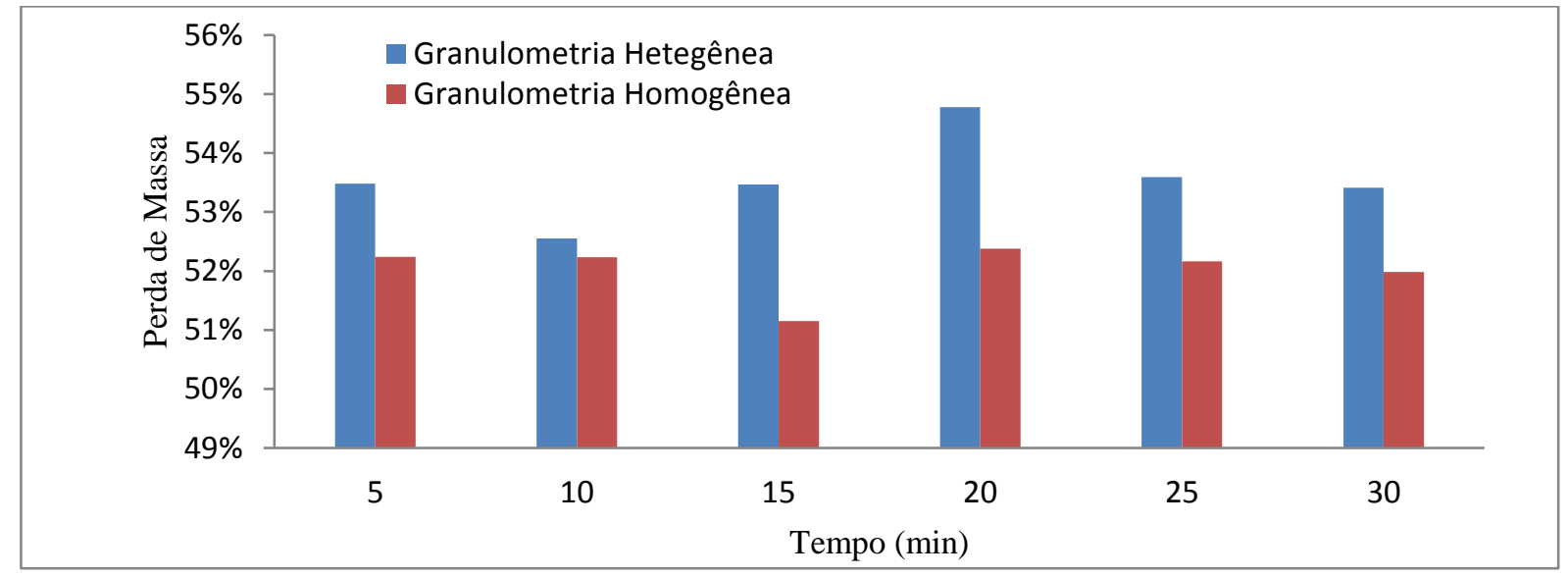

Figura 30. Conversão da decomposição carbotérmica a $700{ }^{\circ} \mathrm{C}$ em função da homogeneidade do $\mathrm{MgSO} 4$

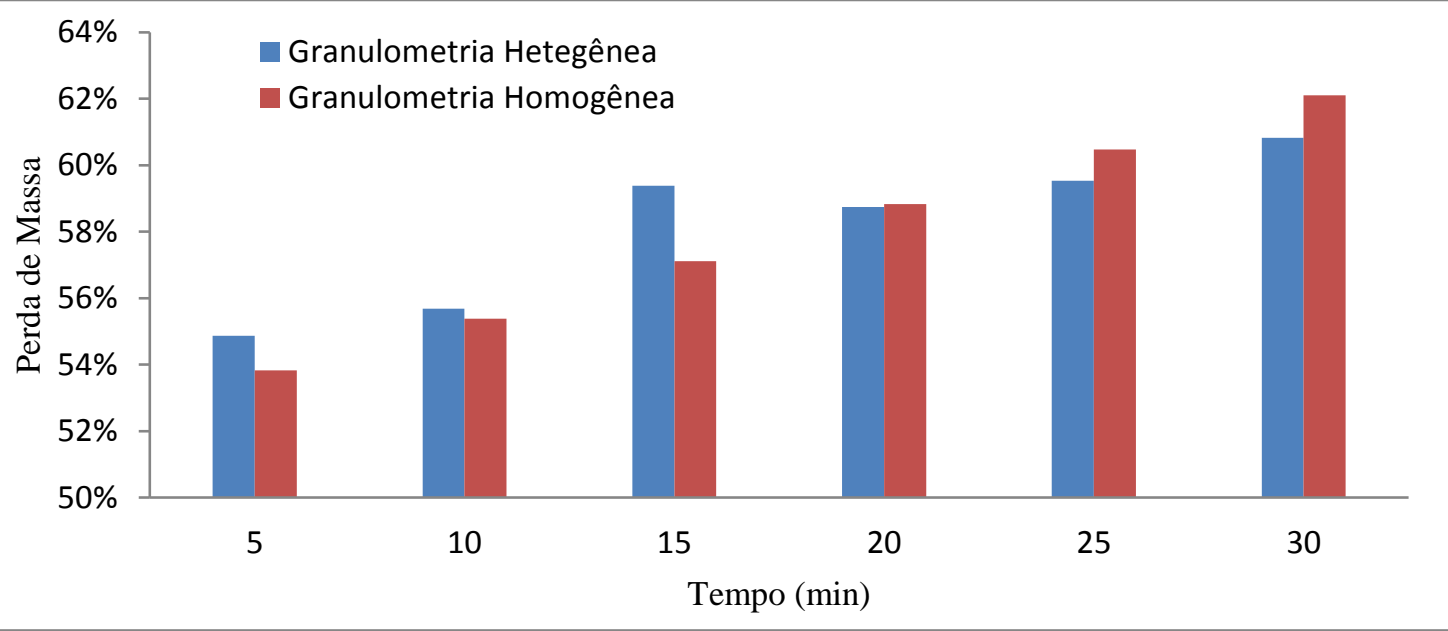


Figura 31. Conversão da decomposição carbotérmica a $800{ }^{\circ} \mathrm{C}$ em função da homogeneidade do $\mathrm{MgSO} 4$

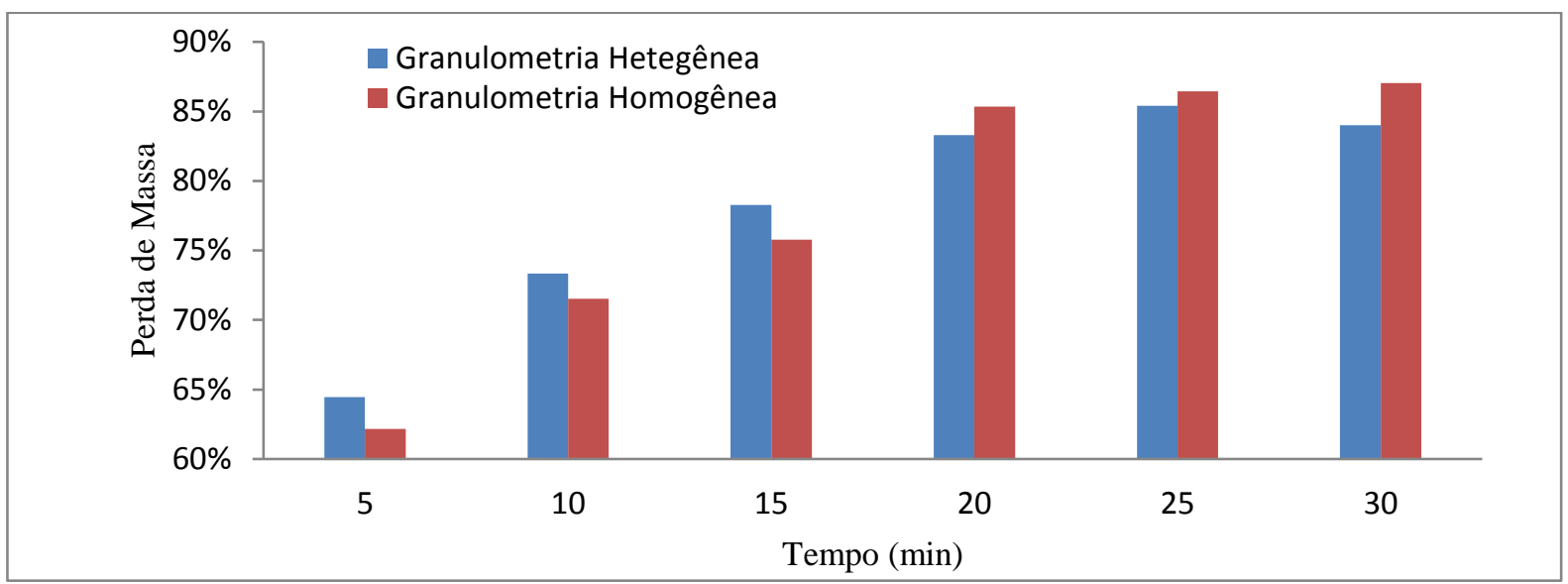

Figura 32. Conversão da decomposição carbotérmica a $900{ }^{\circ} \mathrm{C}$ em função da homogeneidade do $\mathrm{MgSO} 4$

Através das Figuras 29 a 32 é possível verificar que apesar da amostra moída e homogênea do sulfato de magnésio apresentar uma maior área superficial, essa característica não garante uma maior conversão da reação nas condições observadas, visto que a diferença das conversões encontradas não obedece a um padrão que torne possível uma diferenciação entre as duas condições operacionais.

Analisando os valores de perda de massa exibidos na Tabela 14 é possível confirmar esta afirmação uma vez que a diferença entre as perdas de massa com a granulometria heterogênea e com a granulometria homogênea apresenta uma variação entre $-3 \%$ e $3 \%$ aproximadamente em todos os ensaios realizados, uma variação muito baixa para caracterizar uma nítida influência da granulometria.

\subsubsection{Análise do efeito da vazão do gás de arraste sobre o sistema reacional}

A mudança da vazão do gás de arraste pode influenciar no sistema reacional e na sua conversão uma vez que ela muda a composição da atmosfera reacional. Durante o processo de decomposição do sulfato de magnésio, a atmosfera reacional se altera com a presença dos gases provenientes da decomposição, $\mathrm{H}_{2} \mathrm{O}, \mathrm{SO}_{2}, \mathrm{CO}$ e $\mathrm{CO}_{2}$. A presença do $\mathrm{H}_{2} \mathrm{O}$ e do $\mathrm{SO}_{2}$ pode dificultar a decomposição do sulfato tornando a atmosfera reacional desfavorável a reação desejada. Um aumento na 
vazão do gás de arraste pode carrear esses gases para fora do sistema e favorecer a uma melhor conversão da reação.

Os ensaios anteriores foram realizados com uma vazão de argônio de 0,33 L/min e para a análise do efeito da vazão sobre o sistema reacional, foram realizados experimentos com uma vazão de argônio de 1,61 L/min. Os resultados obtidos estão na Tabela 15 e 16.

Tabela 15. Resultados de perda de massa dos ensaios com vazão de 1,61 L/min e temperatura de $800{ }^{\circ} \mathrm{C}$

\begin{tabular}{|c|c|c|c|}
\hline Tempo $(\min )$ & $\mathrm{M}_{\text {Ao }}(\mathrm{g})$ & $\mathrm{M}_{\mathrm{Af}}(\mathrm{g})$ & \% Perda de Massa \\
\hline 5 & 0.546 & 0.265 & $51.47 \%$ \\
\hline 10 & 0.509 & 0.226 & $55.60 \%$ \\
\hline 15 & 0.509 & 0.203 & $60.12 \%$ \\
\hline 20 & 0.543 & 0.231 & $57.46 \%$ \\
\hline 25 & 0.510 & 0.196 & $61.57 \%$ \\
\hline 30 & 0.579 & 0.231 & $60.10 \%$ \\
\hline
\end{tabular}

Tabela 16. Resultados de perda de massa dos ensaios com vazão de 1,61 L/min e temperatura de $900{ }^{\circ} \mathrm{C}$

\begin{tabular}{|c|c|c|c|}
\hline Tempo $(\min )$ & $\mathrm{M}_{\text {Ao }}(\mathrm{g})$ & $\mathrm{M}_{\mathrm{Af}}(\mathrm{g})$ & \% Perda de Massa \\
\hline 5 & 0.503 & 0.210 & $58.25 \%$ \\
\hline 10 & 0.537 & 0.160 & $70.20 \%$ \\
\hline 15 & 0.520 & 0.092 & $82.31 \%$ \\
\hline 20 & 0.522 & 0.084 & $83.91 \%$ \\
\hline 25 & 0.503 & 0.072 & $85.69 \%$ \\
\hline 30 & 0.508 & 0.075 & $85.24 \%$ \\
\hline
\end{tabular}

Com os dados das Tabelas 10, 11, 15 e 16 é possível avaliar o efeito da vazão do gás de arraste sobre o sistema reacional. Pelo exame da Figura 33 é possível verificar que, apesar de a termodinâmica indicar que a pressões menores de $\mathrm{SO}_{2}$ a decomposição seria favorecida, os ensaios demonstram que em intervalos menores de tempo (5 e $10 \mathrm{~min}$ ) tanto para $800{ }^{\circ} \mathrm{C}$ quanto para $900{ }^{\circ} \mathrm{C}$ as conversões foram reduzidas com o aumento da vazão de arraste. Essa diminuição a taxa de conversão inicial pode ser uma influência da retirada do $\mathrm{CO}$, formado pela decomposição junto com o $\mathrm{SO}_{2}$, isto porque o $\mathrm{CO}$ é outro agente redutor e também contribui para a decomposição do $\mathrm{MgSO}_{4}$. Para os demais ensaios pode-se dizer que a influência da vazão é desprezível. 


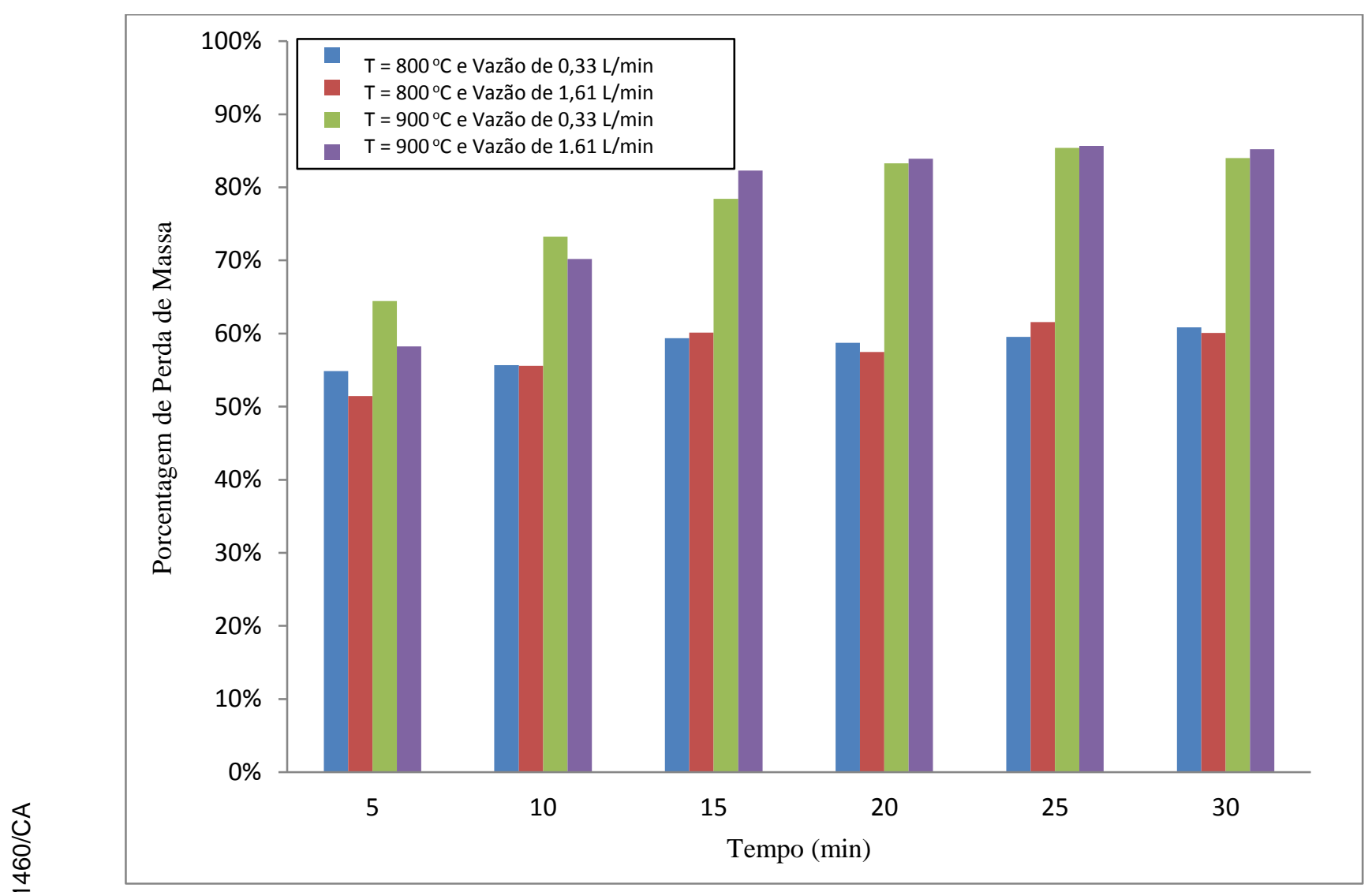

Figura 33. Conversão da decomposição carbotérmica a $900{ }^{\circ} \mathrm{C}$ em função da homogeneidade do $\mathrm{MgSO} 4$

\subsection{Caracterização do produto obtido}

Após a realização dos ensaios e análise de suas variáveis efetuou-se análises no produto obtido pelos ensaios à temperatura de $900{ }^{\circ} \mathrm{C}$ e um tempo de reação de 25 e 30 minutos, de modo a caracterizar o produto final da decomposição carbotérmica do sulfato de magnésio.

\subsubsection{Difração de Raios-X (DR-X)}

Ao analisar o difratograma resultante da análise por difração de raios-X do produto obtido nos ensaios de decomposição carbotérmica do sulfato de magnésio e comparar este resultado com as bases de dados de estruturas cristalinas conhecidas foi possível determinar que o produto obtido é composto em sua maioria por três fases de óxido de magnésio. Este resultado vai de encontro com o esperado após as análises termodinâmicas e a composição química encontrada pela análise de EDS.

O ajuste que possibilitou esta análise da composição mineralógica do produto obtido pode ser observado na Figura 34. A linha em azul foi o sinal capitado pelo 
difratometro proveniente do material analisado, a linha em vermelho foi o valor calculado a partir dos bancos de dados conhecidos. Foi possível observar uma diferença entre estas duas linhas, representada pela linha cinza a baixo das outras duas. Esta diferença indica a existência de outras estruturas cristalinas que não foram ajustadas, devido as baixas amplitudes na linha cinza é plausível admitir que estas estruturas não identificadas estão em menor escala que as do óxido de magnésio.

Ao avaliar a linha cinza pode-se observar a existência de picos de baixo ângulo, entre 16 e 38. Estes picos não ajustados e de menor amplitude representam substancias presentes em menor escala e que provavelmente são formadas de compostos encontrados nas cinzas do carvão. 

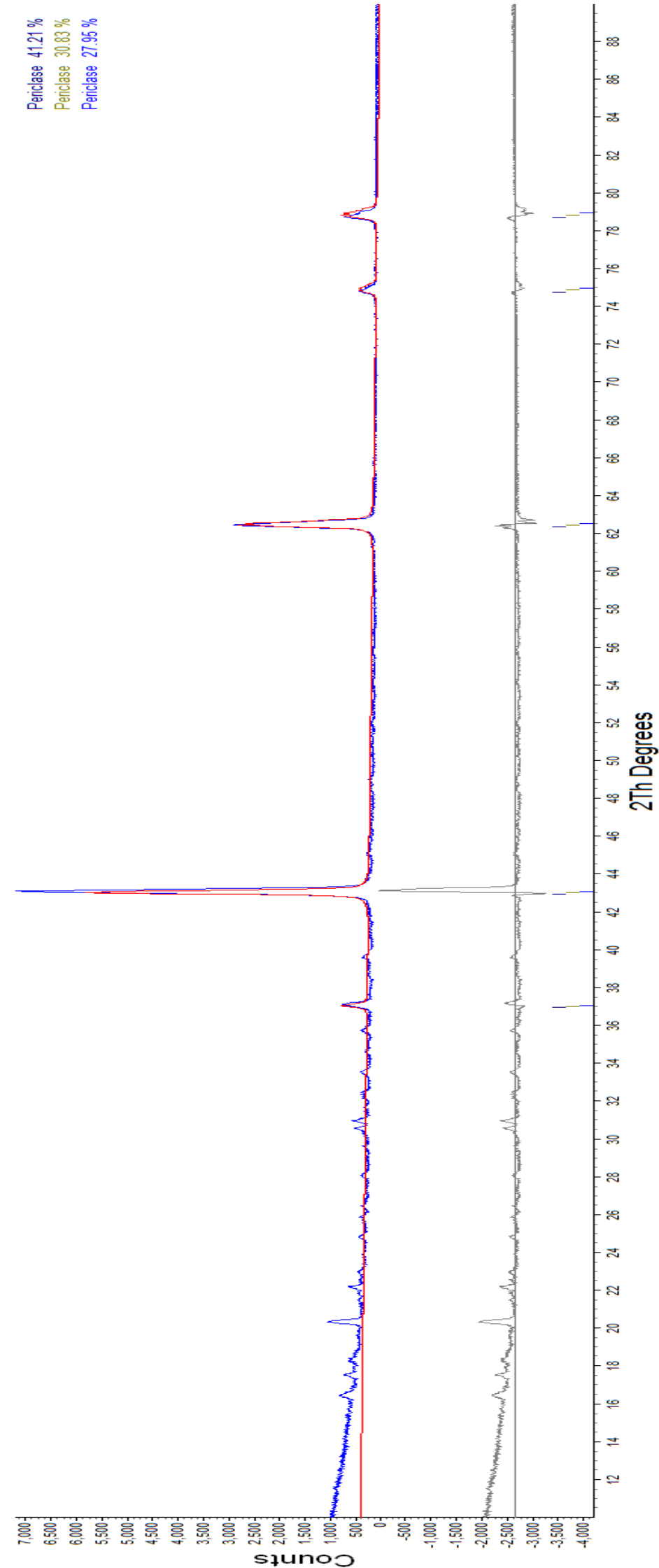

Figura 34. Espectro de difração de raios-X do produto da decomposição carbotérmica, construída a partir do Difratômetro de raios-X. 


\subsubsection{Microscopia eletrônica de varredura/Espectroscopia de Raios- $X$ por dispersão em energia (MEV/EDS)}

O produto obtido foi analisado no MEV para um exame de sua estrutura morfológica. A Figura 35 apresenta o resultado obtido.

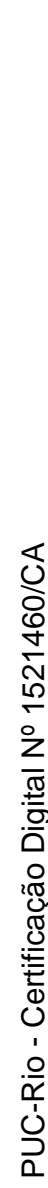
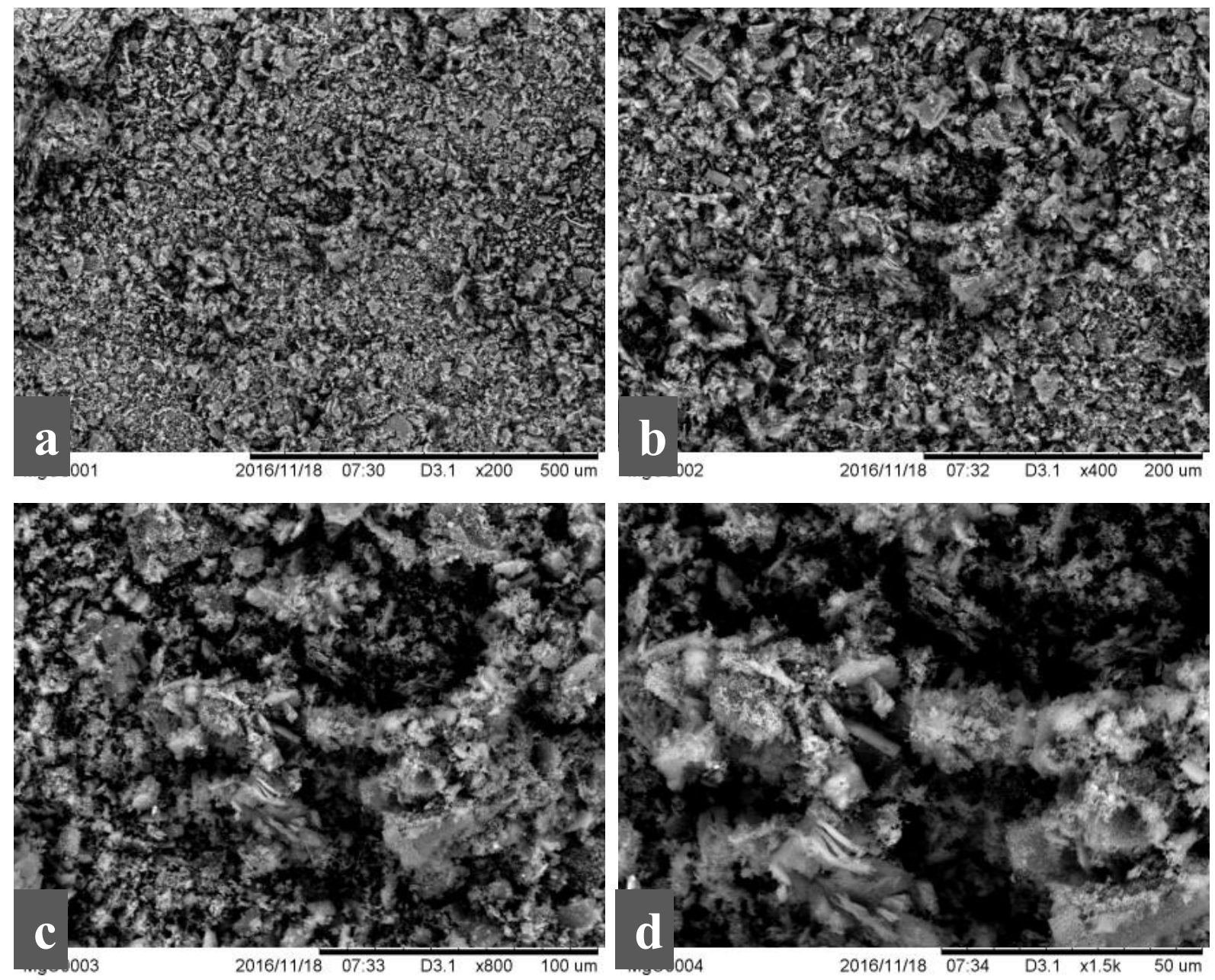

Figura 35. Estrutura morfológica do produto da decomposição carbotérmica obtida por EDS

Pode-se observar a partir da imagem contida na Figura 35 que o material apresenta uma morfologia homogênea com uma composição formada de partículas pequenas. Pela análise da imagem d, pode-se averiguar que estas partículas são menores que $10 \mu \mathrm{m}$. Podemos afirmar que, apesar da formação de pequenos cristais, visualmente o material aparenta possuir uma certa porosidade em sua estrutura.

A fim de se confirmar a composição mineralógica identificada pela análise no DR-X, foram realizadas três análises por EDS para avaliar a composição química 
elementar do material produzido. Cada análise foi realizada em uma diferente área da amostra para obter uma maior amplitude analítica. As Figuras 36 e 37 e a tabela 17 foram obtidas a partir da análise da região 1 .

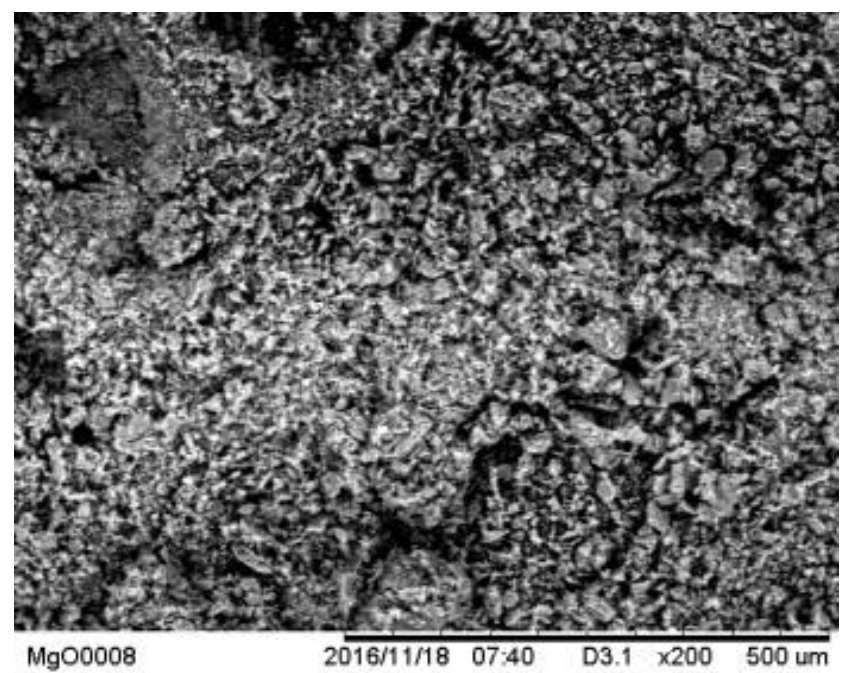

Figura 36. Estrutura morfológica do produto da decomposição carbotérmica obtida por EDS

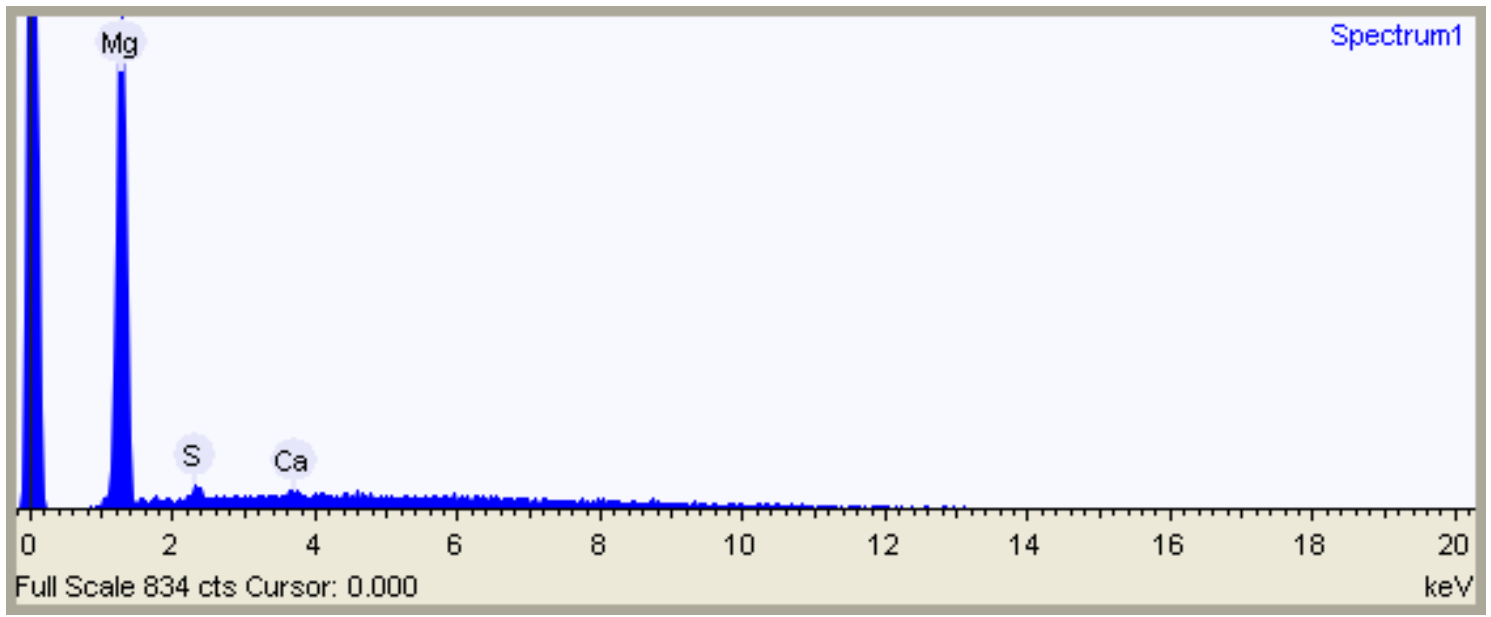

Figura 37. Espectro da análise por EDS na região 1

Tabela 17. Resultados da análise por EDS na região 1

\begin{tabular}{|c|c|}
\hline Elemento & Peso (\%) \\
\hline Magnésio & 94,2 \\
\hline Enxofre & 3,6 \\
\hline Cálcio & 2,2 \\
\hline
\end{tabular}

Os elementos encontrados pela EDS na região 1 foram: magnésio, enxofre e cálcio. Uma vez que o oxigênio não é captado pelo método de análise, o resultado obtido vai de encontro com a análise feita pelo DR-X. Supõe-se que o enxofre que 
foi registrado pela EDS é provavelmente parte do sulfato que não foi convertido em óxido de magnésio. O magnésio, elemento em maior quantidade na amostra está em sua maioria na forma de óxido. O cálcio deve ser proveniente das cinzas do carvão vegetal utilizado nos ensaios.

Outras duas regiões da amostra foram analisadas para que a composição química do material fosse confirmada. A partir da análise da região 2 foram obtidas as Figuras 38 e 39 e a Tabela 18, já a partir da análise da região 2 foram obtidas as Figuras 40 a 41 e a Tabela 19.

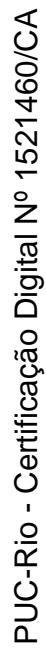

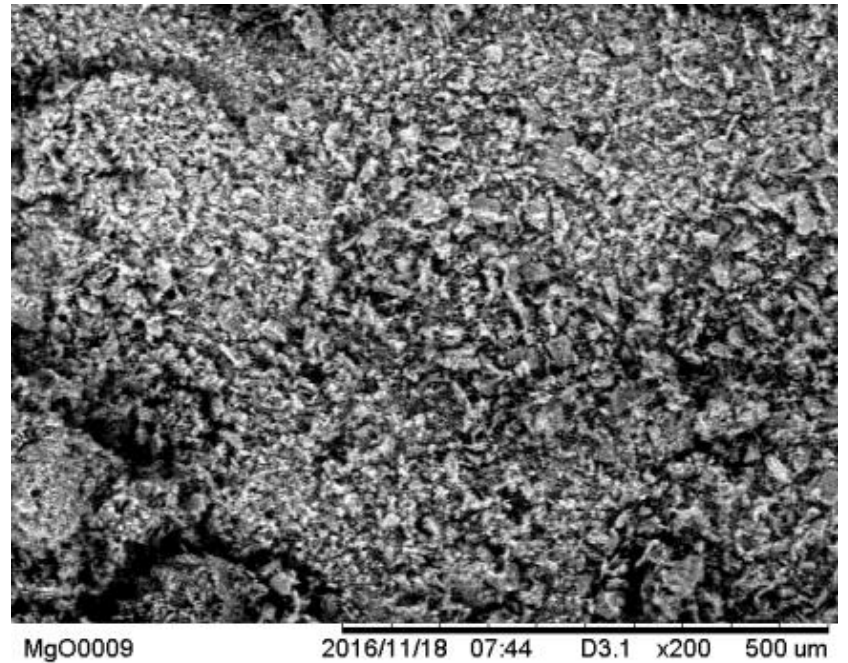

Figura 38. Estrutura morfológica do produto da decomposição carbotérmica obtida por EDS

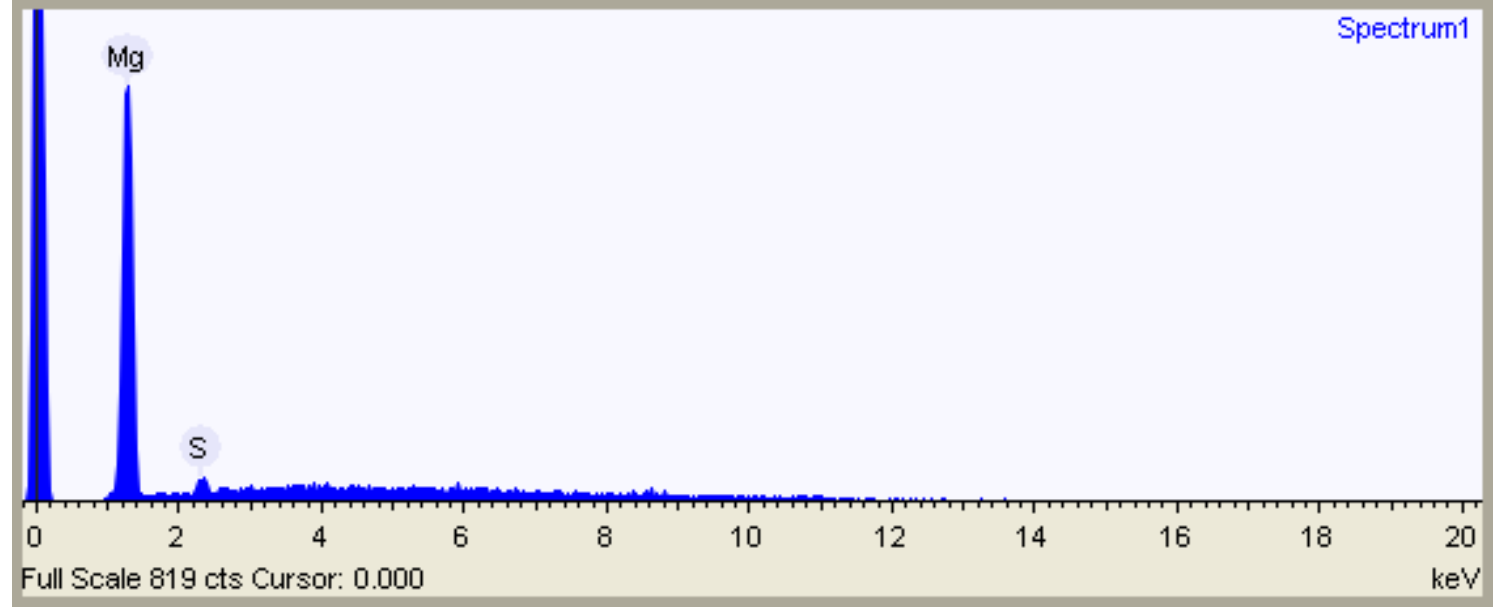

Figura 39. Espectro da análise por EDS na região 2

Tabela 18. Resultados da análise por EDS na região 2

\begin{tabular}{|l|l|}
\hline Elemento & Peso $(\%)$ \\
\hline
\end{tabular}




\begin{tabular}{|c|c|}
\hline Magnésio & 94,7 \\
\hline Enxofre & 5,3 \\
\hline
\end{tabular}

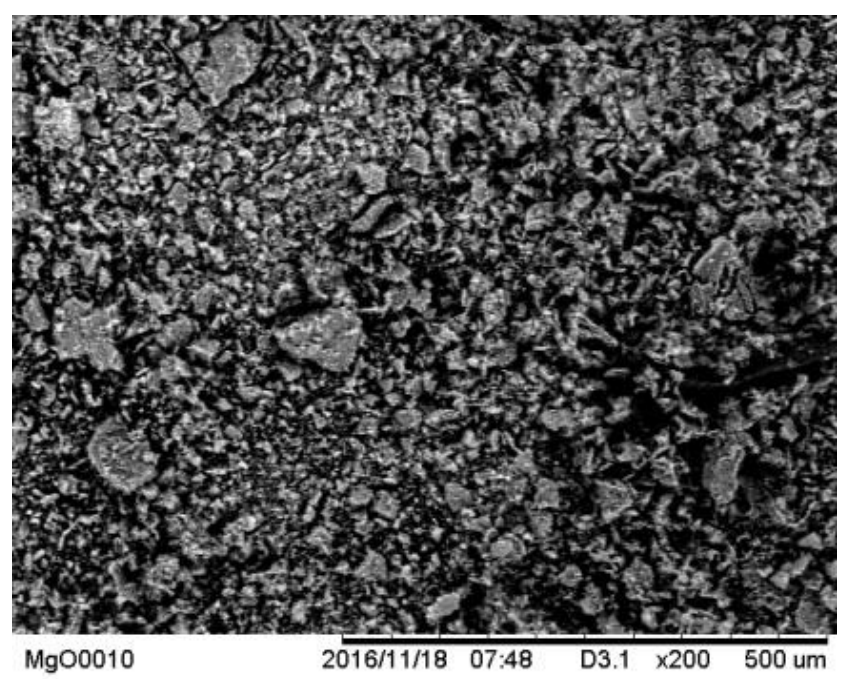

Figura 40. Estrutura morfológica do produto da decomposição carbotérmica obtida por EDS

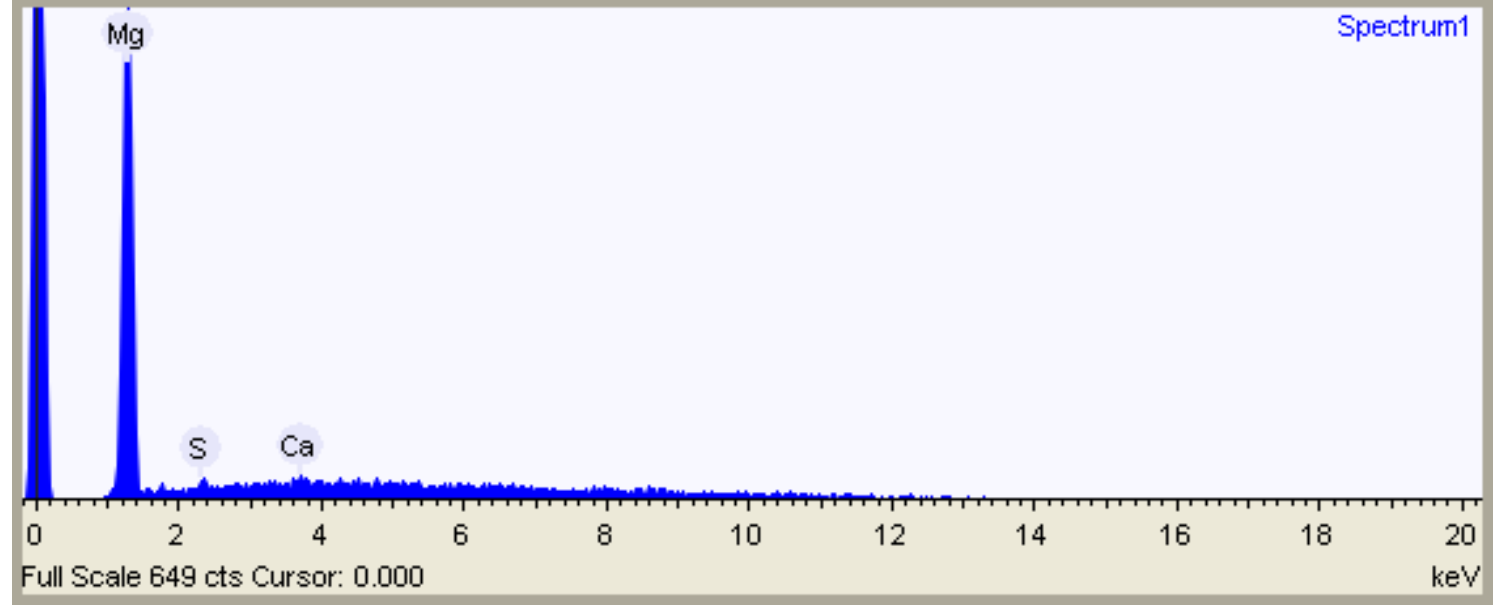

Figura 41. Espectro da análise por EDS na região 3

Tabela 19. Resultados da análise por EDS na região 3

\begin{tabular}{|c|c|}
\hline Elemento & Peso (\%) \\
\hline Magnésio & 94,7 \\
\hline Enxofre & 3,0 \\
\hline Cálcio & 2,3 \\
\hline
\end{tabular}

A avaliação de outros pontos serviu para a confirmação dos elementos presentes no produto, uma vez que as duas regiões observadas, Figura 39 e 41, apresentam 
variações muito pequenas nos espectros obtidas por EDS. A variação mais marcante é o fato da análise realizada na região da Figura 39 não apresentar o cálcio, diferente das regiões das Figuras 37 e 41 . Esse fator indica que o mesmo não estava presente em toda a amostra analisada ou se encontrava em concentrações muito baixas. Isto ocorre pelo cálcio ser potencialmente parte das cinzas do carvão e essas representarem somente $3,5 \%$ do carvão vegetal destilado, utilizado nos ensaios.

Observa-se que os espectros das três regiões analisadas apresentam ruídos desprezíveis, os quais aparentemente proveem de elementos químicos presentes nas cinzas do carvão vegetal, porém em menor quantidade, o que dificulta sua identificação.

\subsection{Teste de reatividade}

Os testes de reatividade foram realizados conforme descrito no item 3.3.5, sendo feitos quatro testes de reatividade, aplicando agitações distintas e reagentes de diferentes origens.

\subsubsection{Análise do efeito da agitação da solução na reatividade do $\mathrm{MgO}$}

Os dois primeiros testes foram realizados com o $\mathrm{MgO}$ obtido a $900{ }^{\circ} \mathrm{C}, 25$ minutos de ensaio e uma vazão de 1,61 L/min. Os dois testes foram realizados com uma solução de ácido cítrico $0,07 \mathrm{~mol} / \mathrm{L}$ a $40{ }^{\circ} \mathrm{C}$. O primeiro teste foi realizado com agitação abaixo de 200 RPM, enquanto o segundo foi realizado com agitação acima de 500 RPM.

O primeiro teste teve uma solução de ácido cítrico com $\mathrm{pH}$ inicial de 2,3. Após dois minutos de teste, a solução estava com um valor de $\mathrm{pH}$ de 4,4. O pH solução demorou trezentos segundos até chegar a 7 e trezentos e sessenta segundos para alcançar a marca de 8,5. O pH máximo foi de 9,07, alcançado após vinte minutos de teste. Como o tempo de reação foi superior ao esperado inicialmente o segundo teste teve uma agitação superior em relação ao primeiro.

A solução de ácido cítrico do segundo teste apresentou um pH inicial de 2,29. $\mathrm{O} \mathrm{MgO}$ elevou o $\mathrm{pH}$ da solução para 7 em sessenta segundos e alcançou a marca de 8,5 em noventa e três segundos. O pH máximo foi de 9,1 e foi alcançado após 
dez minutos de teste. Estes valores alcançados de $\mathrm{pH}$ se mostram satisfatórios quando comparados com dados apresentados por outros trabalhos, como os de Freitas et al., (2009) que alcançou um pH em torno de 6 utilizando o óxido de magnésio e o de Mo et al., (2010) que neutralizou o pH de uma solução ácida com um tempo de 46 segundos.

$\mathrm{O}$ segundo teste, com uma maior rotação, demonstrou que o $\mathrm{MgO}$ obtido tem características necessárias para ser utilizado como regulador de $\mathrm{pH}$. Sendo que o teste com a agitação maior, levou um tempo de reação 5 vezes menor para alcançar a marca de 8,5 de $\mathrm{pH}$.

Os testes em diferentes condições de agitação foram importantes pois demonstraram que em uma larga faixa de agitação o $\mathrm{MgO}$ é capaz de neutralizar o meio, sendo possível um controle da velocidade desta neutralização de acordo com um controle da agitação.

\subsubsection{Análise da temperatura de formação do $\mathrm{MgO}$ na reatividade}

Mais um teste foi realizado com os produtos obtidos a partir de decomposições do sulfato de magnésio, com temperatura de $1000{ }^{\circ} \mathrm{C}$ e sem a presença de um agente redutor. O novo ensaio de decomposição teve um tempo de residência de trinta minutos e presença de ar atmosférico. O ensaio foi realizado a $1000{ }^{\circ} \mathrm{C}$ pois de acordo com a termodinâmica, esta temperatura favorece a formação do $\mathrm{MgO}$ mesmo sem a presença de um agente redutor.

O teste de reatividade foi realizado com o produto da decomposição e uma rotação maior que $500 \mathrm{rpm}$. O pH inicial da solução para esse teste foi de 2,29. A solução, após a mistura de produto, elevou seu pH até o valor de 2,51 em dois minutos. O teste foi realizado com uma duração de dez minutos, entretanto o $\mathrm{pH}$ da solução não sofreu mais alteração após alcançar o valor de 2,51. Com isso, é possível admitir que nos ensaios a uma temperatura de $1000{ }^{\circ} \mathrm{C}$ sem a presença do agente redutor, a decomposição do sulfato praticamente não ocorreu ou o produto não apresentou uma reatividade condizente com a proposta do trabalho, uma vez que, este produto quando foi misturado na solução ácido pouco alterou seu $\mathrm{pH}$. 
Tabela 20. Resultados dos testes de reatividade

\begin{tabular}{|c|c|c|c|c|c|}
\hline Testes & $\mathrm{pH}_{\mathrm{o}}$ & $\mathrm{pH}_{\mathrm{f}}$ & $\mathrm{pH}_{2 \mathrm{~min}}$ & $\begin{array}{c}\text { Tempo para } \\
\mathrm{pH} 7\end{array}$ & $\begin{array}{c}\text { Tempo para } \\
\mathrm{pH} 8,5\end{array}$ \\
\hline Teste 1 & 2,30 & 9,07 & 4,40 & 300 segundos & 360 segundos \\
\hline Teste 2 & 2,29 & 9,10 & 8,75 & 60 segundos & 93 segundos \\
\hline Teste 3 & 2,29 & 2,51 & 2,51 & $\begin{array}{c}\text { Não } \\
\text { alcançado }\end{array}$ & $\begin{array}{c}\text { Não } \\
\text { alcançado }\end{array}$ \\
\hline
\end{tabular}

Com base nos testes de reatividade disponíveis na Tabela 20 e com os dados disponíveis na literatura pode-se observar a diferença de comportamento entre os produtos obtidos. Enquanto os obtidos por redução carbotérmica são apropriados para o intuito do trabalho, o obtido por redução simples não apresenta um bom controle de $\mathrm{pH}$. 


\section{Considerações finais}

Durante este trabalho foram realizados estudos da literatura, uma apreciação termodinâmica e ensaios experimentais para analisar o comportamento do sistema reacional contendo o sulfato de magnésio heptahidratado e o carvão vegetal. Os estudos teóricos e a apreciação termodinâmica serviram como base para determinação das variáveis que foram empregadas nos ensaios experimentais. Enquanto isso os ensaios experimentais serviram para avaliar a influência dessas variáveis no sistema reacional.

A avaliação da apreciação termodinâmica realizada apresentou uma temperatura de decomposição do sulfato de magnésio puro a temperaturas entre $1000^{\circ} \mathrm{C}$ e $1200^{\circ} \mathrm{C}$ e a análise da mesma indicou que, a decomposição do sulfato de magnésio na presença do carbono como agente redutor deveria ocorrer de forma satisfatória a temperaturas entre $600{ }^{\circ} \mathrm{C}$ a $900{ }^{\circ} \mathrm{C}$. Com isso pode-se concluir que a presença do agente redutor teria uma grande influência na diminuição da temperatura de obtenção do óxido de magnésio.

Apesar de a apreciação termodinâmica indicar que o $\mathrm{MgSO}_{4}$ poderia se decompor a partir de $600{ }^{\circ} \mathrm{C}$ na presença do agente redutor, os experimentos realizados, a uma vazão de arraste de $0,33 \mathrm{~L} / \mathrm{min}$, mostraram que a menos de 800 ${ }^{\circ} \mathrm{C}$ não ocorre a decomposição significativa do mesmo. Visto que, nos ensaios realizados a $600{ }^{\circ} \mathrm{C} \mathrm{e} 700{ }^{\circ} \mathrm{C}$ a perda de massa é próxima de $51 \%$, o que corresponde à água presente em sua estrutura, como indicou a análise termogravimétrica.

Para os ensaios realizados a temperatura de $800^{\circ} \mathrm{C}$, é possível concluir que a reação de decomposição do $\mathrm{MgSO}_{4}$ começou a apresentar resultados mais expressivos, tendo os ensaios alcançado uma perda de massa superior a $51 \%$ para todos os tempos analisados, saindo de uma perda de massa de $54,87 \%$ no ensaio de cinco minutos e atingindo um valor de $60,83 \%$ no ensaio de trinta minutos. Valores de perda de massa esses que indicam uma conversão $11,60 \%$ e de 29,48\%, respectivamente.

Já para os ensaios efetuados a temperatura de $900{ }^{\circ} \mathrm{C}$, a amostra apresentou uma perda de massa de $64,46 \%$ para o ensaio com cinco minutos para valores de 
perda de massa de até $85,40 \%$, para o ensaio de trinta minutos de duração, indicando um grande avanço na reação e alcançando uma conversão de aproximadamente $100 \%$.

Os ensaios realizados com a vazão de 1,61 L/min para as temperaturas de 800 ${ }^{\circ} \mathrm{C}$ e $900{ }^{\circ} \mathrm{C}$, indicaram valores próximos aos ensaios com vazão de $0,33 \mathrm{~L} / \mathrm{min}$, apresentando variações médias de $14,21 \%$ para os ensaios a $800{ }^{\circ} \mathrm{C}$ e tempo de 15 a 30 minutos e de $5,13 \%$ para os ensaios a $900^{\circ} \mathrm{C}$ e tempo de 15 a $30 \mathrm{~min}$. Apesar das pequenas variações encontradas para os ensaios de $800{ }^{\circ} \mathrm{C}$ e $900{ }^{\circ} \mathrm{C}$ e tempo de 10 a 30 minutos, os ensaios realizados nessas mesmas temperaturas em tempos de 5 e 10 minutos apresentaram uma maior variação de conversão. Com destaque para a variação entre os valores dos ensaios a 5 minutos, onde a conversão foi $87,97 \%$ vezes menor a $800{ }^{\circ} \mathrm{C}$ e $46,13 \%$ menor a $900{ }^{\circ} \mathrm{C}$. Esses resultados indicam que o aumento da vazão diminuiu a taxa inicial de reação, tal fato se dá pelo arraste do $\mathrm{CO}$ formado na reação que serve para um aumento da atmosfera redutora.

A análise dos ensaios realizados com excesso de agente redutor indicou que o mesmo não apresenta grande influência na conversão final da decomposição, visto que o aumento entre os ensaios de menor e maior perda de massa para cada temperatura não passam de $3,5 \%$, sendo de $2,92 \%$ para os ensaios a $600{ }^{\circ} \mathrm{C}$, de $1,89 \%$ para os ensaios a $700{ }^{\circ} \mathrm{C}$, de $3,16 \%$ para os ensaios a $800{ }^{\circ} \mathrm{C}$ e de $3,33 \%$ para os ensaios a $900{ }^{\circ} \mathrm{C}$.

Os ensaios com a granulometria homogênea não apresentaram um padrão de comportamento em relação aos ensaios com granulometria heterogênea que permitam determinar uma influência positiva ou negativa da granulometria no processo de decomposição do $\mathrm{MgSO}_{4}$ na presença do agente redutor.

Entre todos os ensaios analisados, os experimentos a $900{ }^{\circ} \mathrm{C}$ e com tempos de 25 e 30 minutos foram os que indicaram os melhores resultados experimentais de conversão, tanto para vazão de $0,33 \mathrm{~L} / \mathrm{min}$ quanto para $1,61 \mathrm{~L} / \mathrm{min}$. Sendo assim estes foram os ensaios escolhidos para a realização da caracterização e teste de reatividade foram os ensaios a uma temperatura de $900{ }^{\circ} \mathrm{C}$ e com tempo de 25 minutos. 
A análise de caracterização, em DR-X, do produto obtido nos ensaios escolhidos indica que o $\mathrm{MgO}$ está sendo formado ao fim da reação. Uma vez que o difratograma indica que a composição mineral do produto analisado é formada por três fases da periclase $(\mathrm{MgO})$.

A avaliação do produto em MEV indicou que o produto obtido apresenta uma morfologia homogênea composta de partículas menores que $10 \mu \mathrm{m}$. Visualmente o material aparenta possuir uma porosidade em sua estrutura que pode ser apropriada para sua utilização como regulador de pH. Para se confirmar a composição química elementar da amostra o produto foi analisado com EDS em três regiões da amostra, essas análises indicaram que o produto obtido a $900{ }^{\circ} \mathrm{C}$ e com tempo de 25 minutos eram compostos por Magnésio (>94\%), enxofre e cálcio. Uma vez que a análise não detecta a presença do oxigênio, pode-se concluir que o produto obtido é majoritariamente composto por óxido de magnésio.

Os testes de reatividade do $\mathrm{MgO}$ formado na decomposição carbotérmica indicaram que o mesmo pode ser utilizado como regulador de $\mathrm{pH}$, pois foi capaz de elevar o pH da solução aos níveis desejados nas duas agitações estudadas. Os testes demonstraram que o controle da agitação torna capaz um controle da velocidade de neutralização do $\mathrm{MgO}$, fazendo com que o mesmo possa ser utilizado para processos distintos de neutralização.

O teste de reatividade com produto da decomposição simples a $100{ }^{\circ} \mathrm{C}$ confirma que o material obtido não possui as características necessárias para atuar como regulador de $\mathrm{pH}$. 


\section{Sugestão para trabalhos futuros}

Após a avaliação dos ensaios realizados, dos resultados obtidos e das possíveis conclusões, algumas áreas não abordadas neste trabalho por vir a ser estudados em trabalhos futuros, sendo assim algumas sugestões de análises são propostas:

- Realizar experimentos com outros agentes redutores, como $\mathrm{H}_{2}$ e $\mathrm{CO}$;

- Realizar ensaios de decomposição no vácuo;

- Realizar uma análise no desempenho da decomposição em temperaturas entre $800{ }^{\circ} \mathrm{C}$ e $900{ }^{\circ} \mathrm{C}$;

- Realizar ensaios com um $\mathrm{MgSO}_{4}$ com menores hidratações;

- Realizar uma avaliação do excesso do carbono na taxa inicial de decomposição;

- Realizar uma análise da área superficial do MgO através de BET. 


\section{Referências bibliográficas}

APHANE, M. E. The hydration of magnesium oxide with different reactivities by water and magnesium acetate. Dissertação de mestrado em química. University of South Africa. 2009.

ARAMENDÍA, M. A.; BORAU, V.; JIMÉNEZ, C.; MARINAS, J. M.; RUIZ, J. R.; URBANO, F. J.; Influence of the preparation method on the structural and surface properties of various magnesium oxides and their catalytic activity in the Meerwein-PonndorfVerley reaction. Applied Catalysis A: General, 244(2), 207-215. 2003.

ASTM D1762-84(2013), Standard Test Method for Chemical Analysis of Wood Charcoal. ASTM International, West Conshohocken, PA, 2013. www.astm.org Acessado em 15/06/2016 as 19:30.

BAGHALHA, M.; PAPANGELAKIS, V.G.; Pressure acid leaching of laterites at $250^{\circ} \mathrm{C}$ : a solution chemical model and its applications. Metallurgical and Materials Transactions B, 29, pp. 945-952, 1998.

BARRETO, L. V.; FREITAS, A. C. S.; PAIVA, L. C.; Sequestro de carbono. Centro Cientifico Conhecer. Goiânia, Enciclopédia Biosfera. 2009.

BENIQUE, F. S. B. Contribuição à Auto-redução Carbotérmica de Aglomerados contendo Óxidos de Manganês. Dissertação de mestrado. Curso de Programa de Pós-Graduação em Engenharia Metalúrgica do Departamento de Ciência dos Materiais e Metalurgia. Pontifícia Universidade Católica do Rio de Janeiro. Rio de Janeiro, 2007.

BEURLEN, H.; CASSEDANNE, J.P.; The Brazilian mineral resources. Earth-Science Reviews, 17, pp. 177-206, 1981.

BROCCHI, E. A.; DOI, L.; SOUZA, R. F. M.; SIQUEIRA, R. N. C.; Estudo de viabilidade da redução carbotérmica do sulfato de 
magnésio. In: Encontro Nacional de Tratamento de Minérios e Metalurgia Extrativa, 2013, Goiânia, GO (Brasil). XXV ENTMME, v. III. p. 131-138, 2013.

CALEFFI, R.; HEIDEMANN, T. R.; MOSER, D. K.; CLORETO DE SÓDIO: Análise de sua função na formulação de xampus para manutenção de cabelos quimicamente tratados. 2009.

CANTERFORD, J. H. Mineral Processing and Extractive Metallurgy Review, 2(1-2), pp. 57-104. 1985.

CONAMA - Conselho Nacional do Meio Ambiente, 2016. Resolução 357 de 17 de março de 2005. DOU oo 053, de 18/03/2005, pp. 5863.

CUNHA, F. A.; MARTINS, A.H.; Avaliação de alguns agentes lixiviantes para a remoção do cobre contido em um minério complexo de ouro. Revista Escola de Minas, v.56 n.3, Jul/Set, pp. 187-190, 2003.

DALLASTRA, E. C. Sistemas de produção de carvão vegetal existentes no Brasil: Uma análise de viabilidade econômica. Dissertação de mestrado em agroenergia. FGV. 2010

DING, K.; WANG, S.; LI, S.; YUE, C.; Thermochemical reduction of magnesium sulfate by natural gas: Insights from an experimental study. Geochemical Journal, Vol 45 pp. 97-108. 2011.

FERNANDES, F.R.C.; MATOS, G.M.M; CASTILHOS, Z.C; LUZ, A.B.; Tendências Tecnológicas Brasil 2015: Geociências e Tecnologia Mineral. Rio de Janeiro: CETEM/MCT, 2007.

FREITAS, E. V. D. S.,; NASCIMENTO, C. W. A. D.,; SILVA, A. J.,; DUDA, G. P.; Citric acid enhances lead phytoextraction from a soil contaminated by automotive batteries. Revista Brasileira de Ciência do Solo, 33(2), 467-473. 2009. 
HABASHI, F,; editor. Handbook of Extractive Metallurgy. WileyVCH. Volume I, 1997a.

HABASHI, F,; editor. Handbook of Extractive Metallurgy. WileyVCH. Volume II, pp. 981-1038, 1997b.

HABASHI, F. A short history of hydrometallurgy. Hydrometallurgy, n.79, pp. 15-22, 2005.

HOM, M. B. Remoção de metais da drenagem ácida de minas por precipitação química e por troca iônica com Zeólita NaP1. Dissertação de mestrado. Programa de Pós-Graduação em Engenharia de Minas, Metalúrgica e de Materiais. Universidade Federal do Rio Grande do Sul. Porto Alegre, 2015.

HOTEIT, A.; BOUQUET, E.; SCHÖNNENBECK, C.; GILOT, P.; Sulfate decomposition from circulating fluidized bed combustors bottom ash. Chem Eng Sci; 62:6827-35, 2007.

KATO, T.; MURAKAMI, K.; SUGAWARA, K.; Carbon reduction of gypsum produced from flue gas desulfurization. Chem. Eng. Trans, 29, 805-810. 2012.

LEMOS, F. A.; ANGORA, M. A.; MASSON, I. O. C. - Lixiviação sob pressão de minérios lateríticos. XXII ENTMME / VII MSHMT. Ouro Preto: Comunicação técnica elaborada para o XXII ENTMME / VII MSHMT vol.2, pp. 131-136, 2007.

MENEZES, F. C.; ESQUERRE, K. P. S. O. R.; KALID, R. A.; KIPERSTOK, A.; MATOS, M. C. O.; MOREIRA, R.; Redes Neurais Artificiais aplicada ao processo de coagulação. Eng Saint Ambient, v. 14, n. 4, p. 449-454, 2009.

MO, L.; DENG, M.; TANG, M.; Effects of calcination condition on expansion property of MgO-type expansive agent used in cement-based materials. Cement and Concrete Research, 40(3), 437-446. 2010. 
OKUMURA, S.; MIHARA, N.; OZAWA, S.; ONYANGO, M.S.; KOJIMA, Y.; MATSUDA, $\mathrm{H}_{\text {.; }}$ Recovery of $\mathrm{CaO}$ by reductive decomposition of spent gypsum in a CO.CO2.N2 atmosphere. Industrial Engineering Chemistry Research 42, 6046-6051. 2003.

PERRY, R. H., \& GREEN, D. W.; Perry's chemical engineers' handbook. McGraw-Hill Professional. $7^{\mathrm{TH}}$ Ed, 1999.

PLEWA, J.; STEINDOR, J.; Kinetics of reduction of magnesium sulfate by carbon oxide. Journal of Thermal Analysis, Vol. $32 \mathrm{pp}$. 1809-1820. 1987.

RENNER, R. M.; Sequestro de carbono e a viabilização de novos reflorestamentos no Brasil. Tese de Doutorado. Universidade Federal do Paraná. 2004.

REUTER, M.; HUDSON, C.; VAN SCHAIK, A.; HEISKANEN, K.; MESKERS, C.; HAGELUKEN, C.; Metal Recycling: Opportunities, Limits, Infrastrucuture. United Nations Environment Programme, 2013.

ROINE, A. Outokumpu HSC-Chemistry for Windows, 06120ORC-T, Versão 6.0, Outokumpu Research Oy, Information Service, Pori, Finlândia, 2006.

SCHEIDEMA, M. N.; TASKINEN, P.; Decomposition thermodynamics of magnesium sulfate. Ind Eng Chem Res 50:9550-6, 2011a.

SCHEIDEMA, M. N.; TASKINEN, P.; Reductive Decomposition of Magnesium Sulfate. European Metallurgical Conference, Conference Proceedings 1021-1032. 2011b

SICUPIRA, L. C. Biolixiviação de Sulfetos Secundários de Cobre por Sulfobacillus thermosulfidooxidans. Dissertação de mestrado. Programa de Pós-Graduação em Engenharia de Materiais. REDEMAT. Ouro Preto, 2011. 
SOLER, J. M.; CAMA, J.; GALÍ, S.; MELÉNDEZ, W.; RAMÍREZ, A.; ESTANGA, J.; Composition and dissolution kinetics of garnierite from the nickel laterite deposit of Loma de Hierro, Venezuela. Chemical Geology, 249 (1-2), pp. 191-202, 2008.

TOLENTINO, M. V. C. Estudo da viabilidade técnica do aproveitamento do resíduo arenoso da mineração do Itabirito. Dissertação de mestrado. Curso de Pós-Graduação em Ciência e Tecnologia das radiações, Minerais e Materiais. CDTN, Belo Horizonte, 2010.

TOWNSEND, T.; JANG, Y-CH.; TOLAYMAT, T. Leaching Tests for Evaluating Risk in Solid Waste Management Decision Making. Florida Center for Solid and Hazardous Waste Management. Report No. 03-01. Gainesville, FL, USA. 2003.

VIROLAINEN, S.; Hydrometallurgical recovery of valuable metals from secondary raw materials. (PhD Thesis). Lappeenranta University of Technology, Lappeenranta, Finland, 2013.

YI, Y.; GUC, L.; LIU S.,; JIND F. Magnesia reactivity on activating efficacy for ground granulated blastfurnace slag for soft clay stabilisation. Applied Clay Science 126, 57-62, 2016.

ZHANG, X.; SONG, X.; SUN, Z.; LI, P.; YU, J.; Density functional theory study on the mechanism of calcium sulfate reductive decomposition by carbon monoxide. Ind Eng Chem Res; 51(18):6563-70, 2012.

ZHANG, X.; SONG, X.; SUN, Z.; LI, P.; YU, J.; Density functional theory study on the mechanism of calcium sulfate reductive decomposition by methane. Fuel 110 p. 204-211, 2013. 